School of Finance

University of St.Gallen

\title{
EXTREME DOWNSIDE LIQUIDITY RISK
}

STEFAN RUENZI

MichaEl UNGEHEUER

FLORIAN WEIGERT

WORKING PAPERS ON FINANCE No. 2013/26

SWISS INSTITUTE OF BANKING AND FINANCE (S/BF - HSG)

FEBRUARY 2012

THIS VERSION: JANUARY 2016 


\title{
Extreme Downside Liquidity Risk $^{a}$
}

\author{
Stefan Ruenzi, Michael Ungeheuer and Florian Weigert ${ }^{b}$
}

First Version: February 2012; This Version: January 2016

\begin{abstract}
We merge the literature on downside return risk with that on systematic liquidity risk and introduce the concept of extreme downside liquidity (EDL) risk. We show that the cross-section of expected stock returns reflects a premium for EDL risk. Strong EDL risk stocks deliver a positive risk premium of more than $4 \%$ p.a. as compared to weak EDL risk stocks. The effect is more pronounced after the market crash of 1987. It is not driven by linear liquidity risk or by extreme downside return risk, and it cannot be explained by other firm characteristics or other systematic risk factors.
\end{abstract}

Keywords: Asset Pricing, Crash Aversion, Downside Risk, Liquidity Risk, Tail Risk

JEL Classification Numbers: C12, C13, G01, G11, G12, G17.

\footnotetext{
${ }^{a}$ We thank Olga Lebedeva, Stefan Obernberger, and Christian Westheide for sharing their high-frequency data with us. We would also like to thank Yakov Amihud, Christian Dick, Jean-David Fermanian, Sermin Gungor, Allaudeen Hameed, Robert Korajczyk, Andre Lucas, Thomas Nitschka, Rachel Pownall, Erik Theissen, Julian Thimme, Monika Trapp, seminar participants at the University of Mannheim, the University of Sydney, and participants at the 2012 EEA Meeting, 2012 Erasmus Liquidity Conference, 2012 SMYE Meeting, 2013 Humboldt-Copenhagen Conference, 2013 Financial Risks International Forum, 2013 SGF Conference, 2013 EFA Meeting, 2013 Conference on Copulas and Dependence at Columbia University, 2013 FMA Meeting, 2013 Australasian Finance and Banking Conference, 2014 Risk Management Conference at Mont Tremblant and 2014 Conference on Extreme Events in Finance at Royaumont Abbey for their helpful comments. All errors are our own.

${ }^{b}$ Stefan Ruenzi (corresponding author) and Michael Ungeheuer: Chair of International Finance at the University of Mannheim, Address: L9, 1-2, 68131 Mannheim, Germany, Telephone: +49-621-181-1640, email: ruenzi@bwl.uni-mannheim.de and ungeheuer@bwl.uni-mannheim.de. Florian Weigert: University of St. Gallen, Address: Rossenbergstr. 52, 9000 St.Gallen, Switzerland, Telephone: +41-71-224-7014, e-mail: florian.weigert@unisg.ch.
} 


\section{Introduction}

The recent empirical asset pricing literature documents that investors care about the systematic downside- and crash-exposure of stock returns and shows that stocks with such exposures earn a significant risk-premium (e.g., Ang, Chen, and Xing (2006); Kelly and Jiang (2014); and Chabi-Yo, Ruenzi and Weigert (2015)). At the same time, the theoretical literature shows that investors should care about the systematic component of liquidity risk and there are successful attempts to show empirically that systematic liquidity risk also bears a premium in the cross-section of returns (e.g., Pastor and Stambaugh (2003) and Acharya and Pedersen (2005)). The aim of our paper is to merge these two important strands of the literature for the first time.

The starting point of our paper is the conjecture that investors are less concerned about systematic liquidity risk during normal market conditions than during periods of market stress like return crashes or periods of extreme illiquidity. For example, investors probably care less about how a specific stock's liquidity co-moves with the liquidity of other stocks when markets are relatively calm and when they face no urgent trading needs. However, stocks that suddenly become very illiquid exactly during market crises (e.g., during the liquidity crisis of September 2008) are very unattractive, while assets that still remain relatively liquid in times of market stress are very attractive assets to hold, particularly for institutional investors that might be subject to asset fire sale problems or might strongly depend on funding liquidity conditions. As shown in the theoretical model by Brunnermeier and Pedersen (2009), liquidity tends to be fragile and is characterized by sudden systemic droughts of extreme magnitude. The anticipation of such events should lead investors to demand a premium for holding stocks whose liquidity is particularly sensitive to them. 
In this paper, we introduce the concept of extreme downside liquidity (EDL) risk and show that stocks with high levels of EDL risk bear an economically large and statistically significant risk premium of roughly $4 \%$ per year which is neither subsumed by extreme downside return (EDR) risk (as in Kelly and Jiang (2014) or Chabi-Yo, Ruenzi and Weigert (2015)) nor by linear systematic liquidity (as in Pastor and Stambaugh (2003) or Acharya and Pedersen (2005)). Our empirical approach is closely related to Acharya and Pedersen (2005)'s liquidity-adjusted CAPM. In their model, an asset's joint liquidity risk consists of three different risk components: (i) the (scaled) correlation of an asset's liquidity to market liquidity, (ii) the (scaled) correlation of an asset's return to market liquidity, and (iii) the (scaled) correlation of an asset's liquidity to the market return. However, we want to focus on times of market stress and when focusing on extreme events (e.g. in liquidity and returns), linear correlations fail to measure increased dependence in the tails of the distribution (see Embrechts, McNeil, and Straumann (2002)). Hence, the liquidity-adjusted CAPM cannot account for a stock's EDL risk and, as a result, might be misspecified if investors care especially about extreme joint realizations in liquidity and returns, as hypothesized in this paper. Thus, we use the method to capture EDR risk based on lower tail dependencies between stock and market returns introduced in ChabiYo, Ruenzi and Weigert (2015) and Weigert (2015) and apply it to liquidity to capture EDL risk. Like Acharya and Pedersen (2005) for linear liquidity risk, in doing so we distinguish three components of extreme downside liquidity risk (EDL risk ${ }_{1}$, EDL risk 2 , and EDL risk $\left._{3}\right)$ :

(i) Clustering in the lower left tail of the bivariate distribution between individual stock liquidity and market liquidity (EDL risk 1 ): During extreme market liquidity downturns, funding liquidity is often reduced as well (e.g., margin requirements may increase; see Brunnermeier and Pedersen (2009)). During those times, investors are often forced 
to liquidate assets and realize additional liquidity costs. Hence, strong exposure to

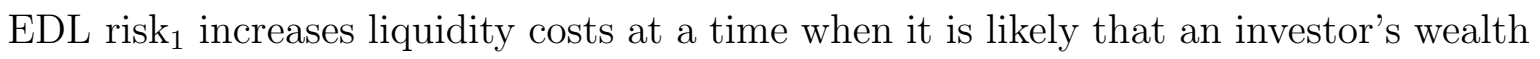
has decreased.

(ii) Clustering in the lower left tail of the bivariate distribution between the individual stock return and market liquidity (EDL risk ${ }_{2}$ ): Investors who face margin or solvency constraints usually have to liquidate some assets to raise cash when their wealth drops critically. If they hold assets with strong EDL risk 2 , such liquidations will occur in times of extreme market liquidity downturns. Liquidation in those times also leads to additional costs, which are especially unwelcome to investors whose wealth has already dropped (see also Pastor and Stambaugh (2003)).

(iii) Clustering in the lower left tail of the bivariate distribution between individual stock liquidity and the market return (EDL risk ${ }_{3}$ ): In times of market return crashes, institutional investors (such as mutual fund managers) are often forced to sell because their investors withdraw funds (Coval and Stafford (2007)) or financial intermediaries withdraw from providing liquidity (Brunnermeier and Pedersen (2009)). If a selling investor holds securities with strong EDL risk ${ }_{3}$, she will suffer from high transaction costs at the precise moment when her wealth has already dropped and additional losses are particularly painful.

We capture the three distinct EDL risk components based on bivariate extreme value theory and copulas, using lower tail dependence coefficients (see Sibuya (1960)). The lower tail dependence coefficient reflects the probability that a realization of one random variable is in the extreme lower tail of its distribution, conditional on the realization of the other random variable also being in the extreme lower tail of its distribution. Furthermore, closely following Acharya and Pedersen (2005), we define the joint EDL risk of a stock as the sum of 
the three different EDL risk components. All else being equal, assets that exhibit strong EDL risk are unattractive assets to hold: they tend to realize the lowest liquidity (return) exactly when the market also realizes its lowest liquidity (return) level. Hence, liquidity-crash-averse investors, who are particularly interested in insuring against such extreme events, will require a premium for holding those stocks.

As our main liquidity proxy we use the Amihud (2002) Illiquidity Ratio. ${ }^{1}$ Using weekly data from 1963 to 2012 we estimate lower tail dependence coefficients for (i) individual stock liquidity and market liquidity (EDL risk 1 ), (ii) individual stock return and market liquidity $\left(\mathrm{EDL} \mathrm{risk}_{2}\right)$, and (iii) individual stock liquidity and the market return (EDL risk 3 ) for each stock $i$ and week $t$ in our sample. Aggregate EDL risk (defined as the value-weighted average of EDL risk over all stocks in the sample) peaks during times of financial crises, such as around 1978-1979 (Second U.S. Oil Crisis), after 1987 (Black Monday Stock Market Crash), between 1997 and 1998 (Asian Financial Crisis), as well as in the years of the U.S. subprime crisis starting in 2007.

We then relate stocks' EDL risk (and the EDL risk components) to future returns. Our asset pricing tests - based on portfolio sorts, factor regressions, and Fama and MacBeth (1973) regressions on the individual firm level — are completely out-of-sample and focus on the relationship between past EDL risk exposure and future excess returns. We document that there exists a positive impact of EDL risk on the cross-section of average future returns. From 1969 to 2012, a portfolio that is long in stocks with strong EDL risk and short in stocks with weak EDL risk yields a significant average excess return of $4.00 \%$ p.a. We confirm that the premium for EDL risk is not explained by other risk- and firm characteristics. Hence, our results suggest that EDL risk is an important determinant of the cross-section

\footnotetext{
${ }^{1}$ We also employ several other low-frequency and high-frequency liquidity measures in robustness checks. Our results remain stable across the different proxies; see Section 4.1.
} 
of expected stock returns. The impact of EDL risk is more pronounced for stocks with a higher probability of extreme (bad) return and liquidity realizations as measured based on the past distributions of their individual return and liquidity realizations.

When investigating the variation of the EDL risk premium over time, we find that the premium has increased in the second half of our sample period. During 1988-2012, a portfolio consisting of the $20 \%$ stocks with the strongest EDL risk exposure delivers a raw return which is $5.91 \%$ p.a. higher than that of a portfolio consisting of the $20 \%$ stocks with the weakest EDL risk exposure, whereas the return difference in the earlier sample period (1969-1987) is $1.49 \%$ p.a. These results suggest that investors have become more concerned about a stock's EDL risk during the second half of our sample. This finding is consistent with results from the empirical option pricing literature. Rubinstein (1994) and Bates (2008) find that deep out-of-the-money index puts (i.e., financial derivatives that offer protection against strong market downturns) became more expensive after the stock market crash in 1987. These results are also consistent with the argument recently put forward by Gennaioli, Shleifer and Vishny (2015) that investors fear a future crash more when there is a recent crash they still vividly remember. Also consistent with increased crash-aversion after market crises, Chabi-Yo, Ruenzi and Weigert (2015) show that the premium for a stock's crash sensitivity increases substantially after severe market downturns.

The stability of our results is confirmed in a battery of additional robustness tests. These tests include using low-frequency and high-frequency liquidity proxies other than the Amihud (2002) Illiquidity Ratio and changing the estimation procedure for the lower tail dependence coefficients.

Our study contributes to three strands of the literature. First, we contribute to the literature on the impact of liquidity and liquidity risk on the cross-section of stock returns. Amihud and Mendelson (1986) convincingly show theoretically and empirically that stocks 
with low levels of liquidity deliver higher returns, a finding that has been confirmed in a large number of studies since then. Closely related to our analysis is a paper by Menkveld and Wang (2011) showing that stocks with higher probabilities of realizing extremely low liquidity levels (called "liquileak probability") command a premium. Thus, while they focus on the impact of individual extreme illiquidity levels, we focus on the joint likelihood that an individual stock is extremely illiquid (has an extremely low return) when market liquidity (the market return) is extremely low, i.e., we focus on a systematic risk component. $^{2}$

There are also numerous studies investigating whether systematic liquidity risk is a priced factor. However, in this case the aggregate evidence is less clear. Pastor and Stambaugh (2003) find that stocks with high loadings on the market liquidity factor outperform stocks with low loadings. Acharya and Pedersen (2005) derive an equilibrium model for returns that includes the liquidity level and a stock's return and liquidity covariation with market liquidity and the market return. They provide some evidence that liquidity risk is a priced factor in the cross-section of stock returns. This finding is confirmed in an international setting in Lee (2011).However, Hasbrouck (2009) raises doubts on the existence of a premium for liquidity risk. He documents that in a long historical sample (U.S. data from 1926 to 2006), there is only weak evidence that liquidity risk is a priced factor. We contribute to the existing literature by investigating a new dimension of liquidity risk: a security's EDL risk. Thus, we provide new evidence that systematic liquidity components are actually priced. $^{3}$

\footnotetext{
${ }^{2}$ In a recent working paper, $\mathrm{Wu}(2015)$ documents that stocks with strong sensitivities to a liquidity-tail factor earn high expected returns. We show that the premium for a stock's EDL risk is not subsumed by this liquidity-tail factor in Panel B of Table 5.

${ }^{3} \mathrm{~A}$ concurrent related working paper by Anthonisz and Putnins (2014) also focuses on asymmetric liquidity risk. They define downside liquidity betas (like Ang, Chen, and Xing (2006)) and downside return beta (and find them to carry a premium), while we focus on extreme downside liquidity events. Furthermore, our later analysis shows that downside liquidity beta has no significant influence on the cross-section of stock
} 
Second, our paper relates to the empirical asset pricing literature on rare disaster and downside crash risk. Ang, Chen, and Xing (2006) find that stocks with high downside return betas earn high average returns. Kelly and Jiang (2014), ChabiYo, Ruenzi and Weigert (2015), and Cholette and Lu (2011) investigate the impact of a stock's return crash risk and return tail risk on the cross-section of expected stock returns. They find that investors demand additional compensation for holding stocks that are crash-prone, i.e., stocks that have particularly bad returns exactly when the market crashes. In an international setting, Berkman, Jacobsen and Lee (2011) show that rare disaster risk premia increase after crises. We complement their findings by showing that EDL risk premia also increase after the 1987 crash.

Third, we extend the literature on the application of extreme value theory and copulas in the cross-sectional pricing of stocks. Copulas are mainly used to model bivariate return distributions between different international equity markets (see Longin and Solnik (2001) and Ané and Kharoubi (2003)) and to measure contagion (see Rodriguez (2007)). ${ }^{4}$ Chabi-Yo, Ruenzi and Weigert (2015) investigate extreme dependence structures between individual stocks and the market and find that extreme dependencies are priced factors in the cross-section of stock returns. Until now, extreme value theory has been applied to describe dependence patterns across different markets and different assets as well as individual stock returns and the market return. However, to the best of our knowledge, ours is the first paper to investigate extreme dependence structures between individual level and market level liquidity and returns, respectively.

returns when controlling for our EDL risk measure, while our measure continues to have a strong impact.

${ }^{4}$ Further applications include the use of copulas in dynamic asset allocation (Patton (2004)). Poon, Rockinger, and Tawn (2004) suggest a general framework to identify tail distributions based on multivariate extreme value theory. 
The rest of this paper is organized as follows. Section 2 provides an overview of the liquidity measure, the estimation of EDL risk and the development of EDL risk over time. Section 3 demonstrates that stocks with high EDL risk earn high future returns. Section 4 performs robustness checks and Section 5 concludes.

\section{Methodology and Data}

Section 2.1 defines our main measure of liquidity and outlines the calculation of liquidity shocks. In Section 2.2 we introduce our estimation method for EDL risk. Section 2.3 describes our stock market data and the development of aggregate EDL risk over time and provides summary statistics.

\subsection{Measuring Liquidity}

Liquidity is a broad, multi-dimensional concept, which makes it hard to find a single theoretically satisfying measure for it. Like Acharya and Pedersen (2005), we assume that the liquidity proxies used in this study should measure the 'ease of trading securities', without focusing on one particular dimension of liquidity. The limited availability of intradaily data (particularly before the 1990s) forces us to rely on a low-frequency liquidity proxy as the main measure of liquidity for our main tests. ${ }^{5}$ Fortunately, many low-frequency proxies are highly correlated with benchmark measures based on high-frequency data (Goyenko, Holden, and Trzcinka (2009); Hasbrouck (2009)).

We follow Amihud (2002), Acharya and Pedersen (2005) and Menkveld and Wang (2011) and use the Amihud Illiquidity Ratio (illiq) as our main measure of illiquidity. Hasbrouck

\footnotetext{
${ }^{5}$ We verify the stability of our results with various other low-frequency (for 1963-2012) and high-frequency (for 1996-2010) liquidity proxies in Section 4.1. A detailed description of all liquidity measures used in this study is given in Internet Appendix A.
} 
(2009) finds that illiq correlates most highly with market microstructure price impact measures. Illiq of stock $i$ in week $t$ is defined as

$$
i l l i q_{t}^{i}=\frac{1}{\operatorname{days}_{t}^{i}} \sum_{d=1}^{\text {days }_{t}^{i}} \frac{\left|r_{t d}^{i}\right|}{V_{t d}^{i}},
$$

where $r_{t d}^{i}$ and $V_{t d}^{i}$ denote, respectively, the return and dollar volume (in millions) on day $d$ in week $t$ and days ${ }_{t}^{i}$ is the number of valid observations in week $t$ for stock $i$. We use $i l l i q_{t}^{i}$ as the illiquidity of stock $i$ in week $t$ if it has at least three valid return and non-zero dollar-volume observations in week $t$.

There are two caveats when using illiq as a proxy for illiquidity. First, illiq can reach extremely high values for stocks with very low trading volume. Second, inflation of dollarvolume (the denominator) makes illiq non-stationary. To solve these problems, we follow Acharya and Pedersen (2005) and define a normalized measure of illiquidity, $c_{t}^{i}$, by

$$
c_{t}^{i}=\min \left(0.25+0.30 \cdot i l l i q_{t}^{i} \cdot P_{t-1}^{m}, 30\right)
$$

where $P_{t-1}^{m}$ is the ratio of the capitalizations of the market portfolio (NYSE and AMEX) at the end of week $t-1$ relative to that at the end of July 1962. The adjustment by $P_{t-1}^{m}$ alleviates problems due to inflation. Additionally, a linear transformation is performed to make $c_{t}^{i}$ interpretable as effective half-spread. Finally, by capping the illiquidity proxy at a maximum value of $30 \%$, we ensure that our results are not driven by unrealistically extreme outliers of illiq.

Finally, to simplify the estimation of EDL risk (as discussed in Section 2.2), we convert normalized illiquidity into normalized liquidity via

$$
d_{t}^{i}=-c_{t}^{i} .
$$


The normalized liquidity measure $d_{t}^{i}$ is very persistent: Ljung-Box tests reject the nullhypothesis of 'no autocorrelation at the first lag' at a 10\% significance level for $92 \%$ of stocks. Thus, we will focus on the innovations of the normalized liquidity measure

$$
l_{t}^{i}=d_{t}^{i}-E_{t-1}\left(d_{t}^{i}\right)
$$

of a stock when computing our EDL risk measures. To calculate the expected normalized liquidity $E_{t-1}\left(d_{t}^{i}\right)$ for each stock $i$ and week $t$, we fit an $\operatorname{AR}(4)$ time series model over the liquidity time series of stock $i{ }^{6}$ Hence,

$$
E_{t-1}\left(d_{t}^{i}\right)=\hat{a}_{0}+\hat{a}_{1} \cdot d_{t-1}^{i}+\hat{a}_{2} \cdot d_{t-2}^{i}+\hat{a}_{3} \cdot d_{t-3}^{i}+\hat{a}_{4} \cdot d_{t-4}^{i} \cdot
$$

We then use $l_{t}^{i}$ for the computation of the EDL risk components for stock $i$ at week $t$ as described in the following section. For a more detailed description of the computation of the liquidity innovations, see Internet Appendix A.

\subsection{Measuring EDL Risk}

We estimate lower tail dependence coefficients to capture (i) EDL risk 1 between individual stock liquidity and market liquidity, (ii) EDL risk 2 between individual stock return and market liquidity, and (iii) EDL risk 3 between individual stock liquidity and market return. Intuitively, the lower tail dependence coefficient between two random variables reflects the likelihood that a realization of one random variable is in the extreme lower tail of its distri-

\footnotetext{
${ }^{6}$ The number of lags is set at 4 since the partial autocorrelation function of $d_{t}^{i}$ becomes insignificant before the fifth lag for most stocks in the sample. In order to consider possible time-variation of the illiquidity process (such as increased mean liquidity or faster mean-reversion) and to keep the innovation estimates fully outof-sample, the AR(4)-parameters are estimated using a three year moving window of data up to week $t-1$ of the liquidity series of stock $i$. We verify the robustness of our results to using simple liquidity-differences instead of estimated liquidity-shocks in Section 4.2.
} 
bution conditional on the realization of the other random variable also being in the extreme lower tail of its distribution. Given two random variables $X_{1}$ and $X_{2}$, lower tail dependence $\lambda_{L}$ is formally defined as

$$
\lambda_{L}:=\lambda_{L}\left(X_{1}, X_{2}\right)=\lim _{u \rightarrow 0+} P\left(X_{1} \leq F_{1}^{-1}(u) \mid X_{2} \leq F_{2}^{-1}(u)\right),
$$

where $u \in(0,1)$ denotes the value of the distribution function, i.e., $\lim _{u \rightarrow 0+}$ indicates the limit if we approach the left tail of the distribution from above. ${ }^{7}$ If $\lambda_{L}$ is equal to zero (as is the case for joint normal distributions), the two variables are asymptotically independent in the lower tail.

The lower tail dependence coefficient between two variables can be expressed in terms of a copula function $C:[0.1]^{2} \mapsto[0,1]{ }^{8}$ McNeil, Frey, and Embrechts (2005) show that a simple expression for $\lambda_{L}$ in terms of the copula $C$ of the bivariate distribution can be derived based on

$$
\lambda_{L}=\lim _{u \rightarrow 0+} \frac{C(u, u)}{u}
$$

if $F_{1}$ and $F_{2}$ are continuous. Equation (7) has analytical solutions for many parametric copulas. In this study we use 12 different basic copula functions. A detailed overview of these basic copulas and the corresponding lower tail dependencies (and upper tail dependencies) is provided in Table B.1 in Internet Appendix B. As in Chabi-Yo, Ruenzi

\footnotetext{
${ }^{7}$ Similarly, the coefficient of upper tail dependence $\lambda_{U}$ can be defined as

$$
\lambda_{U}:=\lambda_{U}\left(X_{1}, X_{2}\right)=\lim _{u \rightarrow 1-} P\left(X_{1} \geq F_{1}^{-1}(u) \mid X_{2} \geq F_{2}^{-1}(u)\right)
$$

${ }^{8}$ Copula functions isolate the description of the dependence structure of the bivariate distribution from the univariate marginal distributions. Sklar (1959) shows that all bivariate distribution functions $F\left(x_{1}, x_{2}\right)$ can be completely described based on the univariate marginal distributions $F_{1}$ and $F_{2}$ and a copula function $C$. For a detailed introduction to the theory of copulas, see Nelsen (2006).
} 
and Weigert (2015) and Weigert (2015), we form 64 convex combinations of the basic copulas consisting of one copula (out of four) that allows for asymptotic dependence in the lower tail, $C_{\lambda_{L}}$, one copula (out of four) that is asymptotically independent, $C_{\lambda_{I}}$, and one copula (out of four) that allows for asymptotic dependence in the upper tail, $C_{\lambda_{U}}$

$$
\begin{aligned}
C\left(u_{1}, u_{2}, \Theta\right)= & w_{1} \cdot C_{\lambda_{L}}\left(u_{1}, u_{2} ; \theta_{1}\right)+w_{2} \cdot C_{\lambda_{I}}\left(u_{1}, u_{2} ; \theta_{2}\right) \\
& +\left(1-w_{1}-w_{2}\right) \cdot C_{\lambda_{U}}\left(u_{1}, u_{2} ; \theta_{3}\right)
\end{aligned}
$$

where $\Theta$ denotes the set of the basic copula parameters $\theta_{i}, i=1,2,3$ and the convex weights $w_{1}$ and $w_{2}$.

To determine which convex copula combinations deliver the best fit for the data, we use 3-year rolling windows of weekly data. We fit all 64 convex copula combinations to the bivariate distribution of each stock's (i) liquidity and market liquidity, (ii) return and market liquidity, and (iii) liquidity and market return in the rolling window. We select a specific copula combination for each stock and EDL risk component based on the estimated loglikelihood value among the 64 different copulas. ${ }^{9}$ We then use the copula with the best fit for the respective stock and EDL risk component over the previous three years in the estimation of tail dependence coefficients using equation (7). As this procedure is repeated for each stock $i$ and week $t$, we end up with a panel of tail dependence coefficients EDL risk $_{i t}^{1}$, EDL risk $_{i t}^{2}$ and EDL risk ${ }_{i t}^{3}$ at the stock-week level.

\footnotetext{
${ }^{9}$ Table B.2 in the Internet Appendix reports the results of this selection method. Over all stock-week ob-

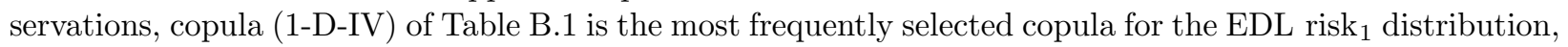
copula (1-A-IV) is the most frequently selected copula for the EDL risk 2 distribution, and copula (1-A-IV) is

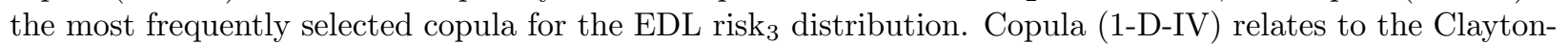
FGM-Rotated Clayton-copula and copula (1-A-IV) relates to the Clayton-Gauss-Rotated Clayton-copula. We verify the robustness of our results to using worse-fitting and likelihood-weighted copulas in Section 4.2.
} 
Joint EDL risk for stock $i$ in week $t$ is subsequently defined as the sum of the EDL risk components:

$$
\mathrm{EDL}_{\mathrm{risk}_{i t}}=\mathrm{EDL} \operatorname{risk}_{i t}^{1}+\mathrm{EDL}_{\mathrm{risk}_{i t}^{2}}^{2} \mathrm{EDL} \operatorname{risk}_{i t}^{3}
$$

For a more detailed description of the estimation method, we refer the reader to Internet Appendix B.

\subsection{Data and the Evolution of Aggregate EDL Risk}

We obtain data for all common stocks (CRSP share codes 10 and 11) traded on the NYSE/AMEX between January 1, 1963 and December 31, 2012. The period from 1963 through 1965 is used for the calculation of first illiquidity innovations and the period from 1966-1968 is used to fit the first copulas and estimate EDL risk (as explained in Section 2.2 and Internet Appendix B). Asset pricing tests are performed in the time period from 1969-2012.

To keep our liquidity measure consistent across stocks, we exclude common stocks traded on NASDAQ since NASDAQ volume data includes interdealer trades and thus is not directly comparable to NYSE/AMEX volume data. For each firm $i$ and each week $t$ we estimate the EDL risk components (EDL risk $_{i t}^{1}, \mathrm{EDL} \mathrm{risk}_{i t}^{2}$ and EDL risk ${ }_{i t}^{3}$ ) based on weekly return- and liquidity data over a rolling 3-year window. We use the weekly value-weighted CRSP market return and the AR(4)-innovations of the value-weighted average of liquidity over all stocks in the sample as market return and market liquidity, respectively. Using a 3-year rolling horizon of weekly data offsets two potential concerns: First, to obtain reliable estimates for the EDL risk coefficients, we need a sufficiently large number of observations. Second, we try to avoid very long estimation in- 
tervals as EDL risk is likely to be time-varying. ${ }^{10}$ EDL risk for stock $i$ in week $t$ is then defined as in equation (9) calculated as the sum of the separate EDL risk components.

To avoid microstructure issues, we exclude data for all weeks $t$ in which the stock's price at the end of week $t-1$ is less than $\$ 2$. We retain the EDL risk estimates of all stocks in week $t$ that have more than $156 / 2=78$ valid weekly return and liquidity observations during the last 3 years. Overall, we obtain 3,670,214 firm-week observations after applying these filters. The number of firms in each year over our sample period ranges from 1,290 to 2, 036 with an average of 1,693. Table 1 provides summary statistics.

[Insert Table 1 about here]

In the first five columns we report the mean, the $25 \%$, the $50 \%$, the $75 \%$ quantile and the standard deviation for EDL risk, the weekly excess return over the risk-free rate, and other key variables in this study. The mean (median) for EDL risk is 0.188 (0.157) with a standard deviation of 0.147. Joint EDL risk can be decomposed into its risk components with average values of $0.066\left(\mathrm{EDL} \mathrm{risk}_{1}\right), 0.066\left(\mathrm{EDL} \mathrm{risk}_{2}\right)$, and $0.056\left(\mathrm{EDL} \mathrm{risk}_{3}\right) .{ }^{11}$ The mean weekly excess return across all stocks is $0.15 \%$. We present the weekly excess return in week $t+2$ as we will relate returns in this week to EDL risk measures determined in week $t$ in our later asset pricing tests (Section 3). Summary statistics of additional firm characteristics and return patterns (that we later use in our empirical analysis mainly as control variables) are displayed in the rest of the table. For detailed descriptions of all variables, see Internet Appendix C.

\footnotetext{
${ }^{10}$ Our results are stable if we use rolling horizons of 1 -year, 2-years, or 5-years, respectively (see Section 4.2).

${ }^{11}$ We also compute the corresponding extreme upside liquidity (EUL) risk coefficients with upper tail dependence coefficients. The mean (median) for EUL risk is much smaller than for EDL risk with a value of 0.139 (0.105). In unreported tests, we do not find an impact of EUL Risk on average future stock returns. Our results on the impact of EDL risk on average future stock returns are unaffected when controlling for EUL Risk.
} 
The last three columns of Table 1 show average characteristics of stocks that are classified as above or below, respectively, the median EDL risk stock according to their EDL risk value in the respective week, as well as the difference between the two. Average future weekly returns for above median EDL risk stocks are $0.17 \%$ (8.84\% p.a.), whereas they are only $0.12 \%$ (6.24\% p.a.) for below median EDL risk stocks. The difference amounts to $0.05 \%$ per week (2.60\% p.a.) and is statistically significant at the $1 \%$-level.

Table 1 also shows that (somewhat surprisingly) above median EDL risk stocks tend to have lower linear liquidity risk as measured by the Acharya and Pedersen (2005) liquidity beta. However (as expected) they tend to have higher downside return and downside liquidity betas (defined following the logic of downside return betas from Ang, Chen, and Xing (2006)) as the sum of the three Acharya and Pedersen (2005) linear liquidity betas conditional on the market return and market liquidity, respectively, being below their respective means). Above median EDL risk stocks also tend to have higher return betas and higher extreme downside return risk (EDR). The two groups also differ with respect to other firm characteristics like size, book-to-market, and liquidity. These patterns mandate that we control for the influence of these variables in our later asset pricing exercise.

We report cross-correlations between the independent variables used in this study in Table 2 .

[Insert Table 2 about here]

Our results reveal that the magnitude of correlations between EDL risk and other independent variables is moderate. ${ }^{12}$ EDL risk is positively correlated with EDR risk (correlation of 0.26 ), downside linear return risk $\beta_{R}^{-}$(correlation of 0.12 ), and negatively correlated with return coskewness (correlation of -0.18). Interestingly, EDL risk is hardly correlated with

\footnotetext{
${ }^{12} \mathrm{By}$ construction, EDL risk is highly correlated with the separate EDL components. The separate EDL risk components display positive relationships (with correlations of $0.12,0.24$ and 0.08 ) among each other.
} 
(downside) linear liquidity risks $\beta_{L}$ and $\beta_{L}^{-}$(correlations of -0.02 and 0.05 ); this provides the first evidence that EDL risk measures a dimension of liquidity risk which is different from linear liquidity risk as analyzed in Acharya and Pedersen (2005).

To better understand the temporal variation of EDL risk, we investigate the development of aggregate EDL risk over time. Aggregate EDL risk, EDL risk ${ }_{m, t}$, is defined as the weekly

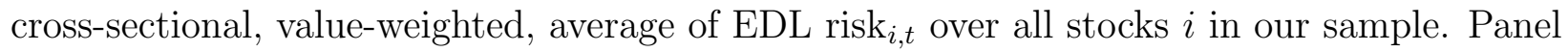
A of Figure 1 plots the time series of EDL risk $m, t$.

[Insert Figure 1 about here]

Aggregate EDL risk appears relatively stationary over time. The graph exhibits occasional spikes in EDL risk Ent $_{t}$ that seem to coincide with worldwide market crises. A large peak in EDL risk $_{m, t}$ occurs during 1987-1990, the time period after Black Monday in October 1987, the largest one-day percentage decline in U.S. stock market history. Other spikes in aggregate EDL risk correspond to the crises of 1978-1979 (Second U.S. Oil Crisis), 1997-1998 (Asian Financial Crisis), and 2008-2011 (Global Financial Crisis). We also plot the development of aggregate EDR (extreme downside return) risk over time in Panel A. ${ }^{13}$ Aggregate EDL risk and aggregate EDR risk are highly correlated with a value of 0.74 , suggesting that both time series are affected by similar sources of economic risk. The general tendency for stronger asymptotic return dependence in the left tail in down markets is well-documented in Ang and Chen (2002) and Chabi-Yo, Ruenzi and Weigert (2015).

In Panel B of Figure 1 we plot the time series of the separate aggregate EDL risk components. All time series are highly correlated with an average value of around 0.59. Interestingly, the graph displays different patterns in the behaviour of the EDL risk components

\footnotetext{
${ }^{13}$ In the same way as the EDL risk components, EDR risk is computed as the lower tail dependence coefficient in the bivariate distribution between individual stock return and the market return. Subsequently, aggregate EDR risk, EDR risk ${ }_{m, t}$ is defined as the weekly cross-sectional, value-weighted, average of EDR risk $i, t$ over all stocks $i$ in our sample.
} 
during financial crises. In the 1987 (Black Monday) stock market crash, the spike in aggregate EDL risk is mainly caused by increasing aggregate EDL risk ${ }_{1}$ and EDL risk ${ }_{2}$. In contrast, all three components of EDL risk drive the aggregate EDL risk peak during 2008-2011.

\section{EDL Risk and Future Returns}

In the main part of the empirical analysis we relate EDL risk estimates at week $t$ to portfolio and individual stock excess returns over week $t+2$. We skip week $t+1$ when investigating the relationship between EDL risk and future returns to avoid spurious correlations due to short-term reversals or bid-ask bounce. Note that we only use data observable to the investor at the end of week $t$ in order to predict stock returns in week $t+2$. Strictly separating the estimation window for EDL risk and the subsequent return prediction window alleviates concerns related to overfitting. The use of weekly return horizons is natural since we estimate EDL risk and other risk measures based on weekly data. However, our results are robust if we relate EDL risk estimates at week $t$ to excess returns over week $t+1$ or if we evaluate monthly return frequencies (see Section 4.3). To properly account for the impact of autocorrelation and heteroscedasticity on statistical significance in portfolio sorts, factor models, and multivariate regressions, we use Newey and West (1987) standard errors.

\subsection{Univariate Portfolio Sorts}

We start our empirical analysis with univariate portfolio sorts. For each week $t$ we sort stocks into five quintiles based on their EDL risk estimated over the past three years as described in Section 2.2. We then investigate the equally-weighted average excess return over the risk-free rate for these quintile portfolios as well as differences in average returns between quintile portfolio 5 (strong EDL risk) and quintile portfolio 1 (weak EDL risk) over week $t+2$. 
[Insert Table 3 about here]

Column (1) reports average EDL risk coefficients of the stocks in the quintile portfolios. There is considerable cross-sectional variation in EDL risk; average EDL risk ranges from 0.04 in the bottom quintile portfolio to 0.39 in the top quintile portfolio. More importantly, in column (2) we find that stocks with strong EDL risk earn significantly higher average future returns than stocks with weak EDL risk. Stocks in the quintile with the weakest (strongest) EDL risk earn an annual average excess return of $5.77 \%(9.77 \%)$. The return spread between quintile portfolio 1 and 5 is $4.00 \%$ p.a., which is statistically significant at the $1 \%$ level (t-statistic of 3.66). ${ }^{14}$ The results also show that the returns are monotonically increasing from the weakest to the strongest EDL risk quintile. This pattern is also confirmed based on the Patton and Timmermann (2010) monotonicity test, which clearly rejects the null hypothesis of a flat or decreasing pattern over the five EDLR portfolio returns at a p-value of $0.2 \%$.

In columns (3) through (8) of Table 3, we disentangle the premium for EDL risk into its three risk components. Columns (3) and (4) show the relationship between EDL risk and annualized average future excess returns. The yearly return spread between quintile portfolios 1 and 5 is only $0.33 \%$ p.a. and is not statistically significant. Columns (5) and (6) document an increasing relationship between EDL risk $k_{2}$ and annualized average future returns. Stocks in the quintile with the weakest (strongest) EDL risk ${ }_{2}$ earn an annualized average excess return of $5.73 \%(9.80 \%)$. Thus, on average, stocks in quintile portfolio 5 outperform stocks in quintile portfolio 1 by $4.08 \%$ p.a., which is statistically significant at the $1 \%$ level (t-statistic of 4.74). Finally, we report the results of portfolio sorts for EDL risk 3

\footnotetext{
${ }^{14}$ As we are sorting stocks by their sensitivity to extreme market states, one might argue that high nonnormality of strong-weak returns could be a problem for the standard measurement of statistical significance in a finite sample. This is not the case: Bootstrapped 99\% confidence intervals (unreported) for the EDLR difference portfolio remain comfortably above zero.
} 
and average future excess returns in columns (7) and (8). We find that stocks in the quintile with the weakest (strongest) EDL risk 3 earn an average excess return of 6.38\% (9.97\%) p.a. The return spread between quintile portfolio 5 and quintile portfolio 1 is $3.59 \%$ p.a., which is again statistically significant at the $1 \%$ level (t-statistic of 3.87 ).

In summary, the results from Table 3 provide evidence that EDL risk has an impact on the cross-section of expected stock returns. Stocks with strong EDL risk exposure earn higher average future returns than stocks with weak EDL risk exposure. The main drivers of the EDL risk premium are the EDL risk 2 and EDL risk ${ }_{3}$ components. The finding that EDL risk 1 (commonality in liquidity) is not priced is analogous to results by Acharya and Pedersen (2005) for linear liquidity risk. In the following sections, we mostly present the results of the impact of joint EDL risk on future returns. However, our results remain stable if we concentrate on the sole impact of EDL risk 2 and EDL risk 3 and are typically insignificant for EDL risk $_{1} \cdot{ }^{15}$

\subsection{Bivariate Portfolio Sorts}

The correlations in Table 2 document that EDL risk is correlated with other related (liquidity and return) risk measures and firm characteristics. For example, an increase in EDL risk tends to go along with an increase in linear downside liquidity $\left(\beta_{L}^{-}\right)$risk and extreme downside return (EDR) risk. Hence, the higher average future returns for strong EDL risk portfolios could be driven by differences in these other variables. To isolate the return premium of EDL risk from the impact of other related characteristics, we now conduct dependent equal-weighted portfolio double sorts. ${ }^{16}$

\footnotetext{
${ }^{15}$ We report robustness tests for the component-wise return premiums - controlling for important determinants of stock returns - in Table 10.

${ }^{16}$ As in Section 3.1, EDL risk as well as $\beta_{L}, \beta_{L}^{-}$and EDR risk in week $t$ are estimated over a threeyear horizon. Firm size and Amihud's illiquidity ratio are from the end of week $t$. We then investigate equally-weighted average excess returns over week $t+2$.
} 
[Insert Table 4 about here]

In Panel A of Table 4, we analyze whether the EDL risk premium is explained by linear liquidity risk, $\beta_{L}$ (see Internet Appendix C), which measures systematic variation in liquidity unconditional on market conditions. We first form five portfolios sorted by $\beta_{L}$. Then, within each $\beta_{L}$ quintile, we sort stocks into five portfolios based on EDL risk. ${ }^{17}$ We report the annualized average weekly $t+2$ portfolio returns in excess of the risk-free rate for the $25 \beta_{L}$ $\times$ EDL risk portfolios.

As in Acharya and Pedersen (2005), we find that average future returns of strong $\beta_{L}$ stocks are higher than those of weak $\beta_{L}$ stocks within the two top EDL risk quintiles, while there is no notable impact of $\beta_{L}$ in the lower EDL risk quintiles. More importantly, we find that strong EDL risk stocks clearly outperform weak EDL risk stocks in all $\beta_{L}$ quintiles. The return difference between the weakest EDL risk quintile and the strongest EDL risk quintile ranges from $2.60 \%$ p.a. in the second-lowest $\beta_{L}$ quintile up to $6.10 \%$ p.a. in the highest $\beta_{L}$ quintile. The return difference is on average $3.68 \%$ p.a., which is statistically significant at the 1\%-level. Hence, regular linear liquidity risk as analyzed in Acharya and Pedersen (2005) cannot account for the reward earned by holding stocks with strong EDL risk.

In Panel B of Table 4, we analyze whether the EDL risk premium is explained by linear downside liquidity risk, $\beta_{L}^{-}$(see Internet Appendix C), which-like EDL risk-focuses on systematic downside liquidity risk. However, the conceptional difference between EDL risk and $\beta_{L}^{-}$risk is that the latter focuses on systematic risk to market returns (liquidity) below the mean, while the former explicitly focuses on extreme events. As above, in a first step we form five portfolios sorting by $\beta_{L}^{-}$. Then, within each $\beta_{L}^{-}$quintile, we sort stocks into five portfolios based on EDL risk and report annualized average excess portfolio returns. We find some evidence that strong $\beta_{L}^{-}$stocks tend to outperform weak $\beta_{L}^{-}$stocks within each

\footnotetext{
${ }^{17}$ Our results (not reported) are stable if we reverse the sorting order or conduct independent sorts.
} 
EDL risk quintile. However, more interestingly in our context, we again find that in all $\beta_{L}^{-}$ quintiles strong EDL risk stocks outperform weak EDL risk stocks significantly. Across all $\beta_{L}^{-}$quintiles stocks in the weak EDL risk portfolios earn average excess returns of $5.75 \%$ p.a., whereas stocks in the strong EDL risk portfolios earn average excess returns of $9.68 \%$ p.a. and the difference is highly significant overall as well within each individual $\beta_{L}^{-}$quintile. Thus, linear downside liquidity risk cannot account for the EDL risk premium either.

In Panel $\mathrm{C}$ of Table 4, we investigate whether EDL risk is different from extreme downside return risk, EDR risk (see Internet Appendix C), which captures systematic crash risk in returns. Again, to explicitly control for variation in EDR risk, we first form quintile portfolios sorted on EDR risk. Then, within each EDR risk quintile, we sort stocks into five portfolios based on EDL risk and report annualized average excess portfolio returns.

As in Chabi-Yo, Ruenzi and Weigert (2015), we find that strong EDR risk stocks outperform weak EDR risk stocks within all EDL risk quintiles. Furthermore, the return difference between the weak EDL risk quintile and the strong EDL risk quintile is again positive in all EDR risk quintiles and statistically significant in four of the five quintiles. On average, the return spread amounts to $3.25 \%$ p.a., which is statistically significant at the $1 \%$ level. Therefore, the impact of EDL risk on future stock returns is also clearly different from the impact of EDR risk.

Finally, in Panel D and Panel E, we analyze whether the EDL risk premium can be explained by firm size or the level of stocks' liquidity costs, as measured by Amihud's illiquidity ratio (see Internet Appendix C). As Amihud (2002), we find that average future returns of illiquid stocks are higher than those of liquid stocks. More importantly, we find that the average EDL risk premium controlling for firm size (the illiquidity level) is 3.87\% (3.89\%) annually and statistically significant at the one percent level in each case. Hence, the EDL risk premium is not explained by firm size nor the level of stocks' liquidity costs. 
To summarize, dependent portfolio double sorts provide strong evidence that EDL risk is not explained by $\beta_{L}, \beta_{L}^{-}$, EDR risk or by firm size and liquidity levels. So far, our analysis relies on return differences and we only control for the impact of systematic risk factors indirectly by double-sorting portfolios based on EDL risk and other risk characteristics of the stock. To control for the exposure to other systematic risk factors, we now investigate whether the EDL risk premium can be explained by alternative multivariate factor models suggested in the literature.

\subsection{Factor Models}

We regress the weekly $t+2$ return of the EDL risk quintile difference portfolio on various factors that have been shown to determine the cross-section of average stock returns. ${ }^{18}$ Since most factors are only available on a monthly basis, we build portfolios, which are rebalanced monthly based on past EDL risk, again leaving a minimum of a one-week gap between calculation of EDL risk and portfolio formation. We then investigate risk-adjusted monthly returns according to these factors. Table 5 reports the results.

\section{[Insert Table 5 about here]}

Results for our main specifications are reported in Panel A of Table 5. In regressions (1) and (2) we adjust the EDL risk quintile difference portfolio for its exposure to the market factor (as in Sharpe (1964)), the Fama and French (1993) three-factor model that additionally corrects for the exposure to size (SMB) as well as to book-to-market (HML), and the Carhart (1997) four-factor model that additionally controls for momentum (MOM). We find that the EDL risk portfolio loads significantly positively on the market factor and

\footnotetext{
${ }^{18}$ The formal definitions of all factors used as well as the respective data sources are provided in Internet Appendix C.
} 
significantly negatively on the momentum factor. The risk-adjusted annualized alpha is significantly positive at the 1\%-level and amounts to $2.70 \%$ for the market-model and $3.52 \%$ for the Carhart (1997) 4-factor alpha.

In regression (3), we include the Pastor and Stambaugh (2003) traded liquidity factor. Surprisingly, we find that the EDL risk portfolio does not load significantly on the Pastor and Stambaugh (2003) factor and the return premium for EDL risk is not reduced. The risk-adjusted alpha of the EDL risk portfolio is $3.52 \%$ p.a. ${ }^{19}$

Regressions (4) through (7) additionally control for the EDR risk factor of Chabi-Yo, Ruenzi and Weigert (2015), the Bali, Cakici, and Whitelaw (2011) factor for lottery-type stocks, the Kelly and Jiang (2014) tail risk factor, and the U.S. equity betting-against-beta factor from Frazzini and Pedersen (2014). Again, the annual alpha of the EDL risk portfolio remains statistically significant at least at the 5\% level in each case and ranges from $2.51 \%$ to $4.10 \%$.

Panel B of Table 5 reports annualized alphas for additional alternative factor models. We regress the EDL risk quintile difference portfolio on the factors from the Fama and French (2015) five-factor model, the Hou, Xue, and Zhang (2015) and Novy-Marx (2013) four-factor models, as well as the Carhart (1997) four-factor model extended by the Fama and French short- and long-term reversal factors, the leverage factor from Adrian, Etula, and Muir (2014), the quality-minus-junk factor from Asness, Frazzini, and Pedersen (2014), the undervalued-minus-overvalued factor from Hirshleifer and Jiang (2010), and the $\mathrm{Wu}$ (2015) liquidity-tail factor. The alpha of our strong minus weak EDL risk

\footnotetext{
${ }^{19}$ In unreported tests, we find that the EDL risk portfolio loads significantly positively on the Pastor and Stambaugh (2003) factor in the period from 1969 through 2000, the time span that is analyzed in their paper. However, the yearly alpha of the EDL risk portfolio is also not reduced by the Pastor and Stambaugh (2003) liquidity factor during this sub-period. We obtain similar results when we adjust the EDL risk quintile difference portfolio for its exposure to the Sadka (2006) liquidity factor (which is based on the permanent-variable component of the price impact function) in our model.
} 
return ranges from $2.80 \%$ p.a. to $4.04 \%$ p.a. and is always statistically significant at the $1 \%$-level.

The results reveal that the premium for EDL risk is robust to controlling for a wide array of alternative factor specifications. However, Daniel and Titman (1997) advocate considering not just factor sensitivities in the analysis of determinants of cross-sectional stock returns. Thus, to also account for firm specific characteristics in our asset pricing tests, we now proceed to run Fama and MacBeth (1973) regressions on the firm level.

\subsection{Fama-MacBeth Regressions}

We perform individual Fama and MacBeth (1973) regressions of excess stock returns over the risk-free rate in week $t+2$ on risk and firm characteristics measured at week $t$ in the period from 1969 to $2012 .{ }^{20}$ Table 6 presents the regression results of future weekly excess returns on EDL risk and various combinations of control variables.

[Insert Table 6 about here]

In regression (1), we include EDL risk as the only explanatory variable. Consistent with our results from portfolio sorts and multivariate factor models, it shows a highly statistically as well as economically positive impact. For example, stocks with top quintile EDL risk earn higher future returns of around $3.35 \%$ p.a. as compared to bottom quintile EDL risk stocks. $^{21}$

\footnotetext{
${ }^{20}$ Running Fama and MacBeth (1973) regressions on the individual firm level has the disadvantage that risk factors are estimated less precisely in comparison to using portfolios as test assets. However, Ang, Liu and Schwarz (2010) show that forming portfolios does not necessarily lead to smaller standard errors of cross-sectional coefficient estimates. Creating portfolios degrades information by shrinking the dispersion of risk factors and leads to larger standard errors.

${ }^{21}$ Top (bottom) quintile EDL risk stocks have an average EDL risk exposure of 0.39 (0.04). Hence, our regressions results indicate an annual return spread of $0.00184 \cdot 0.35 \cdot 52=3.35 \%$.
} 
In regression (2), we add a stock's market return beta $\left(\beta_{R}\right)$, size, book-to-market ratio, and its past yearly return to our model. EDL risk remains statistically significant at the $1 \%$ level when including these additional variables.

In regressions (3) through (5), we expand our model and include a stock's linear liquidity risk $\left(\beta_{L}\right)$ from Acharya and Pedersen (2005), extreme downside return (EDR) risk (ChabiYo, Ruenzi and Weigert (2015)), the illiquidity level (Amihud (2002), 12-month average), exposure to tail risk $\left(\beta_{\text {Tail }}\right)$ from Kelly and Jiang (2014), idiosyncratic volatility (Ang, Hodrick, Xing, and Zhang (2006)), and a stock's coskewness with the market (Harvey and Siddique (2000)).We find that the inclusion of these additional variables only slightly reduces the impact of EDL risk on future returns, which is still statistically significant at the $1 \%$ level.

Finally, in regression (6), we replace $\beta_{R}$ by $\beta_{R}^{-}$and $\beta_{R}^{+}$as well as $\beta_{L}$ by $\beta_{L}^{-}$and $\beta_{L}^{+}$. None of these variables shows any significant impact on returns. In contrast, our main result regarding the impact of EDL risk on future returns remains unchanged - EDL risk is statistically significant at the $1 \%$ level and carries an economically significant positive impact. Top quintile EDL risk stocks earn higher future returns by about $2.64 \%$ p.a. than bottom quintile EDL risk stocks, controlling for the full set of additional variables.

The coefficient estimates for the impact of the control variables broadly confirm findings from the existing literature: Firm size (book-to-market) is shown to have a negative (positive) impact on expected returns (e.g., Banz (1981); Basu (1983); and Fama and French (1993)), while stocks that realize the best (worst) returns over the past 3 to 12 months are found to continue to perform well (poorly) over the subsequent 3 to 12 months (e.g., Jegadeesh and Titman (1993)). EDR risk and $\beta_{\text {Kelly }}$ are positively related to future average returns (Kelly and Jiang (2014) and Chabi-Yo, Ruenzi and Weigert (2015)), whereas idio vola shows 
a negative impact (e.g., Ang, Hodrick, Xing, and Zhang (2006)). However, when adding the full set of explanatory variables, we do not find a statistically significant impact for $\beta_{L}$, illiq or coskew, possibly due to the sometimes high correlations across variables (see Table 2).

In summary, we provide strong evidence that EDL risk is priced in the cross-section of expected stock returns. The premium for EDL risk is robust to portfolio double sorts with regards to $\beta_{L}, \beta_{L}^{-}$, EDR Risk, firm size and stock illiquidity. It is robust to various asset pricing factor models, and remains signficant when controlling for a wide list of firm characteristics.

\subsection{Does the Magnitude of the Extreme Downside Matter?}

Our asset pricing tests examine the impact of EDL risk, defined as the sum of three lower tail dependence coefficients (see equation (6)). A lower tail depenence coefficient is defined as the probability that a realization of one random variable is in the extreme lower tail of its distribution, conditional on the realization of the other random variable also being in the extreme lower tail of its distribution. Thus, EDL risk tells us how likely it is that a stock realizes (i) its worst liquidity at the time when the market realizes its worst liquidity, (ii) its worst return when the market realizes its worst liquidity, and (iii) its worst liquidity when the market realizes its worst return. However, EDL risk does not take into account the severity of the worst return or liquidity shock, i.e., its magnitude. We now check whether the impact of EDL risk is stronger if we can expect the worst outcome for a stock to be particularly bad, i.e., if we interact the probability of the joint outcome with a proxy for the magnitude of the outcome.

As proxies for the magnitude of a bad outcome, we use four ex-ante proxies based on the dispersion of returns (liquidity shocks): a stock's return (liquidity shock) standard deviation during the past three years, its idiosyncratic return (liquidity shock) volatility (controlling 
for value-weighted market returns and liquidity shocks) during the past three years, its Value-at-Risk (VaR, defined as the 5\% quantile of the weekly returns (liquidity shocks) of the stock during the past three years), and its conditional Value-at-Risk (CoVaR, defined as the conditional mean of all weekly returns (liquidity shocks) below the $5 \%$ quantile). The worst outcomes with respect to returns and liquidity shocks tend to be particularly bad for stocks with a high standard deviation (a high idiosyncratic volatility, a low VaR and a low CoVaR) regarding the respective variable.

To examine whether dispersion of returns and liquidity shocks indeed increases the impact of EDL risk, we sort stocks into two categories: Low dispersion stocks which display a standard deviation or idiosyncratic volatility (VaR or CoVar) of returns and liquidity shocks below (above) the respective median measure and high dispersion stocks which display a standard deviation or idiosyncratic volatility (VaR or CoVar) of returns and liquidity shocks above (below) the respective median measure.

Panel A of Table 7 reports the annualized excess portfolio returns of the top (bottom) EDL risk quintile portfolio and differences in returns for the low and the high dispersion samples.

[Insert Table 7 about here]

As expected, our results reveal that the impact of EDL risk on future returns is stronger for the high dispersion stocks, irrespective of which ex-ante proxy for dispersion we use. In the high dispersion sample, top quintile EDL risk stocks outperform bottom quintile EDL risk stocks by an average of $4.95 \%$ p.a. across dispersion measures (significant at the $1 \%$ level). Top quintile EDL risk stocks also clearly outperform bottom quintile EDL risk stocks in the low dispersion sample (significant at the $1 \%$ level). However, in contrast to the high dispersion sample, the outperformance is significantly reduced to $3.33 \%$ p.a. 
To investigate whether these results are driven by correlations of the dispersion measures with other independent variables, we repeat regression (5) of Table 6 for the high and the low dispersion sample separately. ${ }^{22}$ Results for the impact of EDL risk are shown in Panel B of Table 7. The impact of EDL risk is $50 \%$ to $100 \%$ stronger for firms where bad outcomes are particularly severe, i.e., for firms with a high dispersion (high standard deviation, high idiosyncratic volatility, low VaR, and low CoVar) of returns and liquidity shocks. Hence, greater dispersion of returns and liquidity shocks indeed increases the impact of EDL risk on future average stock returns.

\subsection{Temporal Differences in the EDL Risk Premium}

We now investigate whether the premium for EDL risk is stable over time. We first reproduce the results of the univariate portfolio sorts for the time period from January 1969 through December 1987 and from January 1988 through December 2012. As a cutoff for our sample, we select 1987, the year of Black Monday, when the U.S. stock market had its largest one-day percentage decline in history. Focusing on this event is motivated by studies from the empirical option pricing literature (e.g., Rubinstein (1994) and Bates (2008)) which document that premiums for deep-out-of-the-money put options strongly increased after 1987, possibly due to investors becoming more crash-averse. Thus, our conjecture is that this increased crash aversion might also have led to a higher premium for EDL risk in the crosssection of stock returns after 1987. Panel A of Table 8 reports the annualized future excess portfolio returns and alphas of portfolios sorted by EDL risk. We also report differences in average excess returns between quintile portfolio 5 (strong EDL risk) and quintile portfolio 1 (weak EDL risk).

\footnotetext{
${ }^{22}$ We include all other explanatory variables from regression (5) of Table 6 , but suppress them in the Panel.
} 
[Insert Table 8 about here]

The EDL risk premium between the two subperiods varies considerably. In the first subsample from 1969 through 1987, we only find weak evidence of a positive EDL risk premium. The return spread between the strong EDL risk and the weak EDL risk portfolio is $1.49 \%$ p.a. and not statistically significant at conventional levels. The results for the CAPM-alpha and the Carhart (1997) four-factor model are similar. The only statistically significant EDL risk premium is found for the Carhart (1997) specification, where the annualized return spread between the strong and the weak EDL risk portfolio amounts to $2.32 \%$ p.a. and is statistically significant at the $10 \%$-level.

In the post-crash period from 1988 through 2012, the premium for EDL risk strongly increases. Stocks in the quintile with the weakest (strongest) EDL risk earn an annual average excess return of $6.69 \%(12.60 \%)$. The return spread between quintile portfolios 1 and 5 is $5.91 \%$ p.a., which is statistically significant at the $1 \%$ level. We also find that this premium remains when we adjust raw returns for exposures to systematic risk factors using the standard factor models. The return spread with regard to the Carhart (1997) factor alpha is $3.99 \%$ p.a. and strongly significant at the $1 \%$ level.

Panel B of Table 8 reports the results from regressions (1) and (5) of Table 6 separately for the two subperiods. The results are similar to the above results from portfolio sorts. In the earlier time period prior to the 1987 crash, we do not find evidence of a significant EDL risk premium. In contrast, the EDL risk premium in the time period from 1988 through 2012 is statistically significant at the $1 \%$ level and economically large.

Figure 2 shows the temporal variation of the (cumulative) yearly Carhart (1997) factor alpha of the top EDL risk minus bottom EDL risk portfolio during the whole sample from January 1969 through December 2012. ${ }^{23}$

\footnotetext{
${ }^{23}$ When computing the yearly and cumulative alphas for the top EDL risk - bottom EDL risk portfolio,
} 
[Insert Figure 2 about here]

The graph reveals that the highest profits of the trading strategy can be attributed to the years 1990 and 2009. These years are subsequent to two severe market and liquidity crises: namely, the Black Friday stock market crash in 1987 and the financial crisis in 2008. We conjecture that these market crashes have strongly increased the crash aversion of investors, which subsequently has increased the premium (discount) for strong (weak) EDL risk stocks, which is in line with the findings of the empirical option literature mentioned above, which indicate increasing prices (and low expected returns) for securities that offer protection against strong market downturns after 1987.

\section{Robustness Checks}

\subsection{Liquidity Proxies}

The empirical analysis in Section 3 is performed using EDL risk estimates of liquidity innovations based on the Amihud (2002) Illiquidity Ratio, analogous to Acharya and Pedersen (2005). One potential concern is that our main findings are driven by the measurement error component of our proxy for liquidity. Attenuation bias caused by this measurement error would lead to an underestimation of the return premium for EDL risk. Nevertheless, to assure the stability of our findings, we now test whether our results regarding the impact of EDL risk on future returns are robust to using different (low-frequency and highfrequency) proxies of liquidity. As additional low-frequency liquidity proxies we use the Corwin and Schultz (2012) measure (Corwin), the Lesmond, Ogden and Trzcinka (1999)

no trading costs are taken into account. 
measure (Zeros), and the Fong, Holden and Trzcinka (2014) measure (FHT). ${ }^{24}$ As highfrequency liquidity proxies we select the effective spread (EffSpr), the relative spread (RelSpr), the intraday Amihud measure (IntAmi), and the 5-minute price impact measure (PriImp). The high-frequency liquidity proxies are calculated for common stocks traded on the NYSE/AMEX using the TAQ dataset in the period between January 1, 1996 and December 31, 2010. The big advantage of these proxies is their much lower measurement error. We perform asset pricing tests for the high-frequency proxies in the time period from 2002 to $2010 . .^{25}$

In the same way as for the Amihud (2002) Illiquidity Ratio, we estimate liquidity shocks, and subsequently the EDL risk, for each firm $i$ in each week $t$ based on weekly returns and liquidity shocks over 3-year rolling windows. Correlations between EDL risk based on different liquidity proxies are shown in Panel B of Table A.1 in the Internet Appendix. We find that all correlations between EDL risk measures based on low-frequency proxies and those based on high-frequency proxies are positive. EDL risk based on Corwin has the highest positive correlations to the high-frequency measures ranging from 0.48 to $0.57 .^{26}$

To investigate whether EDL risk is a priced factor in the cross-section of expected stock returns if measured based on other liquidity proxies, we perform portfolio sorts, factor regressions and multivariate Fama and MacBeth (1973) regressions similar to the ones from the previous section. Table 9 reports the results.

[Insert Table 9 about here]

\footnotetext{
${ }^{24}$ Detailed definitions of these variables, as well as data requirements, are given in Internet Appendix A.

${ }^{25}$ We compute illiquidity shocks for each stock based on a 3-year time horizon starting in January 1996. We then use the time period from 1999 to 2001 to estimate the first EDL risk values for each stock. Thus, our asset pricing tests using high frequency proxies only start in January 2002.

${ }^{26}$ For additional information about summary statistics and temporal variation of the different liquidity measures, see Internet Appendix A.
} 
Consistent with our previous results, Panel A shows that EDL risk is priced across all lowfrequency measures in our study. The annualized return spread between quintile portfolios 1 and 5 ranges from $1.47 \%$ p.a. for the Zeros measure to $4.00 \%$ p.a. for the illiq measure. We also find that return spreads, risk-adjusted by standard factor models (i.e., the Sharpe (1964) CAPM model and the Carhart (1997) four-factor model) remain positive for all liquidity measures and statistically significant for most of them. Moreover, we find supportive evidence for the pricing of EDL risk when investigating portfolio sorts for the high-frequency liquidity measures. All EDL raw and risk-adjusted return spreads are positive and economically significant. In addition, we find statistically significant impact of EDL risk on future returns for EffSpr, IntAmi, and PriImp. This is a remarkable result given that our sample period for our asset pricing tests is only 9 years in this case, which generally makes it very hard to detect any significant asset pricing patterns.

To confirm that our results are not driven by correlations of EDL risk with other explanatory variables, we repeat regression (5) of Table 6 for the EDL risk based on the alternative liquidity proxies. Our findings indicate that the impact of EDL risk is stable across the different liquidity proxies and not driven by measurement error. All EDL risk coefficients are positive. Except for the Zeros and RelSpr measures, coefficients are also statistically and economically significant, indicating a robust impact of EDL risk on future returns.

\subsection{Estimation Procedures and Weighting Scheme}

The estimation procedure of EDL risk in Section 3 is performed using an estimation horizon of 3 years of weekly returns and AR(4) liquidity-shocks, and a copula function that shows the best fit for each combination of firm, week and EDL risk component in the estimation window. Furthermore, portfolio sorts are conducted on an equally weighted basis. Thus, one concern might be that our results are specific to the details of our procedure. 
To address concerns of overfitting, we now demonstrate the robustness of our results to several changes in the estimation procedure: First, we apply different estimation horizons of 1 year $\left(\right.$ EDL risk $\left.{ }_{1 y}\right), 2$ years $\left(E D L ~\right.$ risk $\left._{2 y}\right)$, and 5 years (EDL risk $5 y$ ) for the estimation of EDL risk. Second, we use simple differences in stock liquidity instead of shocks from an $\operatorname{AR}(4)$ model. This robustness test alleviates concerns, that noise added through the estimation of AR(4)-parameters drives results. Third, we use different copula functions in the estimation procedure of the EDL risk components. In particular, we test the robustness of our results with copulas that performed best $\left(\mathrm{EDL}\right.$ risk $\left._{C 1}\right)$, second-best $\left(\mathrm{EDL}\right.$ risk $\left.\mathrm{C}_{2}\right)$, second-worst $\left(\mathrm{EDL}\right.$ risk $\left._{C 63}\right)$ and worst $\left(\mathrm{EDL}\right.$ risk $\left._{C 64}\right)$ for this stock-week, as well as a copula that is a likelihood-weighted average of all 64 copulas we consider $\left(\mathrm{EDL}\right.$ risk $\left._{C w}\right)$. The robustness of our results to these variations should show that they are not caused by estimation error and overfitting through selecting particular estimation horizons, liquidity-shock estimates, and copula functions. Finally, we check the stability of our results when considering the three different risk components EDL risk ${ }_{1}, \mathrm{EDL}$ risk $_{2}$, and EDL risk 3 in asset pricing tests separately.

To examine whether EDL risk is priced when the estimation procedure is varied, we again perform portfolio sorts, factor model regressions and multivariate Fama and MacBeth (1973) regressions. Results are reported in Table 10.

\section{[Insert Table 10 about here]}

Panel A shows that, in univariate equal-weighted portfolio sorts and based on standard factor models, EDL risk is significantly priced across specifications with alternative estimation horizons, different copulas, and when we use simple differences in stock liquidity instead of shocks from an AR(4) model. The annual EDL risk spread in average excess returns between quintile portfolios 1 and 5 ranges from $2.91 \%$ p.a. for EDL risk Ey $_{y}$ to $5.66 \%$ 
p.a. for the specification with liquidity differences instead of $\mathrm{AR}(4)$ shocks. We also find that risk-adjusted return spreads remain positive and are statistically significant at least at the 5\%-level across different estimation procedures. In line with our results from Section 3.1, we confirm that the premium for EDL risk is driven by the EDL risk 2 and EDL risk 3 components if we control standard factor models.

Finally, in Panel B, we repeat regression (5) of Table 6 of future returns on EDL risk (estimated using different horizons, liquidity differences and different copula functions) and other explanatory variables. Our results reveal that the positive, statistically significant impact of EDL risk on future returns is stable across different estimation procedures even when controlling for a wide array of firm and risk characteristics. Remarkably, we find a significant impact of both EDL risk 2 and EDL risk 3 when performing a joint regression of future stock returns on all EDL risk components at the same time. Overall, our robustness tests show that our main findings are not driven by overfitting or estimation errors.

Our previous portfolio sorts in Section 3 were performed based on equal-weighted portfolios. Thus, even though we exclude $<\$ 2$ - and NASDAQ-stocks, our results could be influenced by overweighting the importance of very small stocks. We now examine the results of value-weighted portfolio sorts. First, we form five portfolios sorted on firm size. Then, within each size quintile, we sort stocks into value-weighted portfolios based on EDL risk. Results are presented in Table 11.

[Insert Table 11 about here]

Consistent with our previous results, Panel A documents that the value-weighted EDL risk premium is positive and economically meaningful within each individual size quintile, ranging from $2.17 \%$ p.a. to $5.22 \%$ p.a. and typically significant at least at the $5 \%$-level. It 
is smallest and not statistically significant at conventional levels in the highest size quintile, which is consistent with the weakest return premium for EDL risk in the top size quintile from Panel D in Table 4. The average value-weighted EDL risk premium across all size quintiles is $3.71 \%$ and is statistically significant at the one percent level.

Panel B repeats the factor model regressions of Table 5 for the average across size quintiles of value-weighted strong-minus-weak EDL risk portfolios. In short, the results are very similar to the results based on equal-weighted porfolios from Table 5. Exposures (suppressed in Table 11) are qualitatively the same and all 7 specifications result in statistically significant annualized alphas ranging from $2.35 \%$ to $3.56 \%$. Overall the results for value-weighted portfolios confirm that the EDL risk premium is not just driven by a large number of tiny firms.

\subsection{Regression Methods and Adjusted Returns}

Our multivariate regression results in Section 3.4 rely on Fama and MacBeth (1973) regressions with winsorized variables. We now vary the regression approach, using the full set of independent variables for the complete sample period from 1969 to 2012. Results are presented in Panel A of Table 12.

[Insert Table 12 about here]

Regression (1) varies the baseline regression (5) from Table 6 by not using Newey-West standard errors in the second stage of the Fama and MacBeth (1973) regressions to determine statistical significance. Regression (2) uses the standard Fama and MacBeth (1973) approach without winsorizing the independent variables. In regression (3) we conduct a pooled OLS regression with time-fixed effects and standard errors clustered by stock. Regression (4) is a variation of (3), where we cluster standard errors by industry using the SIC-2-digits 
classification. ${ }^{27}$ Regressions (5) and (6) use panel data regressions with firm-fixed effects. In regression (6) standard errors are additionally clustered by firm. Finally, in regression (7) we regress excess returns on the independent variables in a random-effect panel regression. In all regression modifications, we document that EDL risk is a highly significant explanatory factor for the cross-section of expected stocks returns. The point estimate for the impact of EDL risk is always above 0.00117 and statistically significant at the $1 \%$ level.

So far, we have used weekly excess returns over week $t+2$ as our dependent variable in the asset pricing exercises. We now test the robustness of our results if we use different return lags, namely weekly returns in $t+1, t+3$, and $t+4$ as our dependent variable. Furthermore, we also investigate the impact of EDL risk on future monthly returns in month $t+1$. Results in Panel B of Table 12 document a stable and statistically significant impact of EDL risk on future returns across the different lags and return horizons.

Next, we adjust the return of each stock by subtracting the return of its corresponding Daniel, Grinblatt, Titman, and Wermers (1997) characteristic-based benchmark (DGTW). ${ }^{28}$ Again, our main result of a significant EDL risk premium remains unaffected.

Finally, some extreme market downturns might be driven by specific industries thus causing our findings to be potentially biased by industry effects. To investigate whether this is the case, we repeat our multivariate regressions with the full set of controls (i.e., regression (5) from Table 6), using industry-adjusted returns instead of raw returns as the dependent variable. To identify and cluster by industries, we use the SIC-2, SIC-3, the SIC-4 digit industry classification (with weekly returns), as well as the Fama-French 12 (FF12) and 48 (FF48) industry classifications (with monthly returns). For all classifications, the EDL risk coefficient remains positive and statistically significant.

\footnotetext{
${ }^{27}$ Results are virtually unchanged whether we cluster by Fama-French 48 or SIC industries.

${ }^{28}$ This test is performed using monthly data. Monthly DGTW benchmarks returns are available via http://www.smith.umd.edu/faculty/rwermers/ftpsite/ Dgtw/coverpage.htm.
} 


\section{Conclusion}

This study investigates whether investors receive compensation for holding stocks with strong extreme downside liquidity (EDL) risk: Strong EDL risk stocks realize their lowest return and liquidity realizations in periods of market return and market liquidity crises. We hypothesize that such stocks are unattractive assets to hold for crash-averse investors requiring them to demand a premium for holding strong EDL risk stocks.

Our empirical analysis provides clear evidence to support this hypothesis: The crosssection of expected stock returns reflects a premium for EDL risk. Stocks that are characterized by strong EDL risk earn significantly higher future returns than stocks with weak EDL risk. A trading strategy that is long in a portfolio consisting of $20 \%$ stocks with the strongest EDL risk delivers a raw return that is $4.00 \%$ p.a. higher than that of a portfolio consisting of $20 \%$ stocks with the weakest EDL risk. The high future returns earned by stocks with strong EDL risk can be explained neither by linear liquidity risk (as in Acharya and Pedersen (2005)) nor by different factor model specifications and are not due to differences in firm characteristics. Our results are stable across different liquidity measures and alternative estimation procedures of EDL risk.

There is evidence that certain investor groups seek (and can identify) stocks with strong tail risk exposure. For example, Agarwal, Ruenzi and Weigert (2015) show that hedge fund managers actively invest in such stocks and are able to earn the associated premium. Overall our results have important implications for portfolio performance management and financial stability. If financial institutions do not suffer the (unmitigated) consequences of a market

crash or liquidity crisis (e.g., because they expect to be bailed out), they are incentivized to buy strong EDL risk assets in order to earn the premium documented in our study. Such behavior would make those institutions, and consequently financial markets, more fragile. 


\section{References}

Acharya, V., Pedersen, L., 2005. Asset pricing with liquidity risk. Journal of Financial Economics $77,375-410$.

Adrian, T., Etula, E., Muir, T., 2014. Financial intermediaries and the cross-section of asset returns. Journal of Finance 69, 2557-2596.

Agarwal, V., Ruenzi, S., Weigert, F., 2015. Tail Risk in Hedge Funds: A Unique View from Portfolio Holdings. Unpublished Working Paper. Georgia State University, University of Mannheim, and University of St. Gallen.

Amihud, Y., Mendelson, H. (1986). Asset pricing and the bid-ask spread. Journal of Financial Economics, 17, pp. 223-249

Amihud, Y., 2002. Illiquidity and stock returns: Cross-section and time-series effects. Journal of Financial Markets 5, 31-56.

Ané, T., Kharoubi, C., 2003. Dependence structure and risk measure. Journal of Business $76,411-438$.

Ang, A., Chen, J., 2002. Asymmetric correlations of equity portfolios. Journal of Financial Economics 63, 443-494.

Ang, A., Chen, J., Xing, Y., 2006. Downside risk. Review of Financial Studies 19, 1191-1239.

Ang, A., Hodrick, R.J., Xing, Y., Zhang, X., 2006. The cross-section of volatility and expected returns. Journal of Finance 61, 259-299.

Ang, A., Liu, J., Schwarz, K., 2010. Using stocks or portfolios in tests of factor models. Unpublished Working Paper. Columbia University and University of Pennsylvania.

Anthonisz, S.A., Putnins, T.J., 2014. Asset pricing with downside liquidity risks. Unpublished Working Paper. University of Technology, Sydney.

Asness, C.S., Frazzini, A., Pedersen, L.H., 2014. Quality minus junk. Unpublished Working Paper. AQR Capital Management, New York University, and Copenhagen Business School 
Bali, T.G., Cakici, N., Whitelaw, R.F., 2011. Maxing out: Stocks as lotteries and the crosssection of expected returns. Journal of Financial Economics 99, 427-446.

Banz, R., 1981. The relation between return and market value of common stocks. Journal of Financial Economics 9, 3-18.

Basu, S., 1983. The relationship between earnings yield, market value, and return for NYSE common stocks: Further evidence. Journal of Financial Economics 12, 129-156.

Bates, D.S., 2008. The market for crash risk. Journal of Economic Dynamics and Control $32,2291-2321$.

Berkman, H., Jacobsen, B., Lee, J.B., 2011. Time-varying rare disaster risk and stock returns. Journal of Financial Economics 101, 313-332.

Brunnermeier, M., Pedersen, L., 2009. Market liquidity and funding liquidity. Review of Financial Studies 22, 2201-2238.

Carhart, M., 1997. On persistence in mutual fund performance. Journal of Finance 52, 57-82.

Chabi-Yo, F., Ruenzi, S., Weigert, F., 2015. Crash sensitivity and the cross-section of expected stock returns. Unpublished Working Paper. Ohio State University, University of Mannheim, and University of St. Gallen.

Cholette, L., Lu, C.-C., 2011. The market premium for dynamic tail risk. Unpublished Working Paper, University of Stavanger and National Chengchi University.

Corwin, S.A., Schultz, P., 2012. A simple way to estimate bid-ask spreads from daily high and low prices. Journal of Finance 67, 719-759.

Coval, J., Stafford, E., 2007. Asset fire sales (and purchases) in equity markets. Journal of Financial Economics 86, 479-512.

Daniel, K., Grinblatt, M., Titman, S., Wermers, R., 1997. Measuring mutual fund performance with characteristic-based benchmarks. Journal of Finance 52, 1035-1058.

Daniel, K., Titman, S., 1997. Evidence on the characteristics of cross sectional variation in stock returns. Journal of Finance 52, 1-33. 
Embrechts, P., McNeil, A., Straumann, D., 2002. Correlation and dependence in risk management: properties and pitfalls. in: M.A.H. Dempster (ed.), Risk Management: Value at Risk and Beyond, Cambridge University Press, Cambridge, 176-223.

Fama, E.F., French, K.R., 1993. Common risk factors in the returns on stocks and bonds. Journal of Financial Economics 33, 3-56.

Fama, E.F., French, K.R., 2015. A five-factor asset pricing model. Journal of Financial Economics 11, 1-22.

Fama, E.F., MacBeth, J.D., 1973. Risk, return, and equilibrium: Empirical tests. Journal of Political Economy 81, 607-636.

Fong, K., Holden, C., Trzcinka, C., 2014. What are the best liquidity proxies for global research. Unpublished Working Paper, University of New South Wales and Indiana University.

Frazzini, A., Pedersen, L.H., 2014. Betting against beta. Journal of Financial Economics $111,1-25$.

Gennaioli, N., Shleifer, A., Vishny, R., 2015. Neglected risks: The psychology of financial crises. American Economic Review 105, 310-314.

Goyenko, R., Holden, C., Trzcinka, C., 2009. Do liquidity measures measure liquidity? Journal of Financial Economics 92, 153-181.

Harvey, C.R., Siddique, A., 2000. Conditional skewness in asset pricing tests. Journal of Finance 55, 1263-1295.

Hasbrouck, J., 2009. Trading costs and returns for US equities: The evidence from daily data. Journal of Finance 64, 1445-1477.

Hirshleifer, D., Jiang, D., 2010. A financing-based misvaluation factor and the cross-section of expected stock returns. Review of Financial Studies 23, 3401-3436.

Hou, K., Xue, C., Zhang, L., 2015. Digesting anomalies: an investment approach. Review of Financial Studies 28, 650-705. 
Jegadeesh, N., Titman, S., 1993. Returns to buying winners and selling losers: Implications for stock market efficiency. Journal of Finance 48, 65-91.

Kelly, B., Jiang, H., 2014. Tail risk and asset prices. Review of Financial Studies 27, 28412871.

Lee, K. 2011. The world price of liquidity risk. Journal of Financial Economics 99, 136-161.

Lesmond, D., Ogden, J., Trzcinka, C., 1999. A new estimate of transaction costs. Review of Financial Studies 12, 1113-1141.

Longin, F., Solnik, B., 2001. Extreme correlation of international equity markets. Journal of Finance 56, 649-676.

McNeil, A.J., Frey, R., Embrechts, P., 2005. Quantitative risk management. Princeton University Press.

Menkveld, A., Wang, T., 2011. Liquileaks. Unpublished Working Paper. VU University of Amsterdam and Tinbergen Institute.

Nelsen, R.B., 2006. An introduction to copulas. Springer Series in Statistics, Second Edition.

Newey, W.K., West, K.D., 1987. A simple positive semi-definite, heteroskedasticity and autocorrelation consistent covariance matrix. Econometrica 55, 703-708.

Novy-Marx, R., 2013. The other side of value: The gross profitability premium. Journal of Financial Economics 108, 1-28.

Pastor, L., Stambaugh, R.F., 2003. Liquidity risk and expected returns. Journal of Political Economy 111, 642-685.

Patton, A.J., 2004. On the out-of-sample importance of skewness and asymmetric dependence for asset allocation. Journal of Financial Econometrics 2, 130-168.

Patton, A.J., Timmermann, A. 2010. Monotonicity in asset returns: New tests with applications to the term structure, the CAPM, and portfolio sorts. Journal of Financial Economics $98,605-625$. 
Poon, S.H., Rockinger, M., Tawn, J., 2004. Extreme value dependence in financial markets: Diagnostics, models, and financial implications. Review of Financial Studies 17, 581-610.

Rodriguez, J.C., 2007. Measuring financial contagion: A copula approach. Journal of Empirical Finance 14, 401-423.

Rubinstein, M., 1994. Implied binomial trees. Journal of Finance 49, 771-813.

Sadka, R., 2006. Momentum and post-earnings-announcement drift anomalies: the role of liquidity risk. Journal of Financial Economics 80, 309-349.

Sharpe, W.F., 1964. Capital asset prices: A theory of market equilibrium under conditions of risk. Journal of Finance 19, 425-442.

Sibuya, M., 1960. Bivariate extreme statistics. Annals of the Institute of Statistical Mathematics 11, 195-210.

Sklar, A., 1959. Fonctions de répartition à $n$ dimensions et leurs marges. Publications de l'Institut de Statistique de l'Université de Paris 14, 229-231.

Wu, Y., 2015. Asset pricing with extreme liquidity risk. Unpublished Working Paper. Stevens Institute of Technology.

Weigert, F., 2015. Crash aversion and the cross-section of expected stock return worldwide. Review of Asset Pricing Studies, forthcoming. 
Figure 1: Aggregate EDL Risk over Time (1969 - 2012)

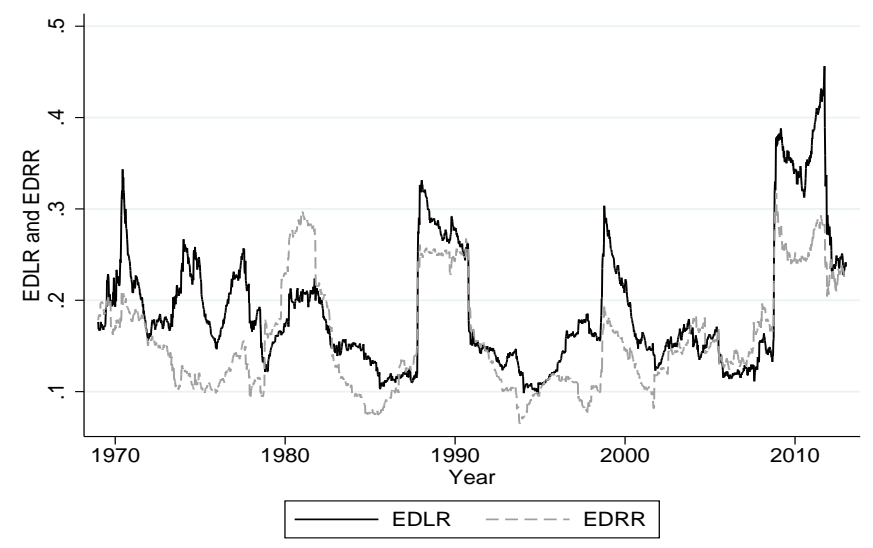

(a) Panel A: Aggregate EDL Risk and EDR Risk over Time

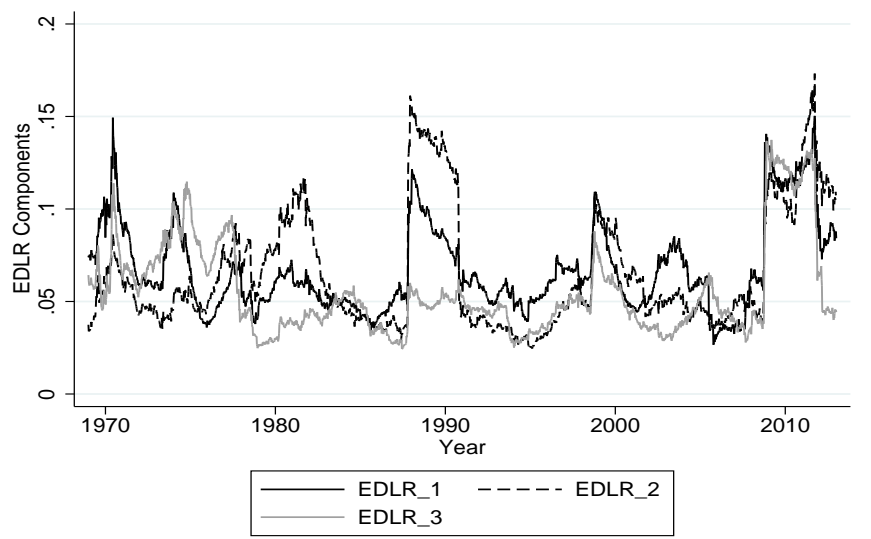

(b) Panel B: Components of Aggregate EDL Risk

This figure displays the evolution of aggregate EDL risk and EDR risk as well as the different components of EDL risk over time. Aggregate EDL risk (EDR risk) in week $t$ is defined as the value-weighted average of EDL risk (EDR risk) over all stocks $i$ in

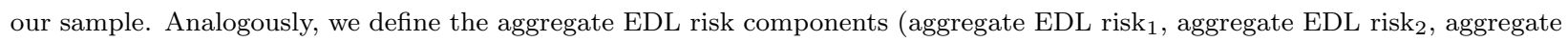
EDL risk 3 ) in week $t$ as the value-weighted average of the EDL risk components (EDL risk 1 , EDL risk 2 , EDL risk 3 ) over all stocks $i$ in our sample. Panel A draws the evolution of aggregate EDL risk (EDR risk) over time. Panel B shows the evolution of the different aggregate EDL risk components. The sample covers all U.S. common stocks traded on the NYSE / AMEX and the sample period is from January 1969 to December 2012. 
Figure 2: Yearly Alpha and Cumulative Alpha of EDL Risk Strategy

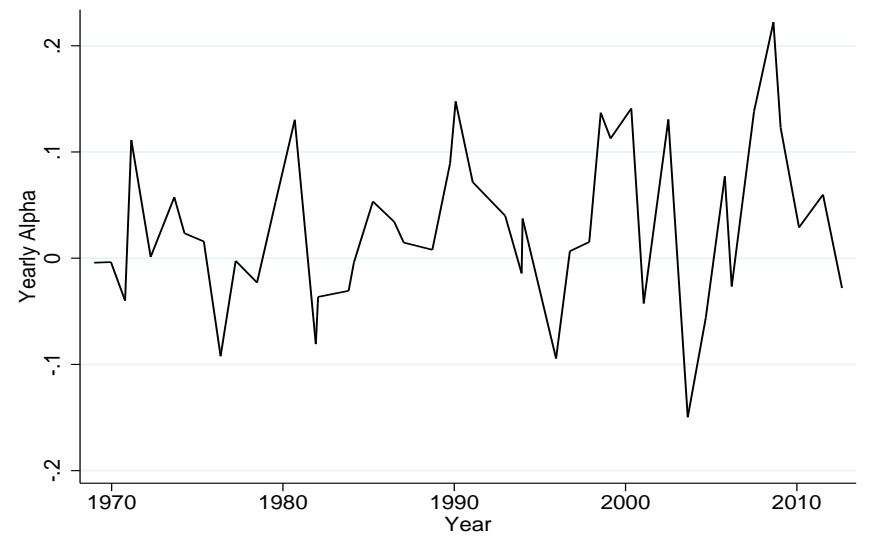

(a) Panel A: Yearly Alpha of EDL Risk Strategy

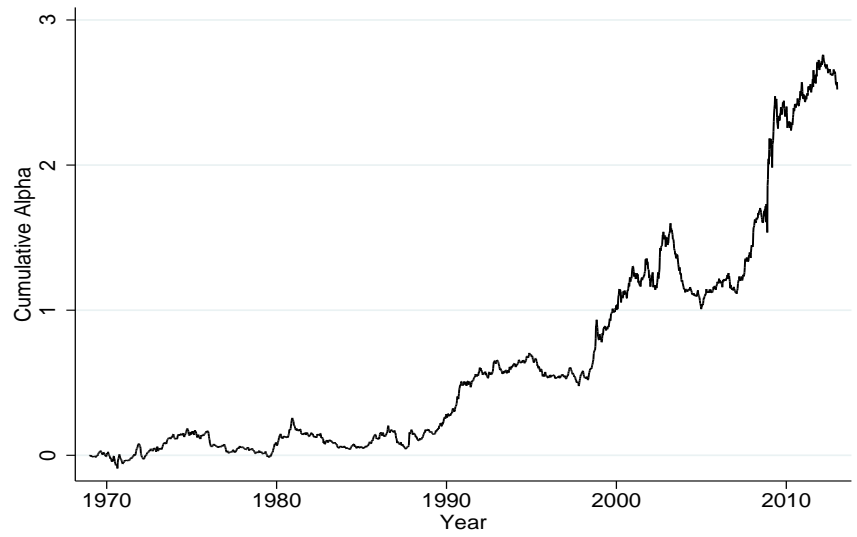

(b) Panel B: Cumulative Alpha of EDL Risk Strategy

This figure displays the evolution of the annualized 1-year Carhart-alpha and the cumulative Carhart-alpha of a trading strategy consisting of buying strong EDL risk stocks and selling weak EDL risk stocks with weekly rebalancing (no trading costs are taken into account). The sample covers all U.S. common stocks traded on the NYSE / AMEX and the sample period is from January 1969 to December 2012. 


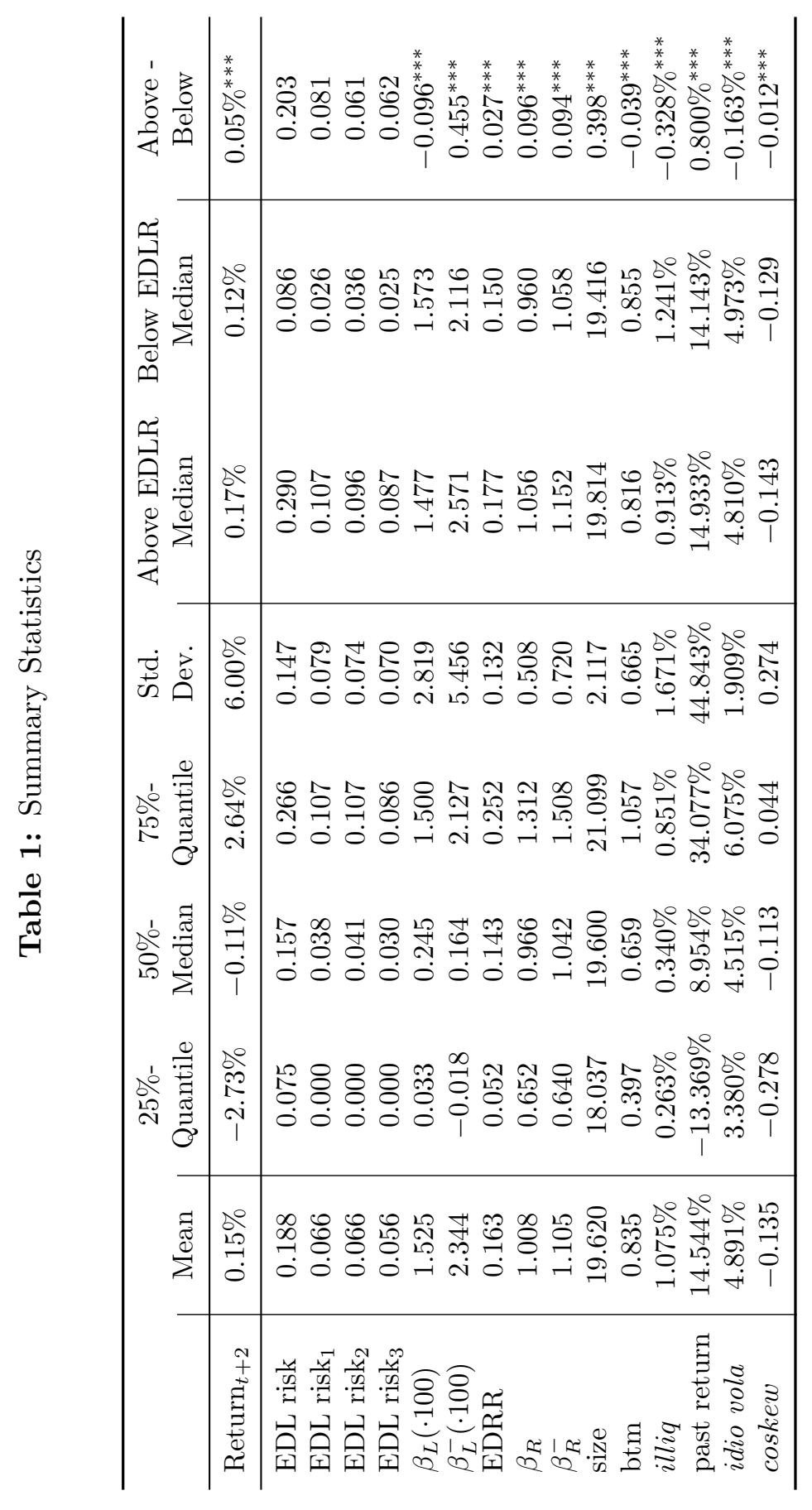

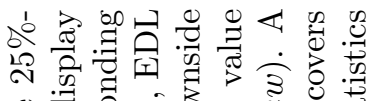

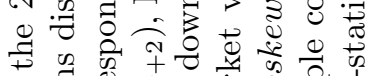

ॠี 范 0

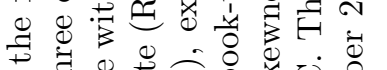

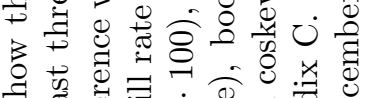

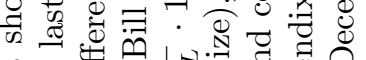
鹤 寻

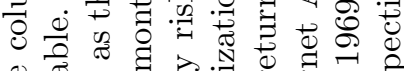

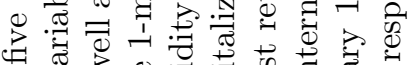
荡 专

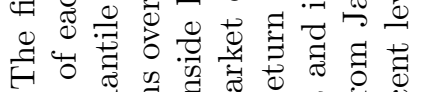

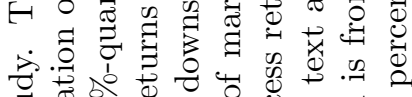

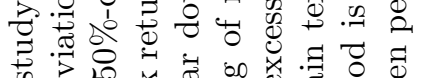

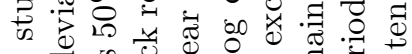

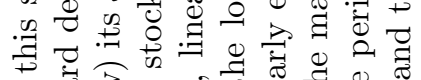
$\exists$ 㺃 0

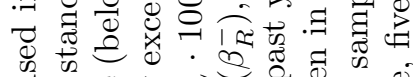

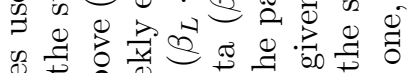
焉焉

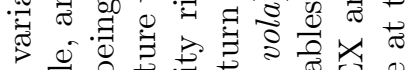

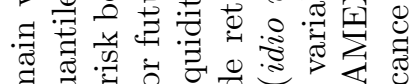
छ

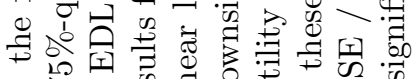

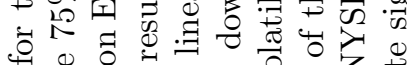

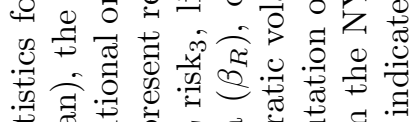

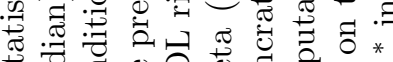

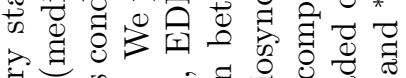

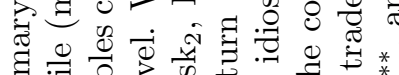

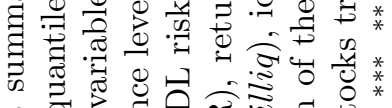

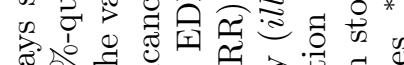

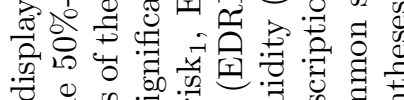

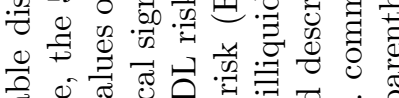

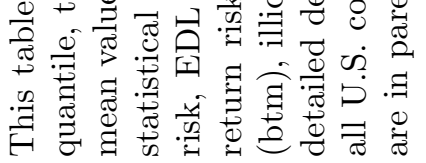




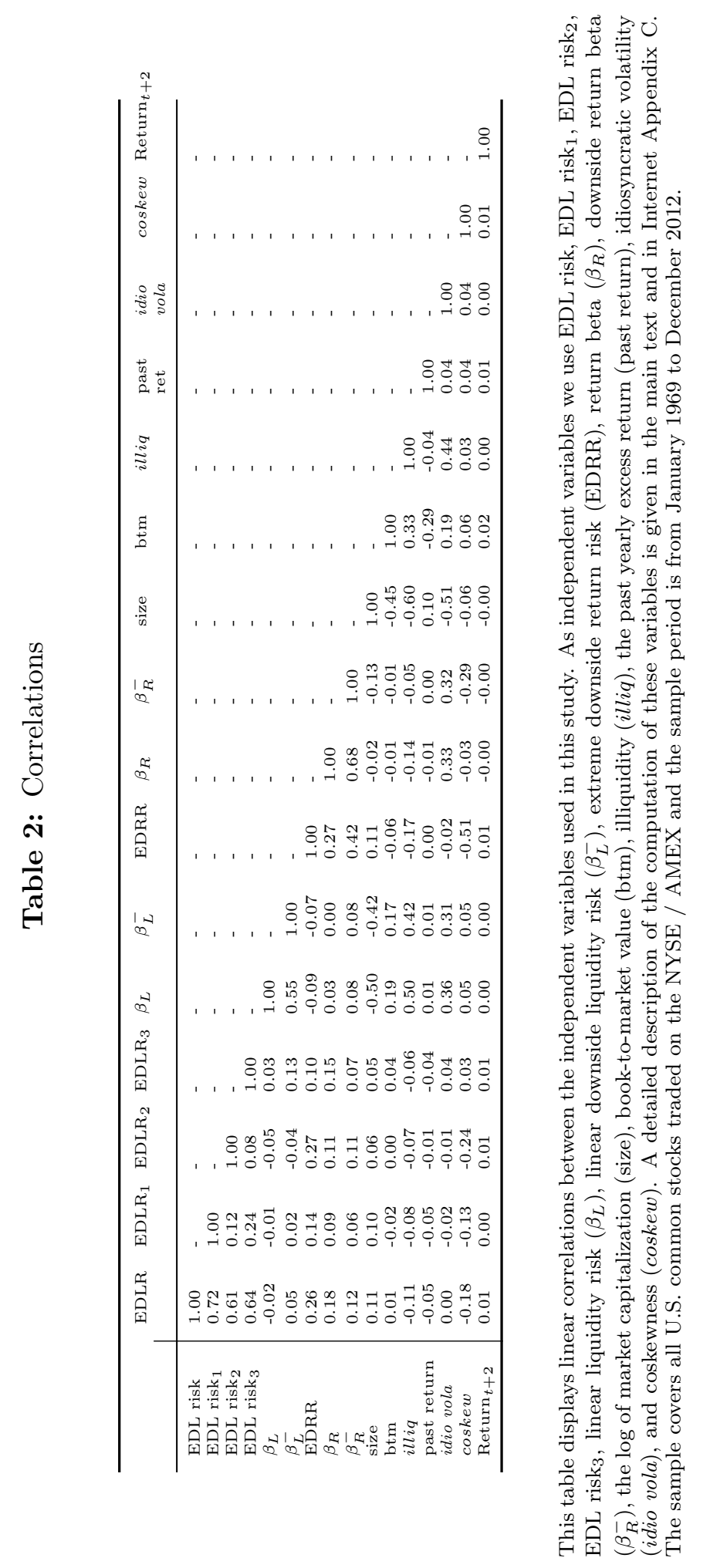




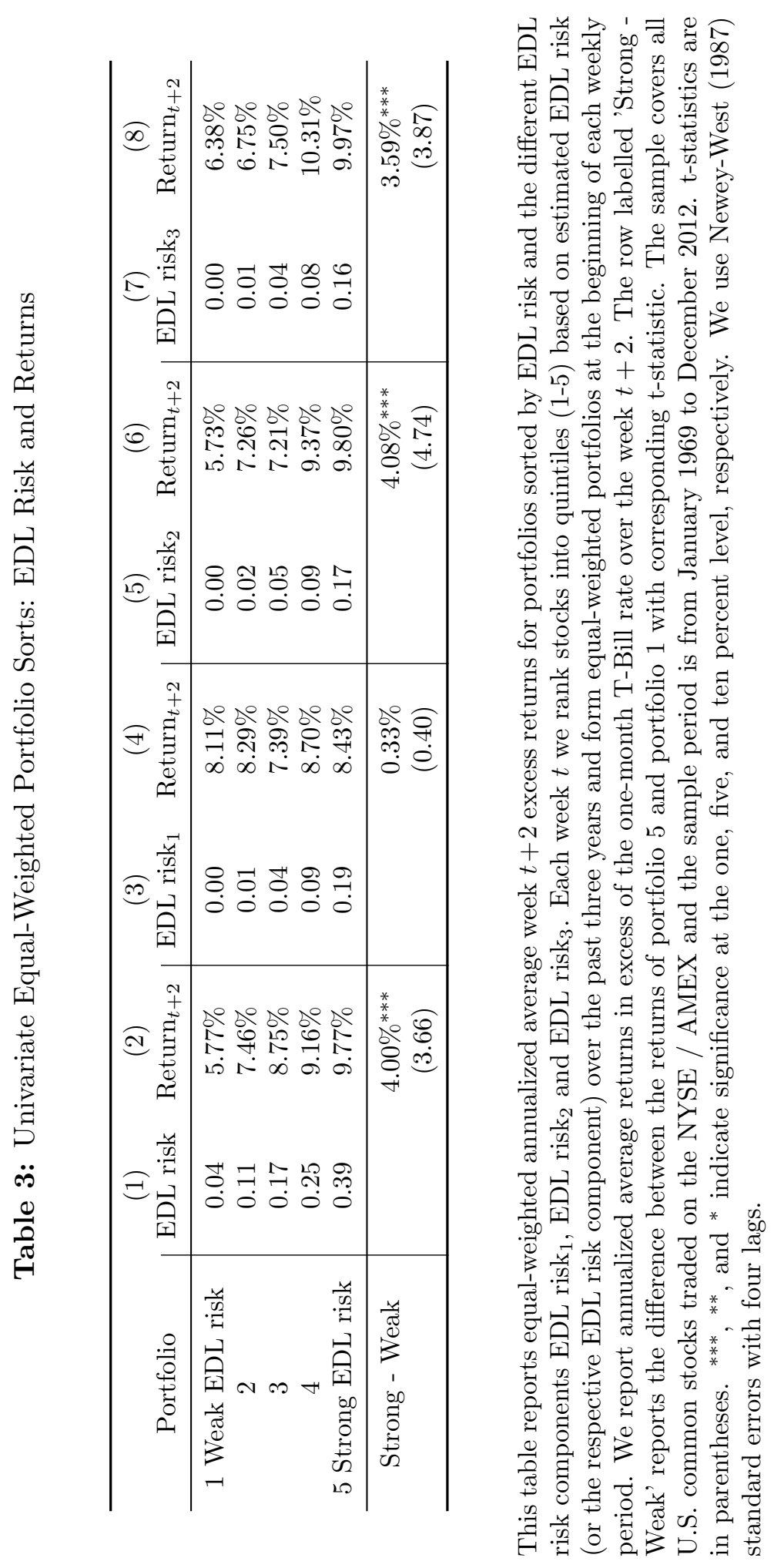


Table 4: Bivariate Equal-Weighted Portfolio Sorts

Panel A: EDL Risk and $\beta_{L}$ Risk

\begin{tabular}{ccccccc}
\hline Portfolio & 1 Weak $\beta_{L}$ & 2 & 3 & 4 & 5 Strong $\beta_{L}$ & Average \\
\hline 1 Weak EDL risk & $6.34 \%$ & $4.78 \%$ & $5.34 \%$ & $6.36 \%$ & $6.04 \%$ & $5.77 \%$ \\
2 & $8.58 \%$ & $5.55 \%$ & $7.02 \%$ & $7.49 \%$ & $8.42 \%$ & $7.41 \%$ \\
3 & $9.18 \%$ & $7.27 \%$ & $8.85 \%$ & $9.85 \%$ & $8.91 \%$ & $8.81 \%$ \\
4 & $10.02 \%$ & $8.26 \%$ & $7.68 \%$ & $10.21 \%$ & $11.04 \%$ & $9.44 \%$ \\
5 Strong EDL risk & $9.80 \%$ & $7.38 \%$ & $8.62 \%$ & $9.32 \%$ & $12.14 \%$ & $9.45 \%$ \\
\hline Strong-Weak & $3.46 \%^{* *}$ & $2.60 \%^{* *}$ & $3.28 \%^{* * *}$ & $2.96 \%^{* *}$ & $6.10 \%^{* * *}$ & $3.68 \%^{* * *}$ \\
& $(2.38)$ & $(2.46)$ & $(2.62)$ & $(2.22)$ & $(3.94)$ & $(4.15)$ \\
\hline
\end{tabular}

Panel B: EDL Risk and $\beta_{L}^{-}$Risk

\begin{tabular}{ccccccc}
\hline Portfolio & 1 Weak $\beta_{L}^{-}$ & 2 & 3 & 4 & 5 Strong $\beta_{L}^{-}$ & Average \\
\hline 1 Weak EDL risk & $6.16 \%$ & $4.64 \%$ & $4.78 \%$ & $6.21 \%$ & $6.96 \%$ & $5.75 \%$ \\
2 & $7.17 \%$ & $6.55 \%$ & $6.94 \%$ & $8.32 \%$ & $8.25 \%$ & $7.44 \%$ \\
3 & $9.46 \%$ & $7.96 \%$ & $8.59 \%$ & $9.24 \%$ & $8.61 \%$ & $8.77 \%$ \\
4 & $8.11 \%$ & $9.05 \%$ & $8.02 \%$ & $9.75 \%$ & $11.27 \%$ & $9.24 \%$ \\
5 Strong EDL risk & $10.34 \%$ & $7.69 \%$ & $8.69 \%$ & $10.03 \%$ & $11.63 \%$ & $9.68 \%$ \\
\hline Strong-Weak & $4.18 \% * * *$ & $3.05 \% * * *$ & $3.91 \%^{* * *}$ & $3.81 \%^{* * *}$ & $4.67 \%^{* * *}$ & $3.93 \%^{* * *}$ \\
& $(2.86)$ & $(2.82)$ & $(3.02)$ & $(2.81)$ & $(2.87)$ & $(4.27)$ \\
\hline
\end{tabular}

Panel C: EDL Risk and EDR Risk

\begin{tabular}{ccccccc}
\hline Portfolio & 1 Weak EDRR & 2 & 3 & 4 & 5 Strong EDRR & Average \\
\hline 1 Weak EDL risk & $3.46 \%$ & $5.04 \%$ & $6.92 \%$ & $6.42 \%$ & $8.73 \%$ & $6.11 \%$ \\
2 & $4.27 \%$ & $6.64 \%$ & $7.84 \%$ & $7.97 \%$ & $11.26 \%$ & $7.60 \%$ \\
3 & $5.84 \%$ & $7.23 \%$ & $10.16 \%$ & $10.00 \%$ & $10.86 \%$ & $8.82 \%$ \\
4 & $5.80 \%$ & $7.85 \%$ & $9.50 \%$ & $10.17 \%$ & $11.65 \%$ & $9.00 \%$ \\
5 Strong EDL risk & $6.89 \%$ & $8.47 \%$ & $10.94 \%$ & $9.70 \%$ & $10.80 \%$ & $9.36 \%$ \\
\hline Strong-Weak & $3.43 \%^{* *}$ & $3.43 \%^{* *}$ & $4.02 \%^{* * *}$ & $3.29 \%^{* *}$ & $2.07 \%$ & $3.25 \%^{* * *}$ \\
& $(2.43)$ & $(2.47)$ & $(2.78)$ & $(2.45)$ & $(1.46)$ & $(3.28)$ \\
\hline
\end{tabular}


Panel D: EDL Risk and Size

\begin{tabular}{ccccccc}
\hline Portfolio & 1 Small & 2 & 3 & 4 & 5 Large & Average \\
\hline 1 Weak EDL risk & $5.86 \%$ & $6.70 \%$ & $6.01 \%$ & $5.96 \%$ & $4.77 \%$ & $5.86 \%$ \\
2 & $8.08 \%$ & $8.74 \%$ & $7.59 \%$ & $7.48 \%$ & $6.15 \%$ & $7.61 \%$ \\
3 & $7.21 \%$ & $9.69 \%$ & $10.24 \%$ & $8.46 \%$ & $7.30 \%$ & $8.58 \%$ \\
4 & $9.19 \%$ & $10.65 \%$ & $9.27 \%$ & $8.77 \%$ & $7.67 \%$ & $9.11 \%$ \\
5 Strong EDL risk & $11.19 \%$ & $10.59 \%$ & $10.57 \%$ & $9.56 \%$ & $6.75 \%$ & $9.73 \%$ \\
\hline Strong-Weak & $5.33 \% * * *$ & $3.89 \% * * *$ & $4.56 \% * * *$ & $3.60 \% * * *$ & $1.98 \%$ & $3.87 \% * * *$ \\
& $(2.98)$ & $(2.68)$ & $(3.11)$ & $(2.92)$ & $(1.64)$ & $(3.71)$ \\
\hline
\end{tabular}

Panel E: EDL Risk and Illiquidity

\begin{tabular}{ccccccc}
\hline Portfolio & 1 Liquid & 2 & 3 & 4 & 5 Illiquid & Average \\
\hline 1 Weak EDL risk & $4.73 \%$ & $4.92 \%$ & $5.69 \%$ & $6.82 \%$ & $6.77 \%$ & $5.78 \%$ \\
2 & $5.72 \%$ & $7.01 \%$ & $7.46 \%$ & $8.70 \%$ & $8.75 \%$ & $7.53 \%$ \\
3 & $6.71 \%$ & $9.06 \%$ & $8.76 \%$ & $9.69 \%$ & $8.96 \%$ & $8.64 \%$ \\
4 & $7.28 \%$ & $8.81 \%$ & $8.84 \%$ & $11.03 \%$ & $10.33 \%$ & $9.26 \%$ \\
5 Strong EDL risk & $6.67 \%$ & $10.51 \%$ & $8.76 \%$ & $11.08 \%$ & $11.32 \%$ & $9.67 \%$ \\
\hline Strong-Weak & $1.94 \%$ & $5.59 \% * * *$ & $3.08 \% * *$ & $4.26 \% \%^{* *}$ & $4.55 \% * *$ & $3.89 \% * * *$ \\
& $(1.57)$ & $(3.95)$ & $(2.12)$ & $(3.18))$ & $(2.64)$ & $(3.76)$ \\
\hline
\end{tabular}

This table reports the results of dependent equal-weighted portfolio sorts. First, we form quintile portfolios sorted on $\beta_{L}$ risk ( $\beta_{L}^{-}$risk, EDR risk, firm size, illiquidity). Then, within each risk quintile, we sort stocks into equal-weighted portfolios based on EDL Risk. Panel A displays annualized average future returns of $25 \beta_{L}$ risk - EDL risk portfolio sorts, Panel B shows annualized average future returns of the $25 \beta_{L}^{-}$- EDL risk sorts, Panel C shows the annualized average future returns of the 25 EDR risk - EDL risk portfolio sorts, Panel D shows the annualized average future returns of the 25 market capitalization EDL risk portfolio sorts and Panel E shows the annualized average future returns of the 25 Amihud illiquidity ratio - EDL risk portfolio sorts. The row labelled 'Strong - Weak' reports the difference between the returns of portfolio 5 and portfolio 1 with corresponding t-statistic. The sample covers all U.S. common stocks traded on the NYSE / AMEX and the sample period is from January 1969 to December 2012. t-statistics are in parentheses. ${ }^{* * *},{ }^{* *}$, and ${ }^{*}$ indicate significance at the one, five, and ten percent level, respectively. We use Newey-West (1987) standard errors with four lags. 
Table 5: EDL Risk and Returns: Factor Models

Panel A: Factor Models

\begin{tabular}{|c|c|c|c|c|c|c|c|}
\hline & $\begin{array}{c}(1) \\
\text { EDL risk } \\
(\text { PF5-1) }\end{array}$ & $\begin{array}{c}(2) \\
\text { EDL risk } \\
(\text { PF5-1) }\end{array}$ & $\begin{array}{c}(3) \\
\text { EDL risk } \\
(\text { PF5-1) }\end{array}$ & $\begin{array}{c}(4) \\
\text { EDL risk } \\
(\text { PF5-1) }\end{array}$ & $\begin{array}{c}(5) \\
\text { EDL risk } \\
(\text { PF5-1) }\end{array}$ & $\begin{array}{c}(6) \\
\text { EDL risk } \\
(\text { PF5-1) }\end{array}$ & $\begin{array}{c}(7) \\
\text { EDL risk } \\
(\text { PF5-1) }\end{array}$ \\
\hline Marketrf & $\begin{array}{c}0.134^{* * *} \\
(4.52)\end{array}$ & $\begin{array}{c}0.133^{* * *} \\
(5.37)\end{array}$ & $\begin{array}{c}0.133^{* * *} \\
(5.41)\end{array}$ & $\begin{array}{c}0.078^{* * *} \\
(2.96)\end{array}$ & $\begin{array}{c}0.108^{* * *} \\
(4.39)\end{array}$ & $\begin{array}{c}0.137^{* * *} \\
(5.16)\end{array}$ & $\begin{array}{c}0.141^{* * *} \\
(5.87)\end{array}$ \\
\hline SMB & & $\begin{array}{l}-0.033 \\
(-0.99)\end{array}$ & $\begin{array}{l}-0.033 \\
(-0.99)\end{array}$ & $\begin{array}{l}-0.026 \\
(-0.79)\end{array}$ & $\begin{array}{c}-0.064^{*} \\
(-1.70)\end{array}$ & $\begin{array}{l}-0.043 \\
(-1.21)\end{array}$ & $\begin{array}{c}-0.031 \\
(-0.97)\end{array}$ \\
\hline HML & & $\begin{array}{c}0.045^{*} \\
(1.21)\end{array}$ & $\begin{array}{l}0.045^{*} \\
(1.63)\end{array}$ & $\begin{array}{c}0.101^{* *} \\
(2.43)\end{array}$ & $\begin{array}{c}0.060^{*} \\
(1.94)\end{array}$ & $\begin{array}{c}0.063^{* *} \\
(2.32)\end{array}$ & $\begin{array}{c}0.101^{* * *} \\
(3.39)\end{array}$ \\
\hline MOM & & $\begin{array}{c}-0.118^{* *} \\
(-2.10)\end{array}$ & $\begin{array}{c}-0.118^{* *} \\
(-2.08)\end{array}$ & $\begin{array}{c}-0.127^{* *} \\
(-2.23)\end{array}$ & $\begin{array}{c}-0.112^{* *} \\
(-2.16)\end{array}$ & $\begin{array}{c}-0.103^{*} \\
(-1.72)\end{array}$ & $\begin{array}{l}-0.096^{*} \\
(-1.84)\end{array}$ \\
\hline PS Liqui & & & $\begin{array}{l}-0.001 \\
(-0.04)\end{array}$ & & & & \\
\hline EDRR & & & & $\begin{array}{c}0.163^{* * *} \\
(3.25)\end{array}$ & & & \\
\hline Max & & & & & $\begin{array}{l}0.037 \\
(0.97)\end{array}$ & & \\
\hline Tail & & & & & & $\begin{array}{l}-0.048 \\
(-1.29)\end{array}$ & \\
\hline $\mathrm{BAB}$ & & & & & & & $\begin{array}{c}-0.103^{* * *} \\
(-3.19)\end{array}$ \\
\hline const & $\begin{array}{c}0.225 \% * * * \\
(2.88)\end{array}$ & $\begin{array}{c}0.293 \%^{* * *} \\
\quad(3.05)\end{array}$ & $\begin{array}{c}0.294 \%^{* * *} \\
\quad(2.89)\end{array}$ & $\begin{array}{c}0.210 \% \text { ** } \\
(2.30)\end{array}$ & $\begin{array}{c}0.316 \%^{* * *} \\
\quad(2.86)\end{array}$ & $\begin{array}{c}0.316 \%^{* * *} \\
\quad(3.09)\end{array}$ & $\begin{array}{c}0.342 \% \text { *** } \\
\quad(3.35)\end{array}$ \\
\hline $\begin{array}{l}\text { yearly } \\
\text { alpha }\end{array}$ & $2.70 \%$ & $3.52 \%$ & $3.52 \%$ & $2.51 \%$ & $3.80 \%$ & $3.78 \%$ & $4.10 \%$ \\
\hline$R^{2}$ & 0.107 & 0.198 & 0.198 & 0.235 & 0.188 & 0.199 & 0.224 \\
\hline
\end{tabular}


Panel B: Other Factor Models

\begin{tabular}{l|l}
\hline Factor Model & Annualized $\alpha$ \\
\hline Fama-French 5-Factor Model (Fama/French, 2015) & $2.80 \%^{* * *}(2.86)$ \\
Novy-Marx 4-Factor Model (Novy-Marx, 2013) & $4.04 \%^{* * *}(2.81)$ \\
Hou-Xue-Zhang 4-Factor Model (Hou/Xue/Zhang, 2014) & $3.08 \%^{* * *}(2.70)$ \\
Carhart 4-Factor Model + short- and long-term reversal & $3.95 \%^{* * *}(2.98)$ \\
Carhart 4-Factor Model + leverage factor (Adrian/Etula/Muir, 2014) & $3.75 \%^{* * *}(3.10)$ \\
Carhart 4-Factor Model + quality-minus-junk (Asness/Frazzini/Israel/Moskowitz/Pedersen, 2015) & $3.85 \%^{* * *}(3.07)$ \\
Carhart 4-Factor Model + undervalued-minus-overvalued (Hirshleifer/Jiang, 2010) & $3.35 \%^{* * *}(3.34)$ \\
Carhart 4-Factor Model + liquidity-tail (Wu, 2015) & $3.77 \%^{* * *}(3.14)$ \\
\hline
\end{tabular}

This table reports monthly OLS-regression results of a trading strategy based on the return-difference between past strong EDL risk (quintile 5) and past weak EDL risk (quintile 1) portfolios on different factor models. The factors we use in Panel A include Marketrf, which is based on Sharpe (1964)'s capital asset pricing model, SMB and HML of the Fama and French (1993) three-factor model, MOM of the four-factor model by Carhart (1997), Pastor and Stambaugh (2003)'s traded liquidity risk factor (PS Liqui), Chabi-Yo, Ruenzi and Weigert (2015)'s equal-weighted EDRR (EDRR) factor, Bali, Cakici, and Whitelaw (2011)'s equal-weighted lottery factor (Max), as well as the equally-weighted tail-risk factor (Tail) proposed by Kelly and Jiang (2014) and the betting-against-beta factor (BAB) proposed by Frazzini and Pedersen (2014). The factor models in Panel B include the the Fama and French (2015) five-factor model, the Hou, Xue, and Zhang (2015) and Novy-Marx (2013) four-factor models as well as the Carhart (1997) four-factor model extended by the Fama and French short- and long-term reversal factors, the leverage factor from Adrian, Etula, and Muir (2014), the quality-minus-junk factor from Asness, Frazzini, and Pedersen (2014), the undervaluedminus-overvalued factor from Hirshleifer and Jiang (2010), and the Wu (2015) liquidity-tail factor. Portfolios of the EDL risk trading strategy are rebalanced monthly. The sample covers all U.S. common stocks traded on the NYSE / AMEX and the sample period is from January 1969 to December 2012. t-statistics are in parentheses. ${ }^{* * *},{ }^{* *}$, and ${ }^{*}$ indicate significance at the one, five, and ten percent level, respectively. We use Newey-West (1987) standard errors with one lag. 
Table 6: Fama and MacBeth (1973) Regressions

\begin{tabular}{|c|c|c|c|c|c|c|}
\hline & $\begin{array}{c}(1) \\
\text { Return }_{t+2}\end{array}$ & $\begin{array}{c}(2) \\
\text { Return }_{t+2}\end{array}$ & $\begin{array}{c}(3) \\
\text { Return }_{t+2}\end{array}$ & $\begin{array}{c}(4) \\
\text { Return }_{t+2}\end{array}$ & $\begin{array}{c}(5) \\
\text { Return }_{t+2}\end{array}$ & $\begin{array}{c}(6) \\
\text { Return }_{t+2}\end{array}$ \\
\hline EDL risk & $\begin{array}{c}0.00184^{* * *} \\
\quad(3.73)\end{array}$ & $\begin{array}{c}0.00137^{* * *} \\
\quad(4.49)\end{array}$ & $\begin{array}{c}0.00133^{* * *} \\
\quad(4.32)\end{array}$ & $\begin{array}{c}0.00113^{* * *} \\
(3.73)\end{array}$ & $\begin{array}{c}0.00137^{* * *} \\
\quad(4.28)\end{array}$ & $\begin{array}{c}0.00145^{* * *} \\
\quad(4.49)\end{array}$ \\
\hline$\beta_{R}$ & & $\begin{array}{c}-0.00008 \\
(-0.19)\end{array}$ & $\begin{array}{c}-0.00009 \\
(-0.24)\end{array}$ & $\begin{array}{c}-0.00029 \\
(-0.74)\end{array}$ & $\begin{array}{c}0.00006 \\
(0.16)\end{array}$ & \\
\hline size & & $\begin{array}{c}-0.00007 \\
(-0.79)\end{array}$ & $\begin{array}{c}-0.00005 \\
(-0.57)\end{array}$ & $\begin{array}{c}-0.00007 \\
(-0.79)\end{array}$ & $\begin{array}{c}-0.00018^{* *} \\
(-2.54)\end{array}$ & $\begin{array}{c}-0.00018^{* *} \\
(-2.65)\end{array}$ \\
\hline btm & & $\begin{array}{c}0.00039^{* * *} \\
(2.89)\end{array}$ & $\begin{array}{c}0.00039^{* * *} \\
(2.90)\end{array}$ & $\begin{array}{c}0.00039^{* * *} \\
(2.92)\end{array}$ & $\begin{array}{c}0.00032^{* * *} \\
\quad(2.27)\end{array}$ & $\begin{array}{c}0.00032^{* * *} \\
(2.26)\end{array}$ \\
\hline past return & & $\begin{array}{c}0.00159^{* * *} \\
\quad(3.80)\end{array}$ & $\begin{array}{c}0.00157^{* * *} \\
(3.75)\end{array}$ & $\begin{array}{c}0.00155^{* * *} \\
(3.73)\end{array}$ & $\begin{array}{c}0.00131^{* * *} \\
(2.98)\end{array}$ & $\begin{array}{c}0.00133^{* * *} \\
(2.98)\end{array}$ \\
\hline$\beta_{L}$ & & & $\begin{array}{c}0.00219 \\
(0.73)\end{array}$ & $\begin{array}{c}0.00279 \\
(0.93)\end{array}$ & $\begin{array}{c}0.00050 \\
(0.15)\end{array}$ & \\
\hline EDR risk & & & & $\begin{array}{c}0.00278^{* * *} \\
\quad(7.16)\end{array}$ & $\begin{array}{c}0.00265^{* * *} \\
(6.54)\end{array}$ & $\begin{array}{c}0.00264^{* * *} \\
\quad(6.21)\end{array}$ \\
\hline illiq & & & & & $\begin{array}{c}0.00010 \\
(0.75)\end{array}$ & $\begin{array}{l}0.00009 \\
(0.62)\end{array}$ \\
\hline$\beta_{\text {Tail }}$ & & & & & $\begin{array}{c}0.00794^{* *} \\
\quad(2.19)\end{array}$ & $\begin{array}{c}0.00748^{* *} \\
(2.04)\end{array}$ \\
\hline idio vola & & & & & $\begin{array}{c}-0.01391^{*} \\
(-1.73)\end{array}$ & $\begin{array}{c}-0.01457^{*} \\
(-1.65)\end{array}$ \\
\hline coskew & & & & & $\begin{array}{c}0.00009 \\
(0.20)\end{array}$ & $\begin{array}{c}-0.00007 \\
(-0.10)\end{array}$ \\
\hline$\beta_{L}^{-}$ & & & & & & $\begin{array}{c}-0.00132 \\
(-0.88)\end{array}$ \\
\hline$\beta_{L}^{+}$ & & & & & & $\begin{array}{c}-0.00006 \\
(-0.03)\end{array}$ \\
\hline$\beta_{R}^{-}$ & & & & & & $\begin{array}{c}0.00004 \\
(0.14)\end{array}$ \\
\hline$\beta_{R}^{+}$ & & & & & & $\begin{array}{c}0.00001 \\
(0.08)\end{array}$ \\
\hline const & $\begin{array}{c}0.00113^{* *} \\
(2.03)\end{array}$ & $\begin{array}{c}0.00239 \\
(1.33)\end{array}$ & $\begin{array}{c}0.00203 \\
(1.14)\end{array}$ & $\begin{array}{c}0.00213 \\
(1.20)\end{array}$ & $\begin{array}{c}0.00510^{* * *} \\
(3.83)\end{array}$ & $\begin{array}{c}0.00531^{* * *} \\
(4.14)\end{array}$ \\
\hline Avg. $\mathrm{R}^{2}$ & 0.0025 & 0.0449 & 0.0465 & 0.0477 & 0.0647 & 0.0653 \\
\hline
\end{tabular}

This table displays the results of multivariate Fama and MacBeth (1973) regressions. We report the results of regressions of weekly excess returns over the risk-free rate at week $t+2$ on EDL risk, $\beta_{R}$, the $\log$ of market capitalization (size), the book-to-market ratio (btm), the past 12-month excess returns (past year return), $\beta_{L}$, EDR risk, illiquidity (illiq), $\beta_{\text {Tail }}$ from Kelly and Jiang (2014), idiosyncratic volatility (idio vola), coskewness (coskew), $\beta_{R}^{-}, \beta_{R}^{+}, \beta_{L}^{-}$, and $\beta_{L}^{+}$. All risk and firm characteristics are calculated using data available at (the end of) week $t$. A detailed description of the computation of these variables is given in the main text and in Internet Appendix C. The sample covers all U.S. common stocks traded on the NYSE / AMEX and the sample period is from January 1969 to December 2012. t-statistics are in parentheses. ${ }^{* * *}$, ${ }^{* *}$, and * indicate significance at the one, five, and ten percent level, respectively. We use Newey-West (1987) standard errors with four lags. 
Table 7: Impact of EDL Risk in Dispersion-Sorted Samples

\section{Panel A: Univariate Sorts}

\begin{tabular}{|c|c|c|c|c|c|c|}
\hline \multirow[b]{2}{*}{ Dispersion Proxy } & \multicolumn{3}{|c|}{ Low Dispersion } & \multicolumn{3}{|c|}{ High Dispersion } \\
\hline & Strong EDL risk & Weak EDL risk & 5-1 Diff & Strong EDL risk & Weak EDL risk & 5-1 Diff \\
\hline Standard Deviation & $8.76 \%$ & $5.58 \%$ & $\begin{array}{c}3.18 \%^{* * *} \\
(3.00)\end{array}$ & $10.56 \%$ & $5.13 \%$ & $\begin{array}{c}5.42 \% * * * \\
(3.78)\end{array}$ \\
\hline Idio Vola & $8.74 \%$ & $5.65 \%$ & $\begin{array}{c}3.08 \%^{* * *} \\
(2.93)\end{array}$ & $10.48 \%$ & $4.69 \%$ & $\begin{array}{c}5.79 \% * * * \\
(3.89)\end{array}$ \\
\hline VaR & $9.02 \%$ & $5.39 \%$ & $\begin{array}{c}3.63 \%^{* * *} \\
(3.32)\end{array}$ & $9.88 \%$ & $5.53 \%$ & $\begin{array}{c}4.35 \% * * * \\
(3.20)\end{array}$ \\
\hline CoVar & $8.99 \%$ & $5.58 \%$ & $\begin{array}{c}3.41 \%^{* * *} \\
(3.17)\end{array}$ & $9.94 \%$ & $5.69 \%$ & $\begin{array}{c}4.25 \% \text { *** } \\
(3.12)\end{array}$ \\
\hline Average & $8.88 \%$ & $5.55 \%$ & $\begin{array}{c}3.33 \%^{* * *} \\
(3.13)\end{array}$ & $10.21 \%$ & $5.26 \%$ & $\begin{array}{c}4.95 \% \%^{* * *} \\
(3.59)\end{array}$ \\
\hline
\end{tabular}

Panel B: Fama-MacBeth (1973) Regressions

\begin{tabular}{|c|c|c|c|c|c|c|c|c|}
\hline & \multicolumn{2}{|c|}{ Standard Deviation } & \multicolumn{2}{|c|}{ Idios. Vola } & \multicolumn{2}{|c|}{ VaR } & \multicolumn{2}{|c|}{ CoVar } \\
\hline & Low Disp. & High Disp. & Low Disp. & High Disp. & Low Disp. & High Disp. & Low Disp. & High Disp. \\
\hline EDL risk & $\begin{array}{c}0.00112^{* * *} \\
\quad(3.54)\end{array}$ & $\begin{array}{c}0.00195^{* * *} \\
\quad(2.58)\end{array}$ & $\begin{array}{c}0.00109^{* * *} \\
\quad(3.44)\end{array}$ & $\begin{array}{c}0.00201^{* * *} \\
\quad(2.67)\end{array}$ & $\begin{array}{c}0.00116^{* * *} \\
\quad(3.56)\end{array}$ & $\begin{array}{c}0.00187^{* *} \\
(2.52)\end{array}$ & $\begin{array}{c}0.00114^{* * *} \\
\quad(3.56)\end{array}$ & $\begin{array}{c}0.00171^{* *} \\
(2.22)\end{array}$ \\
\hline
\end{tabular}

This table displays the results of conditional univariate portfolio sorts and conditional multivariate Fama and MacBeth (1973) regressions. We sort stocks into two categories: Low dispersion stocks which display a standard deviation or idiosyncratic volatility (VaR or CoVar) of returns and liquidity shocks below (above) the respective median measure and high dispersion stocks which display a standard deviation or idiosyncratic volatility (VaR or CoVar) of returns and liquidity shocks above (below) the respective median measure. Panel A reports the results of univariate portfolio sorts based on the high/low dispersion sample. Panel B repeats regression (5) from Table 6 of weekly excess returns over the risk-free rate at week $t+2$ on firm- and risk characteristics conditional on a stock's dispersion measures being below (above) the respective median. We only report the coefficient estimate for the impact of EDL risk. All other explanatory variables of regression specification (5) are included in the regressions, but their coefficient estimates are suppressed. A detailed description of the computation of these variables is given in the main text and in Internet Appendix C. The sample covers all U.S. common stocks traded on the NYSE / AMEX and the sample period is from January 1969 to December 2012. t-statistics are in parentheses. ${ }^{* * *},{ }^{* *}$, and ${ }^{*}$ indicate significance at the one, five, and ten percent level, respectively. We use Newey-West (1987) standard errors with four lags. 


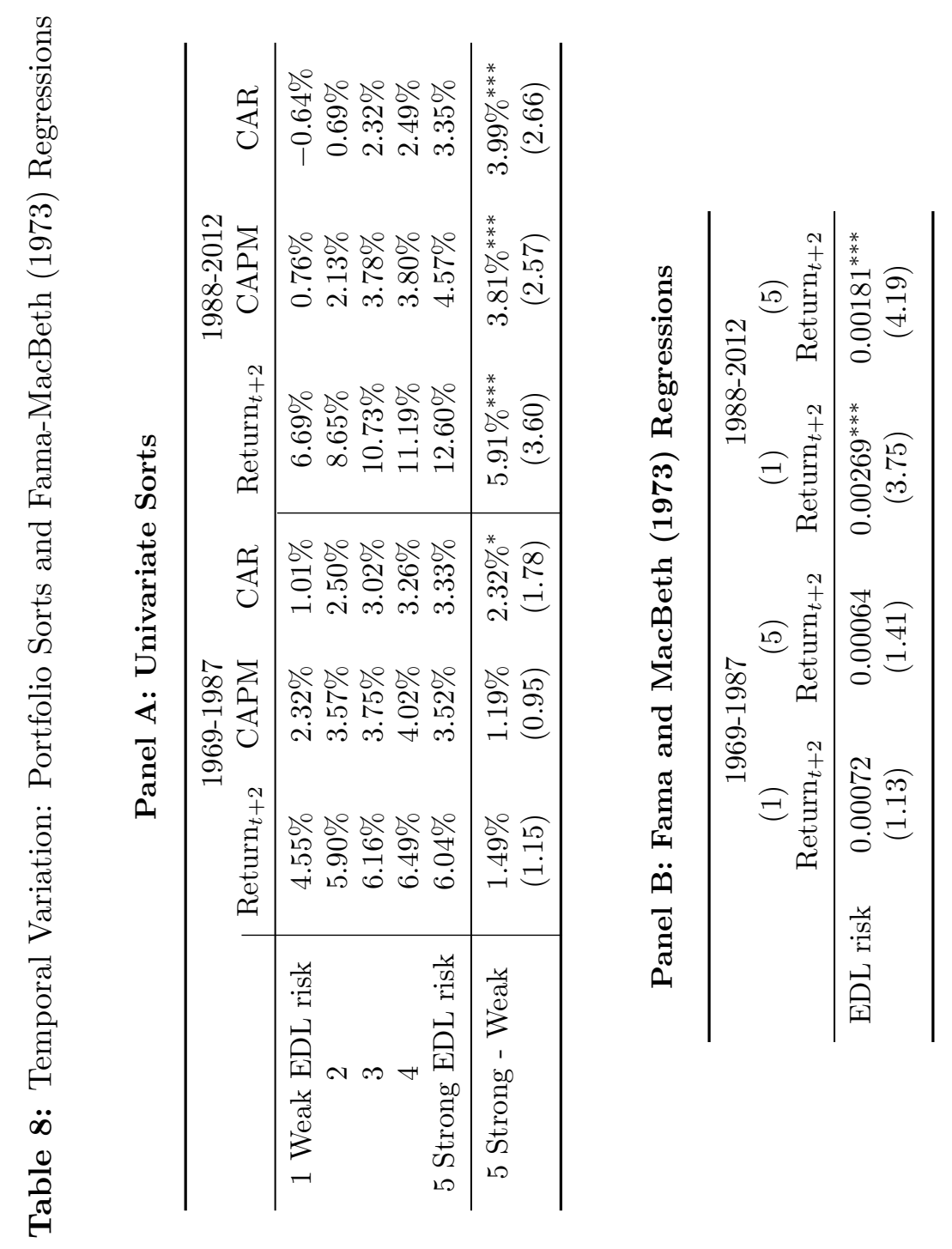

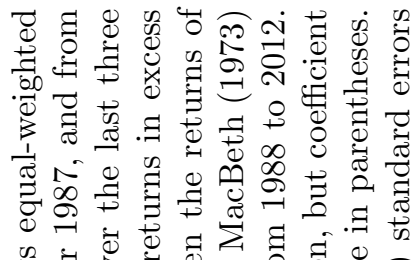

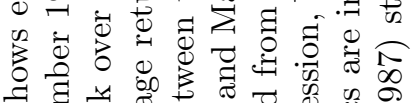
क छี

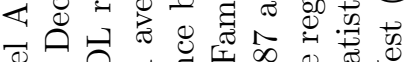

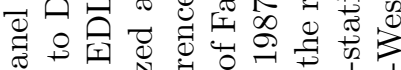

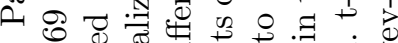
ن.

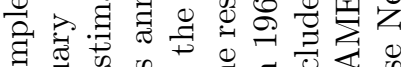

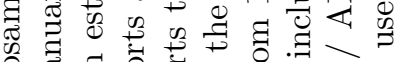

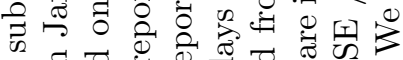

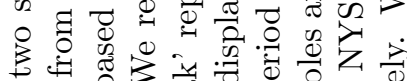

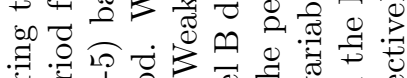
苛离.

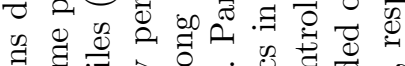

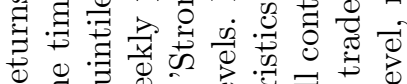

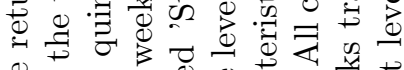

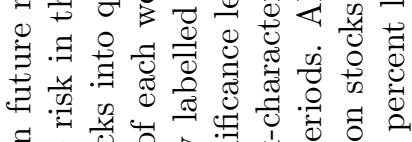

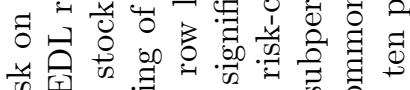

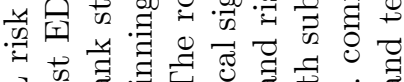

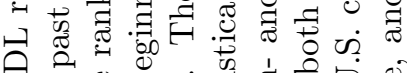

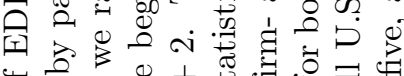

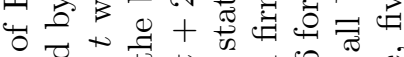

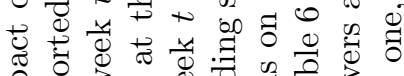

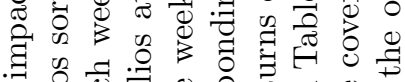

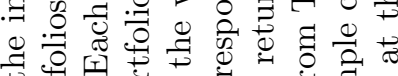

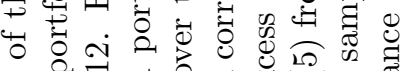

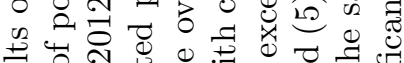

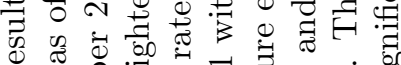

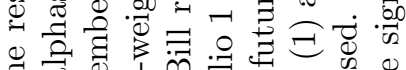
娄

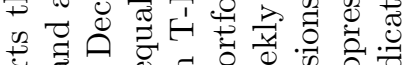

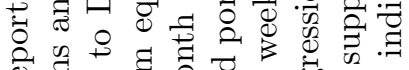

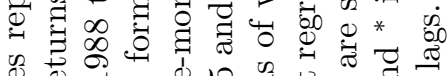
过

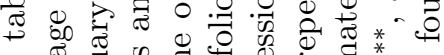

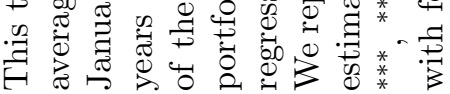


Table 9: Different Liquidity Proxies: Univariate Portfolio Sorts and FMB Regressions

Panel A: Univariate Portfolio Sorts

\begin{tabular}{c|ccc}
\hline Liquidity & Return $_{t+2}$ & CAPM & CAR \\
\hline EDL risk 5-1 & \multicolumn{3}{c}{ Low-Frequency (1969-2012) } \\
\hline illiq & $4.00 \%^{* * *}$ & $2.85 \%^{* * *}$ & $3.03 \%^{* * *}$ \\
& $(3.66)$ & $(2.80)$ & $(2.90)$ \\
Corwin & $2.28 \%^{* *}$ & $0.89 \%$ & $1.98 \%^{* *}$ \\
& $(2.15)$ & $(0.89)$ & $(2.03)$ \\
Zeros & $1.47 \%^{* * *}$ & $1.35 \%^{* *}$ & $1.60 \%^{* * *}$ \\
& $(2.69)$ & $(2.49)$ & $(2.91)$ \\
FHT & $3.40 \%^{* * *}$ & $2.80 \%^{* * *}$ & $3.10 \%^{* * *}$ \\
& $(4.24)$ & $(3.57)$ & $(3.95)$ \\
\hline EDL risk 5-1 & \multicolumn{3}{c}{ High-Frequency $(2002-2010)$} \\
\hline \multirow{2}{*}{ EffSpr } & $4.11 \%^{* *}$ & $3.53 \%^{* *}$ & $3.39 \%^{* *}$ \\
& $(2.24)$ & $(2.14)$ & $(1.94)$ \\
RelSpr & $1.72 \%$ & $0.81 \%$ & $1.24 \%$ \\
& $(0.83)$ & $(0.43)$ & $(0.67)$ \\
IntAmi & $5.53 \%^{* *}$ & $4.51 \%^{* *}$ & $3.82 \%^{*}$ \\
& $(2.03)$ & $(1.98)$ & $(1.80)$ \\
PriImp & $4.67 \%^{* *}$ & $3.93 \%^{* *}$ & $3.78 \%^{*}$ \\
& $(2.18)$ & $(2.03)$ & $(1.85)$ \\
\hline \multicolumn{5}{c}{}
\end{tabular}

Panel B: Fama and MacBeth (1973) Regressions

\begin{tabular}{ccccccccc}
\hline & \multicolumn{3}{c}{ Low-Frequency $(1969-2012)$} & \multicolumn{4}{c}{ High-Frequency $(2002-2010)$} \\
& $(1)$ & $(2)$ & $(3)$ & $(4)$ & $(5)$ & $(6)$ & $(7)$ & $(8)$ \\
& Illiq & Corwin & Zeros & FHT & EffSpr & RelSpr & IntAmi & PriImp \\
\hline EDL risk & $0.00137^{* * *}$ & $0.00085^{* * *}$ & 0.00047 & $0.00167^{* * *}$ & $0.00135^{*}$ & 0.00007 & $0.00192^{* * *}$ & $0.00171^{* *}$ \\
& $(4.28)$ & $(2.69)$ & $(0.98)$ & $(4.49)$ & $(1.83)$ & $(0.14)$ & $(2.59)$ & $(2.23)$ \\
\hline
\end{tabular}

This table reports results of univariate portfolio sorts and Fama and MacBeth (1973) regressions for different liquidity proxies. As high-frequency liquidity proxies we use the effective spread (EffSpr), the relative spread (RelSpr), the intraday Amihud measure (IntAmi), and the price impact measure (PriImp). As low-frequency liquidity proxies we use the Amihud Illiquidity Ratio (illiq), the Corwin measure (Corwin), the Zeros measure (Zeros) and the FHT measure (FHT). A detailed description of the computation of these variables is given in Internet Appendix A. In Panel A we rank stocks into quintiles (1-5) based on estimated past EDL risk of the different liquidity proxies over the last three years and form equal-weighted portfolios at the beginning of each weekly period. We report differences in annualized returns, differences in the CAPM-Alpha based on Sharpe (1964)'s capital asset pricing model and differences in the CAR-alpha based on Carhart (1997)'s four factor model between portfolio 5 and portfolio 1 with corresponding statistical significance levels. Panel B shows the results of regression specification (5) from Table 6 for different liquidity proxies. We only report the coefficient estimate for the impact of EDL risk. All other explanatory variables of specification (5) are included in the regressions, but their coefficient estimates are suppressed. The sample covers all U.S. common stocks traded on the NYSE / AMEX. The sample period for the low-frequency liquidity proxies is from January 1969 to December 2012. The sample period for the high-frequency liquidity proxies is from July 2002 to December 2010. t-statistics are in parentheses. ${ }^{* * *},{ }^{* *}$, and ${ }^{*}$ indicate significance at the one, five, and ten percent level, respectively. We use Newey-West (1987) standard errors with four lags. 
Table 10: Different Estimation Procedures: Univariate Portfolio Sorts and FMB Regressions

Panel A: Univariate Portfolio Sorts

\begin{tabular}{|c|c|c|c|}
\hline Procedure & Return $_{t+2}$ & CAPM & CAR \\
\hline EDL risk 5-1 & \multicolumn{3}{|c|}{ Estimation Horizons \& Liquidity Shocks } \\
\hline $1 \mathrm{y}$ & $\begin{array}{c}2.91 \% \text { *** } \\
(3.40)\end{array}$ & $\begin{array}{c}2.05 \% * * \\
(2.39)\end{array}$ & $\begin{array}{c}2.39 \% * * \\
(2.50)\end{array}$ \\
\hline $2 \mathrm{y}$ & $\begin{array}{c}3.91 \%^{* * *} \\
(3.43)\end{array}$ & $\begin{array}{c}2.67 \%^{* *} \\
(2.53)\end{array}$ & $\begin{array}{c}2.94 \% \text { *** } \\
(2.68)\end{array}$ \\
\hline $5 y$ & $\begin{array}{c}4.22 \%^{* * *} \\
(3.09)\end{array}$ & $\begin{array}{c}2.81 \%{ }^{* *} \\
(2.32)\end{array}$ & $\begin{array}{c}2.56 \% * * \\
(2.16)\end{array}$ \\
\hline diff & $\begin{array}{c}5.66 \% \text { *** } \\
(4.39)\end{array}$ & $\begin{array}{c}4.34 \%^{* * * *} \\
(3.75)\end{array}$ & $\begin{array}{c}3.91 \%^{* * *} \\
(3.31)\end{array}$ \\
\hline EDL risk $5-1$ & \multicolumn{3}{|c|}{ Copula Functions } \\
\hline $\mathrm{C} 1$ & $\begin{array}{c}4.00 \% \text { *** } \\
(3.66)\end{array}$ & $\begin{array}{c}2.85 \%^{* * *} \\
(2.80)\end{array}$ & $\begin{array}{c}3.03 \% * * * \\
(2.90)\end{array}$ \\
\hline $\mathrm{C} 2$ & $\begin{array}{c}4.19 \% * * * \\
(3.94)\end{array}$ & $\begin{array}{c}3.07 \% \text { *** } \\
(3.14)\end{array}$ & $\begin{array}{c}3.22 \% * * * \\
(3.23)\end{array}$ \\
\hline C63 & $\begin{array}{c}4.64 \% \text { *** } \\
(4.27)\end{array}$ & $\begin{array}{c}3.47 \% * * * \\
(3.47)\end{array}$ & $\begin{array}{c}3.59 \% \text { *** } \\
(3.50)\end{array}$ \\
\hline C64 & $\begin{array}{c}4.10 \% \text { *** } \\
(3.78)\end{array}$ & $\begin{array}{c}2.93 \% \%^{* * *} \\
(2.93)\end{array}$ & $\begin{array}{c}3.10 \% \text { *** } \\
(3.01)\end{array}$ \\
\hline $\mathrm{Cw}$ & $\begin{array}{c}5.24 \% \text { *** } \\
(4.41)\end{array}$ & $\begin{array}{c}3.91 \% * * \\
(3.58)\end{array}$ & $\begin{array}{c}4.04 \%^{* * *} \\
(3.61)\end{array}$ \\
\hline EDL risk 5-1 & \multicolumn{3}{|c|}{ EDL risk Components } \\
\hline $\mathrm{EDLR}_{1}$ & $\begin{array}{r}0.33 \% \\
(0.40)\end{array}$ & $\begin{array}{c}-0.32 \% \\
(-0.40)\end{array}$ & $\begin{array}{c}-0.23 \% \\
(-0.28)\end{array}$ \\
\hline $\mathrm{EDLR}_{2}$ & $\begin{array}{c}4.08 \% \text { *** } \\
(4.74)\end{array}$ & $\begin{array}{c}3.32 \% * * * \\
(4.10)\end{array}$ & $\begin{array}{c}3.09 \% * * * \\
(3.69)\end{array}$ \\
\hline $\mathrm{EDLR}_{3}$ & $\begin{array}{c}3.59 \% \text { *** } \\
(3.87)\end{array}$ & $\begin{array}{c}2.70 \% * * * \\
(3.08)\end{array}$ & $\begin{array}{c}2.97 \% * * * \\
(3.39)\end{array}$ \\
\hline
\end{tabular}


Panel B: Fama and MacBeth (1973) Regressions

\begin{tabular}{|c|c|c|c|c|c|}
\hline & $\begin{array}{l}\text { Estim } \\
(1) \\
1 \mathrm{y}\end{array}$ & $\begin{array}{c}\text { tion Horizon } \\
(2) \\
2 \mathrm{y}\end{array}$ & $\begin{array}{c}\text { \& Liquidity } \\
(3) \\
5 y\end{array}$ & $\begin{array}{l}\text { hocks } \\
\qquad \begin{array}{l}\text { (4) } \\
\text { diff }\end{array}\end{array}$ & \\
\hline EDL risk & $\begin{array}{c}0.00068^{* * *} \\
\quad(3.45)\end{array}$ & $\begin{array}{c}0.00108^{* * *} \\
\quad(4.14)\end{array}$ & $\begin{array}{c}0.00167^{* * *} \\
\quad(4.48)\end{array}$ & $\begin{array}{c}0.00226^{* * *} \\
\quad(6.41)\end{array}$ & \\
\hline & $\begin{array}{l}(5) \\
\mathrm{C} 1\end{array}$ & $\begin{array}{l}(6) \\
\mathrm{C} 2\end{array}$ & $\begin{array}{l}\text { pula Functio } \\
\text { (7) } \\
\text { C63 }\end{array}$ & $\begin{array}{l}(8) \\
\text { C64 }\end{array}$ & $\begin{array}{l}(9) \\
\mathrm{Cw}\end{array}$ \\
\hline EDL risk & $\begin{array}{c}0.00137^{* * *} \\
\quad(4.28)\end{array}$ & $\begin{array}{c}0.00125^{* * *} \\
\quad(3.96)\end{array}$ & $\begin{array}{c}0.00156^{* * *} \\
(4.65)\end{array}$ & $\begin{array}{c}0.00127^{* * *} \\
\quad(3.92)\end{array}$ & $\begin{array}{c}0.00178^{* * *} \\
\quad(4.44)\end{array}$ \\
\hline
\end{tabular}

EDL risk Components (joint estimate)

\begin{tabular}{cccc} 
& \multicolumn{3}{c}{$(10)$} \\
& $\mathrm{EDLR}_{1}$ & $\mathrm{EDLR}_{2}$ & $\mathrm{EDLR}_{3}$ \\
\hline EDL risk & -0.00003 & $0.00234^{* * *}$ & $0.00276^{* * *}$ \\
& $(-0.06)$ & $(3.61)$ & $(4.55)$ \\
\hline
\end{tabular}

This table reports results of univariate portfolio sorts and Fama-MacBeth (1973) regressions for different estimation horizons, liquidity shocks, copula functions, and on the EDL risk component level. We estimate EDL risk with different estimation horizons of 1-year, 2-years, and 5-years, as well as based on liquidity-differences instead of -shocks from an AR-model. Furthermore we estimate EDL risk with different copulas (C1-C4 and $\mathrm{Cw}$ ). We also analyze the component-wise effect of the three risk factors EDL risk 1 , EDL risk 2 , and EDL risk 3 . A detailed description of the computation of these variables is given in the main text and Internet Appendix C. In Panel A we rank stocks into quintiles (1-5) based on estimated past EDL risk of the different estimation horizons, different copulas and EDL risk components, and form equal-weighted portfolios at the beginning of each weekly period. We report differences in annualized returns, differences in the CAPM-Alpha based on Sharpe (1964)'s capital asset pricing model and differences in the CAR-alpha based on Carhart (1997)'s four factor model between portfolio 5 and portfolio 1 with corresponding statistical significance levels. Panel B shows the results of regression specification (5) from Table 6 for different estimation procedures. We only report the coefficient estimate for the impact of EDL risk. In Specification (10) of Panel B, we adjust specification (5) from Table 6 by replacing EDL risk by its three components and estimating jointly. The sample covers all U.S. common stocks traded on the NYSE / AMEX. The sample period is from January 1969 to December 2012. t-statistics are in parentheses. ${ }^{* *},{ }^{* *}$, and ${ }^{*}$ indicate significance at the one, five, and ten percent level, respectively. We use Newey-West (1987) standard errors with four lags. 

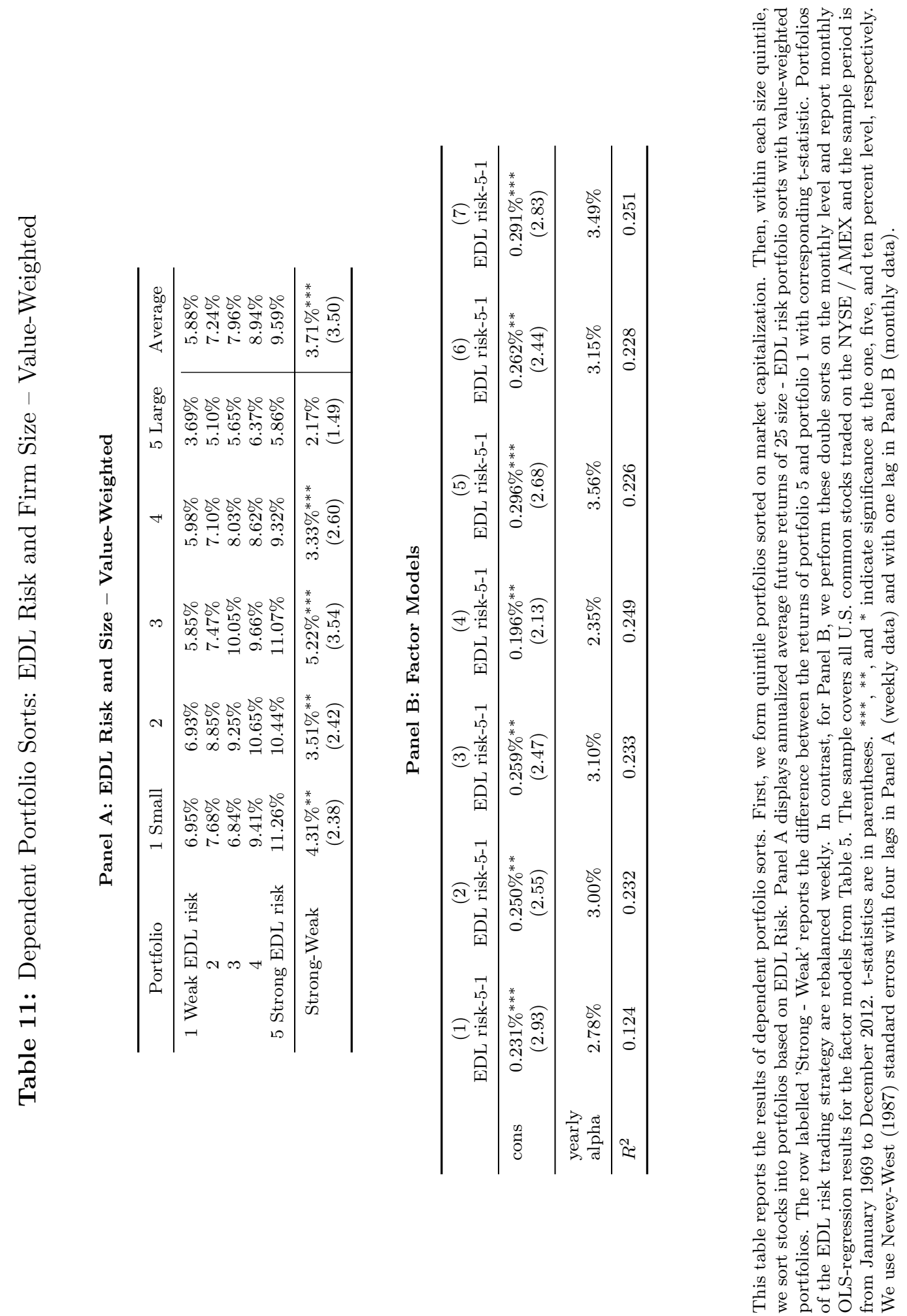
Table 12: Different Regression Methods

Panel A: Different Regression Methods

\begin{tabular}{|c|c|c|c|c|c|c|c|}
\hline Regression & (1) & $(2)$ & $(3)$ & $(4)$ & $(5)$ & $(6)$ & $(7)$ \\
\hline EDL risk & $\begin{array}{c}0.00137^{* * * *} \\
(4.24)\end{array}$ & $\begin{array}{c}0.00117^{* * *} \\
(3.60)\end{array}$ & $\begin{array}{c}0.00214^{* * *} \\
(8.88)\end{array}$ & $\begin{array}{c}0.00214^{* * *} \\
(7.99)\end{array}$ & $\begin{array}{c}0.00243^{* * *} \\
(8.57)\end{array}$ & $\begin{array}{c}0.00243^{* * *} \\
(8.89)\end{array}$ & $\begin{array}{c}0.00240^{* * *} \\
(8.56)\end{array}$ \\
\hline Controls & yes & yes & yes & yes & yes & yes & yes \\
\hline Method & $\mathrm{fmb}$ & $\mathrm{fmb}$ & ols & ols & panel & panel & panel \\
\hline Winsorized & yes & no & yes & yes & yes & yes & yes \\
\hline Time-Fixed Effects & & & yes & yes & yes & yes & yes \\
\hline Firm Effects & & & no & no & fixed & fixed & random \\
\hline Clustered SE & & & firm & industry & no & firm & no \\
\hline Newey-West SE & no & yes & no & no & no & no & no \\
\hline$R^{2}$ & 0.065 & 0.064 & 0.195 & 0.187 & 0.202 & 0.202 & \\
\hline
\end{tabular}

Panel B: Adjusted Returns

\begin{tabular}{|c|c|c|c|}
\hline & $\begin{array}{c}\text { EDL risk } \\
\text { (t-stat) }\end{array}$ & $\begin{array}{c}\text { return } \\
\text { adjustment }\end{array}$ & $\begin{array}{c}\text { EDL risk } \\
\text { (t-stat) }\end{array}$ \\
\hline $\begin{array}{l}\operatorname{Return}_{t+1} \\
\text { (weekly) }\end{array}$ & $\begin{array}{c}0.00157^{* * *} \\
(4.90)\end{array}$ & $\begin{array}{c}\text { SIC-2 } \\
\text { (weekly) }\end{array}$ & $\begin{array}{c}0.00096^{* * *} \\
(3.52)\end{array}$ \\
\hline $\begin{array}{l}\text { Return }_{t+3} \\
\text { (weekly) }\end{array}$ & $\begin{array}{c}0.00150^{* * *} \\
(4.71)\end{array}$ & $\begin{array}{c}\text { SIC-3 } \\
\text { (weekly) }\end{array}$ & $\begin{array}{c}0.00085^{* * *} \\
(2.83)\end{array}$ \\
\hline $\begin{array}{l}\operatorname{Return}_{t+4} \\
\text { (weekly) }\end{array}$ & $\begin{array}{c}0.00148^{* * *} \\
(4.77)\end{array}$ & $\begin{array}{c}\text { SIC-4 } \\
\text { (weekly) }\end{array}$ & $\begin{array}{c}0.00074^{* * *} \\
(3.27)\end{array}$ \\
\hline $\begin{array}{l}\text { Monthly Return } \\
\text { (monthly) }\end{array}$ & $\begin{array}{c}0.00447^{* * *} \\
(3.24)\end{array}$ & $\begin{array}{c}\text { FF12 } \\
\text { (monthly) }\end{array}$ & $\begin{array}{c}0.00468^{* *} \\
(2.19)\end{array}$ \\
\hline $\begin{array}{l}\text { DGTW } \\
\text { (monthly) }\end{array}$ & $\begin{array}{c}0.00263^{*} \\
(1.72)\end{array}$ & $\begin{array}{c}\text { FF48 } \\
\text { (monthly) }\end{array}$ & $\begin{array}{c}0.00451^{* *} \\
(2.18)\end{array}$ \\
\hline
\end{tabular}

Panel A reports the results of different multivariate regressions on a weekly frequency. Regression (1) repeats the baseline regression (5) from Table 6, but we now do not use Newey-West standard errors in the second stage of the Fama-MacBeth (1973) regressions. Regression (2) repeats the standard Fama-MacBeth (1973) regression, but we do not winsorize the independent variables. In regression (3) we perform a pooled OLS regression with time-fixed effects and standard errors clustered by stock. Regression (4) is identical, but we cluster standard errors by the SIC-2-digits classification. Regressions (5) and (6) perform panel regressions with firm-fixed effects. In regression (6) standard errors are additionally clustered by firm. Finally, in regression (7) we regress excess returns on the independent variables via a random-effect panel regression. Panel B reports the result of regression (5) of Table 6 with different return adjustments. We use weekly returns in $t+1, t+3$, and $t+4$, as well as monthly returns, DGTW alphas (results are displayed on the left side of Panel B), and industry-adjustments (results are displayed on the right side of Panel B). The sample period is from January 1969 to December 2012. ***,**, and * indicate significance at the one, five, and ten percent level, respectively. We use Newey-West (1987) standard errors with four lags for weekly data and with one lag for monthly data. 


\title{
Internet Appendix for "Extreme Downside Liquidity Risk"
}

\begin{abstract}
The Internet Appendix consists of three sections. Internet Appendix A contains information on the eight liquidity proxies used in this study, as well as the computation of liquidity shocks. In Internet Appendix B, we provide the technical details of the copula estimation and selection procedure. Internet Appendix $\mathrm{C}$ defines the main variables used in the study and gives detailed data sources.
\end{abstract}




\section{A Internet Appendix: Liquidity Measures}

Internet Appendix A provides the definitions of the eight liquidity proxies used in this study, along with data requirements, details about the computation of liquidity shocks and a short analysis of how well EDL risk estimates based on low-frequency proxies correlate with high-frequency benchmark values.

\section{A.1 Liquidity Proxy Definitions and Data Requirements}

The low-frequency data for proxies (1)-(4) comes from CRSP. The high-frequency proxies (5)-(8) use data from the NYSE TAQ database.

(1) The Amihud (2002) Illiquidity Ratio (Illiq) is defined as in Acharya and Pedersen (2005):

$$
c_{t}^{i}=\min \left(0.25+0.30 \cdot i l l i q_{t}^{i} \cdot P_{t-1}^{m}, 30\right) \%
$$

with

$$
i l l i q_{t}^{i}=\frac{1}{\operatorname{days}_{t}^{i}} \sum_{d=1}^{\operatorname{days}_{t}^{i}} \frac{\left|r_{t d}^{i}\right|}{V_{t d}^{i}}
$$

where $r_{t d}^{i}$ and $V_{t d}^{i}$ are respectively the return and dollar volume (in millions) on day $d$ in week $t$ and days $_{t}^{i}$ is the number of valid (available return and non-zero dollar-volume) observations in week $t$ for stock $i$. $c_{t}^{i}$ can be interpreted as the effective half-spread of stock $i$.

(2) The Corwin and Schultz (2012) illiquidity measure (Corwin) is defined as follows:

$$
c_{t}^{i}=\frac{1}{\operatorname{days}_{t}^{i}-1} \sum_{d=2}^{\operatorname{days}_{t}^{i}} \max \left(\frac{2 \cdot\left(e^{\alpha_{t d}^{i}}-1\right)}{e^{\alpha_{t d}^{i}}+1}, 0\right)
$$


with

$$
\begin{aligned}
\alpha_{t d}^{i} & =\frac{\sqrt{2 \cdot \beta_{t d}^{i}}-\sqrt{\beta_{t d}^{i}}}{3-2 \cdot \sqrt{2}}-\sqrt{\frac{\gamma_{t d}^{i}}{3-2 \cdot \sqrt{2}}} \\
\beta_{t d}^{i} & =\left(\log \left(\frac{h i_{t, d-1}^{i}}{\operatorname{lo} o_{t, d-1}^{i}}\right)\right)^{2}+\left(\log \left(\frac{h i_{t, d}^{i}}{\operatorname{lo} o_{t, d}^{i}}\right)\right)^{2} \\
\gamma_{t d}^{i} & =\left(\log \left(\frac{t d h i_{t, d}^{i}}{t d l o_{t, d}^{i}}\right)\right)^{2}
\end{aligned}
$$

where $h i_{t, d}^{i}$ and $l o_{t, d}^{i}$ stand for high- and low-prices on day $d$ in week $t$ for stock $i$, $t d h i_{t, d}^{i}$ and $t d l o_{t, d}^{i}$ stand for 2-day high- and low-prices on days $d-1$ and $d$ in week $t$ for stock $i$ and days $_{t}^{i}$ is the number of days for which high-, low- and closing prices are available. We use the same adjustments for strong overnight price changes and thinly traded stocks as Corwin and Schultz (2012). $c_{t}^{i}$ can be interpreted as the spread of stock $i$.

(3) The Lesmond, Ogden and Trzcinka (1999) illiquidity measure (Zeros) is defined as:

$$
c_{t}^{i}=\frac{x_{t d}^{i}}{\operatorname{days}_{t}^{i}}
$$

where $x_{t d}^{i}$ is the number of zero-return days and $d a y s_{t}^{i}$ is the number of available daily returns in week $t$ for stock $i$.

(4) The Fong, Holden and Trzcinka (2014) illiquidity measure (FHT) is defined as follows:

$$
c_{t}^{i}=2 \cdot \sigma_{t}^{i} \cdot N^{-1}\left(\frac{1+Z \operatorname{eros} 2}{2}\right)
$$

with

$$
Z \operatorname{eros} 2=\frac{x_{t}^{i}}{7}
$$

where $x_{t}^{i}$ is the number of zero-return days for week $t, \sigma_{t}^{i}$ is the standard-deviation of daily returns in week $t$, and $N^{-1}(\cdot)$ is the inverse of the standard normal cdf. $c_{t}^{i}$ can be interpreted as the spread of stock $i$. 
(5) The relative spread (RelSpr) is defined as:

$$
c_{t}^{i}=\frac{1}{\operatorname{days}_{t}^{i}} \sum_{d=1}^{\operatorname{days}_{t}^{i}} \frac{1}{N_{t d}^{i}} \sum_{n=1}^{N_{t d}^{i}} R S_{t d n}^{i}
$$

with

$$
R S_{t d n}^{i}=\frac{A_{t d n}^{i}-B_{t d n}^{i}}{Q_{t d n}^{i}}
$$

where $A_{t d n}^{i}, B_{t d n}^{i}$ and $Q_{t d n}^{i}=\frac{A_{t d n}^{i}+B_{t d n}^{i}}{2}$ are prevailing ask quote, prevailing bid quote and quote midpoint price in transaction $n$ of day $d$ in week $t$. days $_{t}^{i}$ is the number of days with available transactions of stock $i$ in week $t$ and $N_{t d}^{i}$ is the number of transactions of stock $i$ on day $d$ in week $t$. The prevailing bid- and ask-quotes are the latest available quotes up to at least one second before the trade.

(6) The effective spread (EffSpr) is defined as follows:

$$
c_{t}^{i}=\frac{1}{\operatorname{days}_{t}^{i}} \sum_{d=1}^{\operatorname{days}_{t}^{i}} \frac{1}{N_{t d}^{i}} \sum_{n=1}^{N_{t d}^{i}} E S_{t d n}^{i}
$$

with

$$
E S_{t d n}^{i}=\frac{2 \cdot\left|P_{t d n}^{i}-Q_{t d n}^{i}\right|}{Q_{t d n}^{i}}
$$

where all variables are defined as above and $P_{t d n}^{i}$ is the transaction price of transaction $n$ of day $d$ in week $t$.

(7) The 5-minute price impact (PriImp) is defined as follows:

$$
c_{t}^{i}=\frac{1}{\operatorname{days}_{t}^{i}} \sum_{d=1}^{\operatorname{days}_{t}^{i}} \frac{1}{N_{t d}^{i}} \sum_{n=1}^{N_{t d}^{i}} P I_{t d n}^{i}
$$

with

$$
P I_{t d n}^{i}=\frac{2 \cdot\left|Q_{t d n 5}^{i}-Q_{t d n}^{i}\right|}{Q_{t d n}^{i}}
$$


where all variables are defined as above and $Q_{t d n 5}^{i}$ is the quote midpoint 300 seconds after transaction $n$ of day $d$ in week $t$.

(8) The intraday Amihud measure (IntAmi) is defined as follows:

$$
c_{t}^{i}=\frac{1}{\operatorname{days}_{t}^{i}} \sum_{d=1}^{\operatorname{days}_{t}^{i}} \frac{1}{N_{t d}^{i}} \sum_{n=1}^{N_{t d}^{i}} I A_{t d n}^{i}
$$

with

$$
I A_{t d n}^{i}=\frac{2 \cdot\left|Q_{t d n 5}^{i}-Q_{t d n}^{i}\right|}{Q_{t d n}^{i} \cdot w_{t d n}^{i}}
$$

where all variables are defined as above and $w_{t d n}^{i}$ is the transaction volume (in shares) of transaction $n$ of day $d$ in week $t$.

For all liquidity proxies, a missing value is recorded if there are less than three daily observations for week $t$ and stock $i$, i.e., $\operatorname{days}_{t}^{i}<3$. $^{1}$

\section{A.2 Computation of Illiquidity Shocks and Analysis of EDL Risk Estimates For Different Proxies}

As explained in the main text, we use $d_{t}^{i}=-c_{t}^{i}$, i.e., liquidity(-shocks) instead of illiquidity(shocks) for the estimation of EDL risk (see Internet Appendix B) in order to facilitate the interpretation of extreme downside liquidity risk. As $d_{t}^{i}$ is highly persistent for most of the stocks in our sample, we estimate liquidity shocks based on the difference between the normalized realized liquidity value $d_{t}^{i}$ and the expected normalized liquidity $E_{t-1}\left(d_{t}^{i}\right)$ for each stock $i$ and week $t$. Expected normalized liquidity $E_{t-1}\left(d_{t}^{i}\right)$ is computed via an AR - time series model.

In order to deal with possible time-variation of parameters and to keep estimates fully outof-sample, the estimation is run on a 3-year rolling window basis. The choice of a persistent but mean-reverting process seems natural for liquidity. Statistical tests - based on nonoverlapping 3-year periods between 1963 and $2011^{2}$ - generally support this choice. First,

\footnotetext{
${ }^{1}$ We make an exception for the week of September $11^{\text {th }} 2001$, when just one trading day occurred on NYSE/AMEX. For this week the minimum number of observations is lowered to 1.

${ }^{2}$ The results are qualitatively the same, if the model-selection is done for just 1963-1968, so that the EDL risk-estimates can still be interpreted as fully out-of-sample.
} 
the null-hypothesis of 'no autocorrelation at the first lag' is rejected by Ljung-Box tests at a $10 \%$ significance level for most stocks (e.g., $92 \%$ of stocks for the Amihud Illiquidity Ratio). Second, Augmented Dickey-Fuller tests - with four lagged difference terms, with drift and without time-trend - reject the null-hypothesis of 'unit root present' at a $10 \%$ significance level for most stocks (e.g., 78\% of stocks for the Amihud Illiquidity Ratio). Additionally, the partial autocorrelation function becomes insignificant at the fourth lag or less for most stocks (e.g., $86 \%$ of stocks for the Amihud Illiquidity Ratio). These results generalize to most proxies. Thus, it seems reasonable to use an $\operatorname{AR}(4)$-model to estimate $E_{t-1}\left(d_{t}^{i}\right)$, as given in equation (5).

In order to assess the quality of our EDL risk estimates for different liquidity proxies, we perform a comparison between our weekly low-frequency proxies (illiq, Corwin, Zeros and FHT) and high-frequency benchmarks (EffSpr, RelSpr, IntAmi, and PriImp) from 1996 to 2010, when both are available. Panel A of Table A.1 displays average time-series correlations between proxy-levels for the sample period from 1996 to 2010. As expected, all low-frequency proxies are positively correlated with high-frequency benchmarks. Illiq and Corwin show the highest correlations with the high-frequency proxies. In Panel B of Table A.1 we report average time-series correlations between proxy-EDL risk estimates. We again find that EDL risk estimates of the illiq and the Corwin measure are more highly correlated with the highfrequency proxies than risk estimates of the Zeros and the FHT measure. The positive correlations between low-frequency proxy EDL risks and high-frequency proxy EDL risks suggest, that - in spite of all the noise in weekly low-frequency liquidity shocks - our method captures lower tail dependence in actual liquidity. Additionally, the magnitude of correlations suggests that Corwin and illiq lead to more precise EDL risk estimates than FHT and Zeros. The same ranking emerges in unreported tests, when average cross-sectional correlations on the stock-level, time-series correlations for the value-weighted market shocks, and Spearman, i.e., rank correlations between liquidity-shocks, are analyzed.

To investigate the temporal variation of the different EDL risk proxy measures, we plot the development of aggregate EDL risks over time. As before, we define aggregate EDL risk as the weekly cross-sectional, value-weighted average of EDL risk ${ }_{i, t}$ over all stocks $i$ in our sample. Figure A.1 plots the time series of EDL risk ${ }_{m, t}$ for the different low-frequency and high-frequency measures. It reveals that EDL risk $\mathrm{m}_{m, t}$ based on low-frequency proxies experiences the largest spikes during the time period after Black Monday in October 1987 
and the financial crisis starting in 2007. The same spike in 2007 emerges for the EDL risk measures based on high-frequency proxies, which are only available after 2001 . We attribute the difference in EDL risk levels across proxies to the noisiness of liquidity measures. Noise (without tail dependence) could cause lower EDL risk estimates. This would explain why our noisier proxies (FHT and Zeros, see Table A.1) are at lower absolute EDL risk levels than EDL risk estimates based on Corwin and illiq. 
Table A.1: Average Time-Series Correlations between Liquidity Proxy Levels and EDL Risk Estimates

Panel A: Average Time-Series Correlations between Proxy Levels

\begin{tabular}{|c|c|c|c|c|c|c|c|c|}
\hline & \multicolumn{4}{|c|}{ High-Frequency Proxies } & \multicolumn{4}{|c|}{ Low-Frequency Proxies } \\
\hline & EffSpr & RelSpr & Int $A m i$ & PriImp & illiq & Corwin & Zeros & FHT \\
\hline EffSpr & 1.00 & & & & & & & \\
\hline RelSpr & 0.41 & 1.00 & & & I & & & \\
\hline IntAmi & 0.58 & 0.35 & 1.00 & & ! & & & \\
\hline PriImp & 0.75 & 0.33 & 0.79 & 1.00 & i & & & \\
\hline$-\bar{i} l \overline{l i} q^{-}$ & $\overline{0} . \overline{2} 5$ & $\overline{0} . \overline{4} 1-$ & $\overline{0} . \overline{2} \overline{9}$ & $0 . \overline{19}$ & $\overline{1.00}$ & & & \\
\hline Corwin & 0.12 & 0.20 & 0.19 & 0.11 & 0.16 & 1.00 & & \\
\hline Zeros & 0.04 & 0.06 & 0.02 & 0.01 & -0.03 & -0.03 & 1.00 & \\
\hline$F H T$ & 0.11 & 0.14 & 0.09 & 0.07 & 0.09 & 0.07 & 0.70 & 1.00 \\
\hline
\end{tabular}

\section{Panel B: Average Time-Series Correlations between EDL Risk Estimates}

\begin{tabular}{c|cccccccc}
\hline & \multicolumn{3}{|c}{ High-Frequency Proxies } & \multicolumn{5}{c}{ Low-Frequency Proxies } \\
& EffSpr & RelSpr & IntAmi & Primp & illiq & Corwin & Zeros & FHT \\
\hline EfSSpr & 1.00 & & & & & & & \\
RelSpr & 0.48 & 1.00 & & & & & & \\
IntAmi & 0.62 & 0.47 & 1.00 & & & & & \\
PriImp & 0.73 & 0.48 & 0.75 & 1.00 & & & & \\
- illiq $^{-}$ & $-\overline{0} \overline{3} \overline{9}$ & $-\overline{0} \overline{3} \overline{6}$ & $0.3 \overline{5}$ & $0 . \overline{3} \overline{8}$ & $1.0 \overline{0}$ & & & \\
Corwin & 0.49 & 0.48 & 0.57 & 0.53 & 0.36 & 1.00 & & \\
Zeros & 0.04 & 0.02 & 0.03 & 0.04 & 0.02 & 0.01 & 1.00 & \\
FHT & 0.13 & 0.10 & 0.11 & 0.13 & 0.10 & 0.13 & 0.23 & 1.00 \\
\hline
\end{tabular}

This table displays correlations between liquidity levels (Panel A) and EDL risk coefficients (Panel B) based on the different liquidity proxies used in this study. A detailed description of the computation of the proxy-levels and shocks is given above in Internet Appendix A. The calculation of EDL risk coefficients is explained in Internet Appendix B. The sample covers all U.S. common stocks traded on the NYSE / AMEX. The sample period for proxy levels (EDL risk estimates) is from January 1996 to December 2010 (January 2000 to December 2010). 
Figure A.1: Aggregate EDL Risk Over Time for Different Liquidity Measures

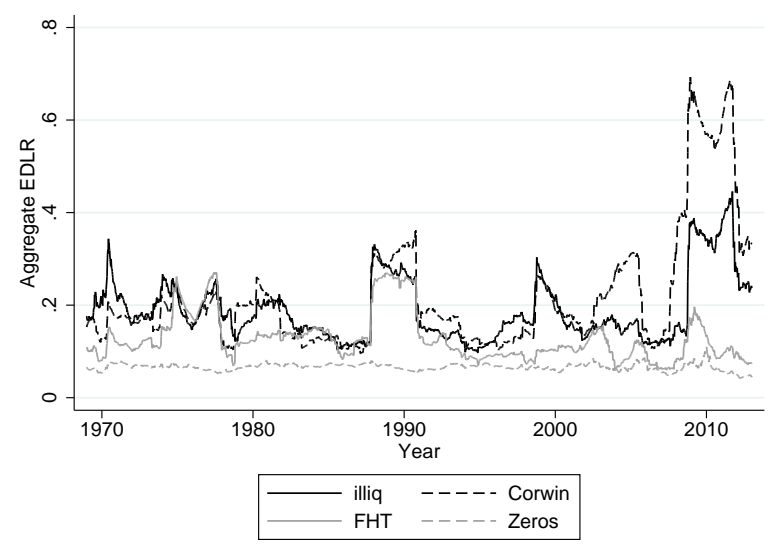

(a) Panel A: Low-Frequency Measures (1969 - 2012)

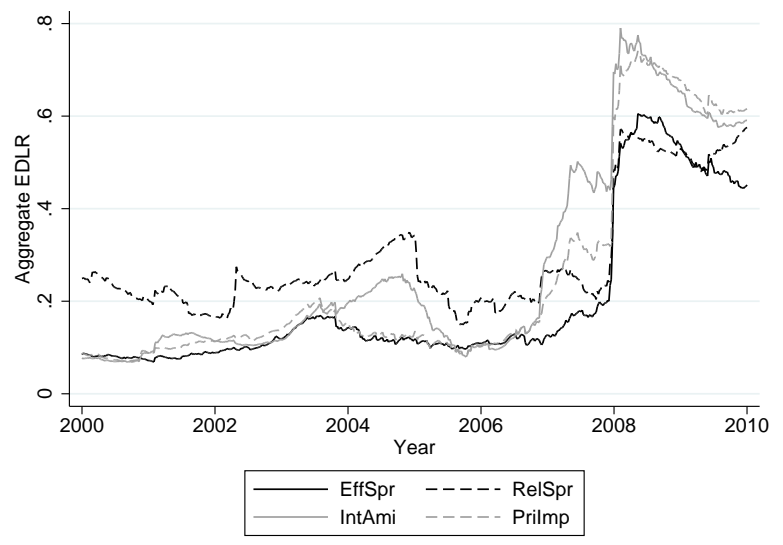

(b) Panel B: High-Frequency Measures (2002-2010)

This figure displays the evolution of aggregate EDL risk for different low-frequency and high-frequency liquidity measures. A detailed description of the computation of these variables is given in Internet Appendix A. Panel A draws the evolution of aggregate EDL risk of the low-frequency measures, Panel B shows the evolution for the high-frequency measures. The sample covers all U.S. common stocks traded on the NYSE / AMEX and the sample period for low- (high-)frequency proxies is from 1969 (2000) to 2012 (2010). 


\section{B Internet Appendix: Estimating Tail Dependence Co- efficients}

Internet Appendix B provides the technical details of the copula estimation and selection procedure and the calculation of the respective tail dependence coefficients. The estimation procedure follows the approach of Chabi-Yo, Ruenzi and Weigert (2015).

\section{B.1 The Estimation Procedure}

Bivariate extreme value distributions (such as in this paper) cannot be characterized by a fully parametric model in general, which leads to more complicated estimation techniques (see Frahm, Junker, and Schmidt (2005)). Our estimation approach relies on the entire set of weekly returns $r_{t}$ and liquidity innovations $l_{t}$ of a firm $i$ and the market in a 3-year period.

Coefficients of tail dependence have closed-form solutions for several basic parametric copulas (see Table B.1), but these basic copulas do not allow us to model upper and lower tail dependence simultaneously. However, Tawn (1988) shows that every convex combination of existing copula functions is again a copula. Thus, if $C_{1}\left(u_{1}, u_{2}\right), C_{2}\left(u_{1}, u_{2}\right), \ldots, C_{n}\left(u_{1}, u_{2}\right)$ are bivariate copula functions, then

$$
C\left(u_{1}, u_{2}\right)=w_{1} \cdot C_{1}\left(u_{1}, u_{2}\right)+w_{2} \cdot C_{2}\left(u_{1}, u_{2}\right)+\ldots+w_{n} \cdot C_{n}\left(u_{1}, u_{2}\right)
$$

is again a copula for $w_{i} \geq 0$ and $\sum_{i=1}^{n} w_{i}=1$.

To allow for the maximum possible flexibility, we consider 64 possible convex combinations of the afore mentioned basic copulas from Table B.1. Each combination consists of one copula that allows for asymptotic dependence in the lower tail, $C_{\mathrm{LTD}}$, one copula that is asymptotically independent, $C_{\mathrm{NTD}}$, and one copula that allows for asymptotic dependence in the upper tail, $C_{\mathrm{UTD}}$ :

$$
\begin{aligned}
& C\left(u_{1}, u_{2}, \Theta\right)=w_{1} \cdot C_{\mathrm{LTD}}\left(u_{1}, u_{2} ; \theta_{1}\right) \\
& \quad+w_{2} \cdot C_{\mathrm{NTD}}\left(u_{1}, u_{2} ; \theta_{2}\right)+\left(1-w_{1}-w_{2}\right) \cdot C_{\mathrm{UTD}}\left(u_{1}, u_{2} ; \theta_{3}\right),
\end{aligned}
$$


where $\Theta$ denotes the set of the basic copula parameters $\theta_{i}, i=1,2,3$ and the weights $w_{1}$ and $w_{2}$.

For the sake of convenience, we only outline the estimation approach of lower tail dependence in the distribution of a stock's liquidity and market liquidity (EDL risk $)_{1}$. The

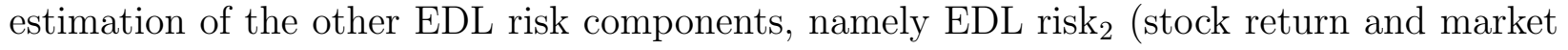
liquidity) as well as EDL risk 3 (stock liquidity and market return) follows analogously.

Starting with 1966-1968, we determine the copula convex combination that shows the best fit for the bivariate distribution of liquidity shocks for each stock and 3-year window. First, based on weekly liquidity innovations, we estimate a set of copula parameters $\Theta_{j}$ for $j=1, \ldots, 64$ different copulas $C_{j}\left(\cdot, \cdot ; \Theta_{j}\right)$ between individual stock liquidity $l_{t}^{i}$ and market liquidity $l_{t}^{m}$ for each stock $i$ based on a 3-year rolling window. Each of these convex combinations requires the estimation of five parameters: one parameter $\theta_{i}(i=1,2,3)$ for each of the three basic copulas and two parameters for the weights $w_{1}$ and $w_{2}$. The copula parameters $\Theta_{j}$ are estimated via the canonical maximum likelihood procedure of Genest, Ghoudi, and Rivest (1995). The details of this step are described in Section B.2.

Second, for each stock $i$ and week $t$ we compare the estimated log-likelihood values of all 64 copulas $C_{j}$ and select the parametric copula $C_{i}^{*}\left(\cdot, \cdot ; \Theta^{*}\right)$ that has the highest log-likelihood value. The result of this step is summarized in Table B.2 where we present the percentage frequency by which each of the possible 64 combinations is chosen. Most frequently, copula (1-D-IV) of Table B.1 is the best fit for the distribution for EDL risk 1 and copula (1-A-IV) is the best fit for the distributions for EDL risk 2 as well as EDL risk 3 . Copula (1-D-IV) relates to the Clayton-FGM-Rotated Clayton-copula and copula (1-A-IV) relates to the ClaytonGauss-Rotated Clayton-copula.

Third, for each stock $i$ and week $t$, we compute the tail dependence coefficients $\lambda_{L}$ implied by the estimated parameters $\Theta^{*}$ of the selected copula $C^{*}\left(\cdot, \cdot ; \Theta^{*}\right)$. The computation of $\lambda_{L}$ is straightforward if the copula in question has a closed form, as all the basic copulas used in this study do. Column (3) of Table B.1 displays the closed-form solutions to determine $\lambda_{L}$ for the respective copula. The lower tail dependence coefficient of the convex combination is calculated using $\lambda_{L}^{*}=w_{1}^{*} \cdot \lambda_{L}\left(\theta_{1}^{*}\right)$. As this procedure is repeated for each stock and week, we end up with a panel of tail dependence coefficients at the stock-week level. 


\section{B.2 Estimation of the Copula Parameters}

The estimation of the set of copula parameters $\Theta$ for a copula $C(\cdot, \cdot ; \Theta)$ is performed as follows (see also Chabi-Yo, Ruenzi and Weigert (2015)):

Let $\left\{l_{i, k}, l_{m, k}\right\}_{k=1}^{n}$ be a random sample from the bivariate distribution

$$
F\left(l_{i}, l_{m}\right)=C\left(F_{i}\left(l_{i}\right), F_{m}\left(l_{m}\right)\right)
$$

between individual stock liquidity $l_{i}$ and market liquidity $l_{m}$, where $n$ denotes the number of weekly return observations in a 3 -year period. The marginal distributions $F_{i}$ and $F_{m}$ of individual stock liquidity $l_{i}$ and market liquidity $l_{m}$ are estimated non-parametrically by their scaled empirical distribution functions

$$
\widehat{F}_{i}(x)=\frac{1}{n+1} \sum_{k=1}^{n} \mathbb{1}_{l_{i, k} \leq x} \quad \text { and } \quad \widehat{F}_{m}(x)=\frac{1}{n+1} \sum_{k=1}^{n} \mathbb{1}_{l_{m, k} \leq x} .
$$

This non-parametric estimation approach avoids an incorrect specification of the marginal distributions. We then estimate the set of copula parameters $\Theta$ parametrically. The parameters $\Theta$ are estimated via the maximum likelihood estimator

$$
\widehat{\Theta}=\operatorname{argmax}_{\Theta} L(\Theta) \quad \text { with } \quad L(\Theta)=\sum_{k=1}^{n} \log \left(c\left(\widehat{F}_{i, l_{i, k}}, \widehat{F}_{m, l_{m, k}} ; \Theta_{j}\right)\right),
$$

where $L(\Theta)$ denotes the $\log$-likelihood function and $c(\cdot, \cdot ; \Theta)$ the copula densitiy. $\widehat{\Theta}$ is a consistent and asymptotic normal estimate of the set of copula parameters $\Theta$ under standard regularity conditions (e.g., Genest, Ghoudi, and Rivest (1995)), assuming that $\left\{l_{i, k}, l_{m, k}\right\}_{k=1}^{n}$ is an i.i.d. random sample. 


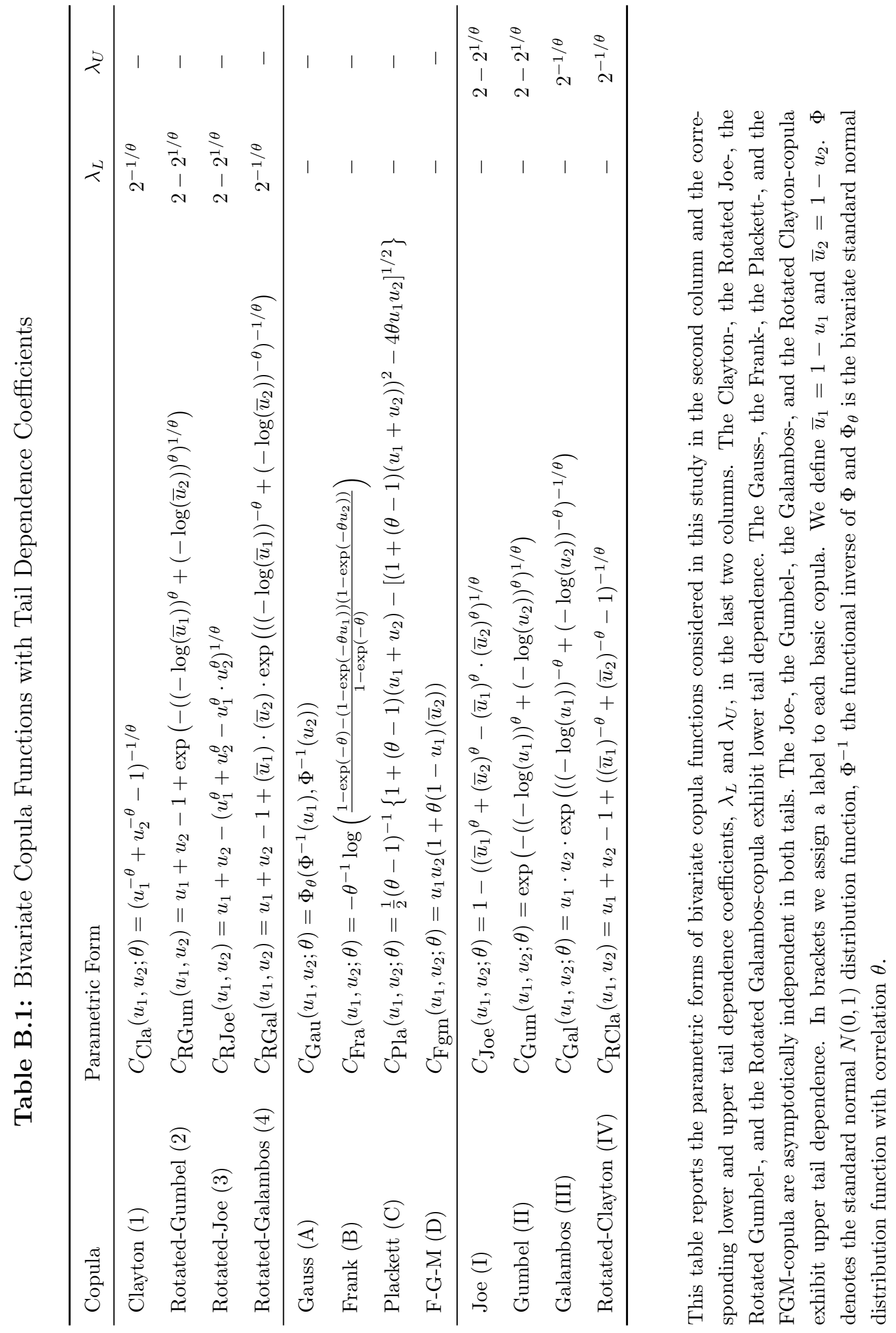




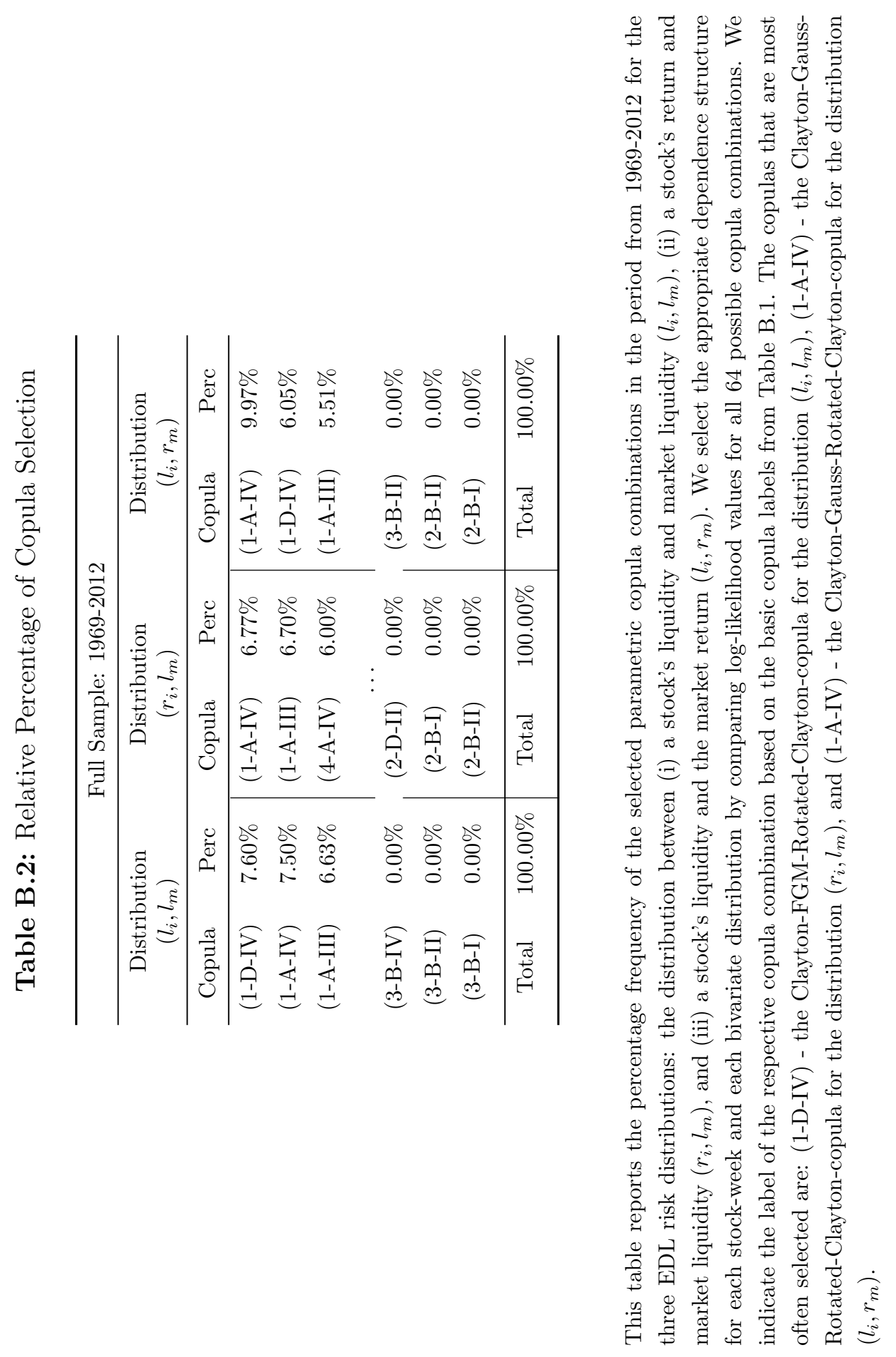




\section{Internet Appendix: Brief Definitions and Data Sources of Main Variables}

The following table briefly defines the main variables used in our empirical analysis. Abbreviations for the data sources are:

(i) CRSP: CRSP's Stocks Database

(ii) KF: Kenneth French's Data Library

(iii) CS: Compustat

(iv) OP: The homepages of authors of the respective original papers

EST indicates that the variable is estimated or computed based on original variables from the respective data sources. Note that the eight liquidity proxies we use are defined separately in Internet Appendix A. 


\begin{tabular}{|c|c|c|}
\hline Variable Name & Description & Source \\
\hline $\operatorname{Return}_{t}$ & $\begin{array}{l}\text { Raw excess return of a portfolio (stock) over the risk-free rate in week } t \text {. } \\
\text { As risk-free rate we use the 1-month T-Bill rate. }\end{array}$ & $\begin{array}{l}\text { CRSP, KF, } \\
\text { EST }\end{array}$ \\
\hline EDL risk 1 & $\begin{array}{l}\text { Extreme Downside Liquidity Risk } 1 \text { of a stock. Lower tail dependence be- } \\
\text { tween stock liquidity-shocks and (value-weighted) market liquidity-shocks, } \\
\text { estimated based on weekly data from a } 3 \text {-year rolling window, as detailed } \\
\text { in Internet Appendix B. }\end{array}$ & $\begin{array}{l}\text { CRSP } \\
\text { EST }\end{array}$ \\
\hline EDL risk ${ }_{2}$ & $\begin{array}{l}\text { Extreme Downside Liquidity Risk } 2 \text { of a stock. Lower tail dependence } \\
\text { between stock returns and (value-weighted) market liquidity-shocks, esti- } \\
\text { mated based on weekly data from a } 3 \text {-year rolling window, as detailed in } \\
\text { Internet Appendix B. }\end{array}$ & $\begin{array}{l}\text { CRSP } \\
\text { EST }\end{array}$ \\
\hline $\mathrm{EDL} \mathrm{risk}_{3}$ & $\begin{array}{l}\text { Extreme Downside Liquidity Risk } 3 \text { of a stock. Lower tail dependence } \\
\text { between stock liquidity-shocks and (value-weighted) market returns, esti- } \\
\text { mated based on weekly data from a } 3 \text {-year rolling window, as detailed in } \\
\text { Internet Appendix B. }\end{array}$ & $\begin{array}{l}\text { CRSP } \\
\text { EST }\end{array}$ \\
\hline EDR (EUR) risk & $\begin{array}{l}\text { Extreme Downside (Upside) Return Risk of a stock. Lower (Upper) tail } \\
\text { dependence between stock returns and (value-weighted) market returns, } \\
\text { estimated based on weekly data from a 3-year rolling window, as detailed } \\
\text { in Internet Appendix B. }\end{array}$ & $\begin{array}{l}\text { CRSP } \\
\text { EST }\end{array}$ \\
\hline EDL risk & $\begin{array}{l}\text { Joint Extreme Downside Liquidity Risk of a stock. EDL risk }=\text { EDL risk } 1+ \\
\text { EDL risk }{ }_{2}+\text { EDL risk } 3 \text {, as detailed in the main text. }\end{array}$ & $\begin{array}{l}\text { CRSP, } \\
\text { EST }\end{array}$ \\
\hline Aggregate EDL risk & $\begin{array}{l}\text { Aggregate Extreme Downside Liquidity Risk. Value-weighted average of } \\
\text { EDL risk }\left(\mathrm{EDL} \mathrm{risk}_{i}\right) \text { for each week over all stocks in the sample, as detailed } \\
\text { in the main text. }\end{array}$ & $\begin{array}{l}\text { CRSP, } \\
\text { EST }\end{array}$ \\
\hline Aggregate EDR risk & $\begin{array}{l}\text { Aggregate Extreme Downside Return Risk. Value-weighted average of EDR } \\
\text { risk for each week over all stocks in the sample, as detailed in the main text. }\end{array}$ & $\begin{array}{l}\text { CRSP, } \\
\text { EST }\end{array}$ \\
\hline $\mathrm{EDL}_{\text {risk }_{x y}}$ & $\begin{array}{l}\text { As EDL risk, but based on an } x \text {-year rolling window, as detailed in the } \\
\text { main text. }\end{array}$ & $\begin{array}{l}\text { CRSP } \\
\text { EST }\end{array}$ \\
\hline $\mathrm{EDL}_{\text {risk }} C x$ & $\begin{array}{l}\text { As EDL risk, but based on copula function } C x \text {, as detailed in the main text } \\
\text { and Internet Appendix B. }\end{array}$ & $\begin{array}{l}\text { CRSP, } \\
\text { EST }\end{array}$ \\
\hline
\end{tabular}




\begin{tabular}{|c|c|c|}
\hline Variable Name & Description & Source \\
\hline$\beta_{R}$ & $\begin{array}{l}\text { Factor loading on the market factor from a CAPM one-factor regression es- } \\
\text { timated based on a } 3 \text {-year rolling window of weekly data: } \beta_{R}=\frac{\operatorname{COV}\left(r_{i}, r_{m}\right)}{\operatorname{VAR}\left(r_{m}\right)} \text {. }\end{array}$ & $\begin{array}{l}\text { CRSP, } \\
\text { EST }\end{array}$ \\
\hline$\beta_{R}^{-}$ & $\begin{array}{l}\text { Downside beta estimated based on a } 3 \text {-year rolling window of weekly data, } \\
\text { as defined in Ang, Chen, and Xing (2006): } \\
\beta_{R}^{-}=\frac{\operatorname{COV}\left(r_{i}, r_{m} \mid r_{m}<\mu_{m}\right)}{\operatorname{VAR}\left(r_{m} \mid r_{m}<\mu_{m}\right)} \text {, where } \mu_{m} \text { is the mean market return. }\end{array}$ & $\begin{array}{l}\text { CRSP, } \\
\text { EST }\end{array}$ \\
\hline$\beta_{R}^{+}$ & $\begin{array}{l}\text { Upside beta. As } \beta_{R}^{-} \text {, but with inverted signs within the conditional } \\
\text { (co)variance. }\end{array}$ & $\begin{array}{l}\text { CRSP, } \\
\text { EST }\end{array}$ \\
\hline$\beta_{L 1}$ & $\begin{array}{l}\text { Liquidity beta } 1 \text { as defined in Acharya and Pedersen }(2005) \text {, estimated } \\
\text { based on a } 3 \text {-year rolling window of weekly data: } \beta_{L 1}=\frac{\mathrm{COV}\left(l_{i}, l_{m}\right)}{\operatorname{VAR}\left(r_{m}-l_{m}\right)} \text {, where } \\
l_{i} \text { and } l_{m} \text { are the stock- and market-liquidity innovations, as described in } \\
\text { the main text and Internet Appendix B. }\end{array}$ & $\begin{array}{l}\text { CRSP, } \\
\text { EST }\end{array}$ \\
\hline$\beta_{L 2}$ & $\begin{array}{l}\text { Liquidity beta } 2 \text { as defined in Acharya and Pedersen }(2005) \text {, estimated } \\
\text { based on a } 3 \text {-year rolling window of weekly data: } \beta_{L 2}=\frac{\operatorname{COV}\left(r_{i}, l_{m}\right)}{\operatorname{VAR}\left(r_{m}-l_{m}\right)}\end{array}$ & $\begin{array}{l}\text { CRSP, } \\
\text { EST }\end{array}$ \\
\hline$\beta_{L 3}$ & $\begin{array}{l}\text { Liquidity beta } 3 \text { as defined in Acharya and Pedersen }(2005) \text {, estimated } \\
\text { based on a } 3 \text {-year rolling window of weekly data: } \beta_{L 3}=\frac{\operatorname{COV}\left(l_{i}, r_{m}\right)}{\operatorname{VAR}\left(r_{m}-l_{m}\right)}\end{array}$ & $\begin{array}{l}\text { CRSP, } \\
\text { EST }\end{array}$ \\
\hline$\beta_{L}$ & Joint linear liquidity risk. $\beta_{L}=\beta_{1}+\beta_{2}+\beta_{3}$ & $\begin{array}{l}\text { CRSP, } \\
\text { EST }\end{array}$ \\
\hline$\beta_{L 1}^{-}$ & $\begin{array}{l}\text { Downside liquidity beta } 1 \text {, estimated based on a } 3 \text {-year rolling window of } \\
\text { weekly data: } \beta_{L 1}^{-}=\frac{\operatorname{COV}\left(l_{i}, l_{m} \mid l_{m}<\mu_{l_{m}}\right)}{\operatorname{VAR}\left(r_{m}-l_{m} \mid l_{m}<\mu_{l_{m}}\right)} \text {, where } \mu_{u_{m}} \text { is the mean weekly } \\
\text { market liquidity innovation. }\end{array}$ & $\begin{array}{l}\text { CRSP, } \\
\text { EST }\end{array}$ \\
\hline$\beta_{L 2}^{-}$ & $\begin{array}{l}\text { Downside liquidity beta } 2 \text {, estimated based on a } 3 \text {-year rolling window of } \\
\text { weekly data: } \beta_{L 2}^{-}=\frac{\operatorname{COV}\left(r_{i}, l_{m} \mid l_{m}<\mu_{l_{m}}\right)}{\operatorname{VAR}\left(r_{m}-l_{m} \mid l_{m}<\mu_{l_{m}}\right)}\end{array}$ & $\begin{array}{l}\text { CRSP, } \\
\text { EST }\end{array}$ \\
\hline$\beta_{L 3}^{-}$ & $\begin{array}{l}\text { Downside liquidity beta } 3 \text {, estimated based on a } 3 \text {-year rolling window of } \\
\text { weekly data: } \beta_{L 3}^{-}=\frac{\operatorname{COV}\left(l_{i}, r_{m} \mid r_{m}<\mu_{r_{m}}\right)}{\operatorname{VAR}\left(r_{m}-l_{m} \mid r_{m}<\mu_{r_{m}}\right)} \text {, where } \mu_{r_{m}} \text { is the mean weekly } \\
\text { market return. }\end{array}$ & $\begin{array}{l}\text { CRSP, } \\
\text { EST }\end{array}$ \\
\hline
\end{tabular}




\begin{tabular}{|c|c|c|}
\hline Variable Name & Description & Source \\
\hline$\beta_{L}^{-}$ & Joint linear downside liquidity risk. $\beta_{L}^{-}=\beta_{L 1}^{-}+\beta_{L 2}^{-}+\beta_{L 3}^{-}$. & $\begin{array}{l}\text { CRSP, } \\
\text { EST }\end{array}$ \\
\hline$\beta_{L}^{+}$ & $\begin{array}{l}\text { Joint linear upside liquidity risk. As } \beta_{L}^{-} \text {, but with inverted signs within the } \\
\text { (co)variances. }\end{array}$ & $\begin{array}{l}\text { CRSP, } \\
\text { EST }\end{array}$ \\
\hline$\beta_{\text {Tail }}$ & Exposure to tail risk, as measured in Kelly and Jiang (2014). & $\begin{array}{l}\text { CRSP, } \\
\text { EST }\end{array}$ \\
\hline $\begin{array}{l}\text { CAPM-Alpha, } \\
\text { FF-Alpha, } \\
\text { CAR-Alpha }\end{array}$ & $\begin{array}{l}\text { Sharpe (1964)-based alpha, Fama and French (1993) three-factor alpha, and } \\
\text { Carhart (1997) four-factor alpha of a portfolio. We use monthly portfolio } \\
\text { returns to estimate the alphas. }\end{array}$ & $\begin{array}{l}\text { CRSP, KF, } \\
\text { EST }\end{array}$ \\
\hline idio vola & $\begin{array}{l}\text { A stock's idiosyncratic volatility, defined as the } 3 \text {-year rolling window stan- } \\
\text { dard deviation of the CAPM-residuals of its weekly returns. }\end{array}$ & $\begin{array}{l}\text { CRSP, } \\
\text { EST }\end{array}$ \\
\hline coskew & $\begin{array}{l}\text { The coskewness of a stock's } 3 \text {-year rolling window weekly returns with the } \\
\text { market: } \\
\text { coskew }=\frac{E\left[\left(r_{i}-\mu_{i}\right)\left(r_{m}-\mu_{m}\right)^{2}\right]}{\sqrt{\operatorname{VAR}\left(r_{i}\right)} \operatorname{VAR}\left(r_{m}\right)}\end{array}$ & $\begin{array}{l}\text { CRSP, } \\
\text { EST }\end{array}$ \\
\hline Marketrf & Value-weighted CRSP market-return in excess of the risk-free rate. & $\mathrm{KF}$ \\
\hline $\mathrm{SMB}$ & Small-Minus-Big factor portfolio return, available for each month. & $\mathrm{KF}$ \\
\hline HML & High-Minus-Low factor portfolio return, available for each month. & $\mathrm{KF}$ \\
\hline Mom & $\begin{array}{l}\text { Winner-Minus-Loser (momentum) factor portfolio return, available for each } \\
\text { month. }\end{array}$ & $\mathrm{KF}$ \\
\hline Past Return & Last year's return for a given stock. & $\begin{array}{l}\text { CRSP, } \\
\text { EST }\end{array}$ \\
\hline PS Liqui & Pastor and Stambaugh (2003)'s traded liquidity risk factor. & OP \\
\hline Sadka Liqui & Sadka (2006)'s liquidity factor. & $\mathrm{OP}$ \\
\hline EDRR & $\begin{array}{l}\text { Chabi-Yo, Ruenzi and Weigert (2015)'s equally-weighted EDR risk factor } \\
\text { portfolio return. }\end{array}$ & $\mathrm{OP}$ \\
\hline illiq & Amihud (2002) illiquidity ratio (average over last year). & $\begin{array}{l}\text { CRSP, } \\
\text { EST }\end{array}$ \\
\hline Tail & Kelly and Jiang (2014)'s equal-weighted tail risk factor portfolio return. & $\begin{array}{l}\text { CRSP, } \\
\text { EST }\end{array}$ \\
\hline $\mathrm{BAB}$ & Frazzini and Pedersen (2014)'s U.S. equity betting-against-beta return. & OP \\
\hline
\end{tabular}




\begin{tabular}{|c|c|c|}
\hline Variable Name & Description & Source \\
\hline $\operatorname{Max}$ & Bali, Cakici, and Whitelaw (2011)'s equally-weighted lottery factor. & $\mathrm{OP}$ \\
\hline $\begin{array}{l}\text { Standard- } \\
\text { Deviation }\end{array}$ & Standard-deviation of the past 3 years' weekly returns or liquidity shocks. & $\begin{array}{l}\text { CRSP, } \\
\text { EST }\end{array}$ \\
\hline VaR & $\begin{array}{l}\text { Value at Risk. } 5 \% \text { quantile of the past } 3 \text { years' weekly returns or liquidity } \\
\text { shocks. }\end{array}$ & $\begin{array}{l}\text { CRSP, } \\
\text { EST }\end{array}$ \\
\hline CoVaR & $\begin{array}{l}\text { Conditional Value at Risk. Conditional mean of the past } 3 \text { years' weekly } \\
\text { returns or liquidity shocks below the } 5 \% \text { quantile. }\end{array}$ & $\begin{array}{l}\text { CRSP, } \\
\text { EST }\end{array}$ \\
\hline \multicolumn{3}{|c|}{ Panel B: Other Firm Characteristics } \\
\hline Variable Name & Description & Source \\
\hline size & $\begin{array}{l}\text { The natural logarithm of a firm's equity market capitalization in million } \\
\text { USD. }\end{array}$ & $\mathrm{CS}$ \\
\hline btm & $\begin{array}{l}\text { A firm's book-to-market ratio computed as the ratio of CS book value of } \\
\text { equity per share (i.e., book value of common equity less liquidation value } \\
\text { (CEQL) divided by common share outstanding (CSHO)) to share price } \\
\text { (i.e., market value of equity per share). }\end{array}$ & e \\
\hline SIC $2,3,4$ & 2-, 3- and 4-digit Standard Industrial Classification. & CRSP \\
\hline FF 12,48 & Fama and French's 12 and 48 industry classifications. & $\mathrm{KF}$ \\
\hline DGTW & $\begin{array}{l}\text { Daniel, Grinblatt, Titman, and Wermers (1997)'s characteristic-based } \\
\text { benchmark, available via Russ Wermer's homepage. }\end{array}$ & $\mathrm{OP}$ \\
\hline
\end{tabular}




\section{References}

Acharya, V., Pedersen, L., 2005. Asset pricing with liquidity risk. Journal of Financial Economics $77,375-410$.

Amihud, Y., 2002. Illiquidity and stock returns: Cross-section and time-series effects. Journal of Financial Markets 5, 31-56.

Ang, A., Chen, J., Xing, Y., 2006. Downside risk. Review of Financial Studies 19, 1191-1239.

Bali, T.G., Cakici, N., Whitelaw, R.F., 2011. Maxing out: Stocks as lotteries and the crosssection of expected returns. Journal of Financial Economics 99, 427-446.

Carhart, M., 1997. On persistence in mutual fund performance. Journal of Finance 52, 57-82.

Chabi-Yo, F., Ruenzi, S., Weigert, F., 2015. Crash sensitivity and the cross-section of expected stock returns. Unpublished Working Paper, Ohio State University, University of Mannheim, and University of St. Gallen.

Corwin, S.A., Schultz, P., 2012. A simple way to estimate bid-ask spreads from daily high and low prices. Journal of Finance 67, 719-759.

Daniel, K., Grinblatt, M., Titman, S., Wermers, R., 1997. Measuring mutual fund performance with characteristic-based benchmarks. Journal of Finance 52, 1035-1058.

Fama, E.F., French, K.R., 1993. Common risk factors in the returns on stocks and bonds. Journal of Financial Economics 33, 3-56.

Fong, K., Holden, C., Trzcinka, C., 2014. What are the best liquidity proxies for global research? Unpublished Working Paper, University of New South Wales and Indiana University.

Frahm, G., Junker, M., Schmidt, R., 2005. Estimating the tail-dependence coefficient: Properties and pitfalls. Insurance: Mathematics and Economics 37, 80-100.

Frazzini, A., Pedersen, L.H., 2014. Betting against beta. Journal of Financial Economics $111,1-25$. 
Genest, C., Ghoudi, K., Rivest, L.P., 1995. A semiparametric estimation procedure of dependence parameters in multivariate families of distributions. Biometrika 82, 543-552.

Kelly, B., Jiang, H., 2014. Tail risk and asset prices. Review of Financial Studies 27, 28412871.

Lesmond, D., Ogden, J., Trzcinka, C., 1999. A new estimate of transaction costs. Review of Financial Studies 12, 1113-1141.

Pastor, L., Stambaugh, R.F., 2003. Liquidity risk and expected returns. Journal of Political Economy 111, 642-685.

Sadka, R., 2006. Momentum and post-earnings-announcement drift anomalies: the role of liquidity risk. Journal of Financial Economics 80, 309-349.

Sharpe, W.F., 1964. Capital asset prices: A theory of market equilibrium under conditions of risk. Journal of Finance 19, 425-442.

Tawn, J., 1988. Bivariate extreme value theory: models and estimation. Biometrika 75, $397-415$. 